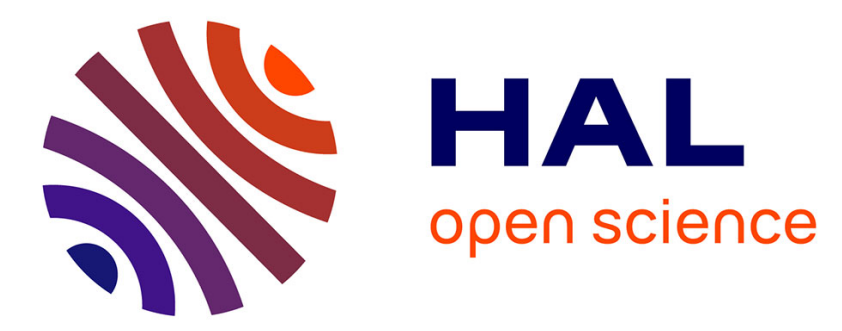

\title{
Metal-Catalyzed Azide-Alkyne "Click" Reactions: Mechanistic Overview and Recent Trends
}

Changlong Wang, Djamila Ikhlef, Samia Kahlal, Jean-Yves Saillard, Didier Astruc

\section{- To cite this version:}

Changlong Wang, Djamila Ikhlef, Samia Kahlal, Jean-Yves Saillard, Didier Astruc. Metal-Catalyzed Azide-Alkyne "Click" Reactions: Mechanistic Overview and Recent Trends. Coordination Chemistry Reviews, 2016, 316, pp.1-20. 10.1016/j.ccr.2016.02.010 . hal-01282461

HAL Id: hal-01282461 https://hal-univ-rennes1.archives-ouvertes.fr/hal-01282461

Submitted on 26 Apr 2016

HAL is a multi-disciplinary open access archive for the deposit and dissemination of scientific research documents, whether they are published or not. The documents may come from teaching and research institutions in France or abroad, or from public or private research centers.
L'archive ouverte pluridisciplinaire HAL, est destinée au dépôt et à la diffusion de documents scientifiques de niveau recherche, publiés ou non, émanant des établissements d'enseignement et de recherche français ou étrangers, des laboratoires publics ou privés. 


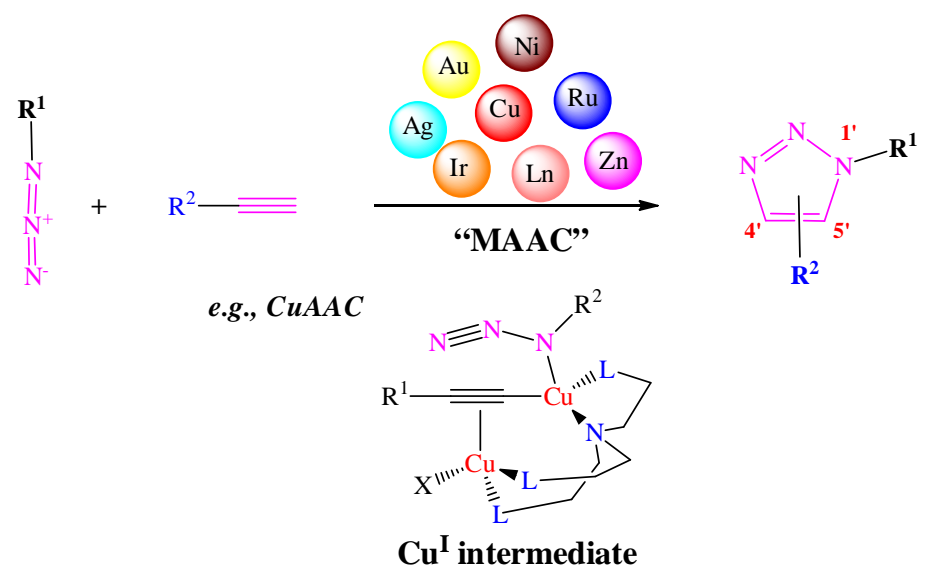
Metal-Catalyzed Azide-Alkyne "Click” Reactions: Mechanistic Overview and Recent
Trends

Changlong Wang, Djamila Ikhlef, Samia Kahlal, Jean-Yves Saillard,* and Didier Astruc*

\section{Highlights}

- The review is focused on the mechanistic aspects and recent trends (since 2012) of the metal-catalyzed azide-alkyne cycloaddition (MAAC) so-called "click" reactions with catalysts based on various metals $(\mathrm{Cu}, \mathrm{Ru}, \mathrm{Ag}, \mathrm{Au}, \mathrm{Ir}$, $\mathrm{Ni}, \mathrm{Zn}, \mathrm{Ln})$, although $\mathrm{Cu}(\mathrm{I})$ catalysts are still the most used ones.

- These MAAC reactions are by far the most common click reactions relevant to the "green chemistry" concept.

- Mechanistic investigations are essential to reaction improvements and subsequent applications, and indeed as shown in this review the proposed mechanisms have been multiple during the last decade based on theoretical computations and experimental search of intermediates.

- New trends are also presented here often representing both exciting approaches for various applications and new challenges for further mechanistic investigations. 


\section{Metal-Catalyzed Azide-Alkyne "Click" Reactions: Mechanistic Overview and Recent Trends}

Changlong Wang, ${ }^{\mathrm{a}}$ Djamila Ikhlef, ${ }^{\mathrm{b}, \mathrm{c}}$ Samia Kahlal, ${ }^{\mathrm{b}}$ Jean-Yves Saillard, ${ }^{\mathrm{b}}{ }^{*}$ and Didier Astruc ${ }^{\mathrm{a}} *$

${ }^{a}$ ISM, UMR CNRS N` 5255, Univ. Bordeaux, 33405 Talence Cedex, France

E-mail: d.astruc@ism.u-bordeaux.fr

${ }^{\mathrm{b}}$ ISCR UMR CNRS 6226, University of Rennes 1, 35042 Rennes Cedex, France E-mail : saillard@univ-rennes1.fr

${ }^{c}$ Laboratoire de Physico-Chimie Théorique et Chimie Informatique, Université des Sciences et de la Technologie Houari Boumédienne, B.P. 32, El Alia, Alger, Algeria

\section{Contents}

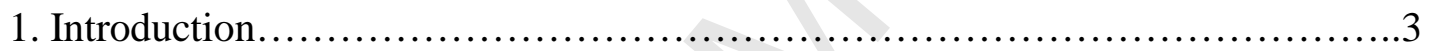

2. MAAC reactions with various metal catalysts.................................4

2.1. The CuAAC reactions....................................................4

2.2. The RuAAC reactions............................................... 10

2.3. The AgAAC reactions....................................................14

2.4. The AuAAC reactions.................................................. 17

2.5. The IrAAC reactions................................................... 18

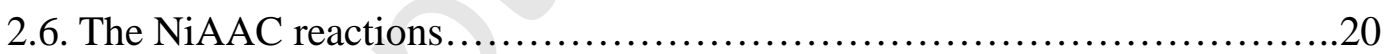

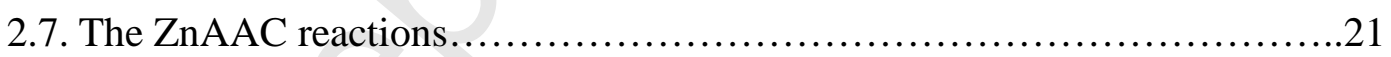

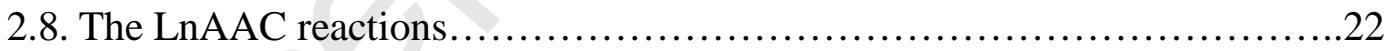

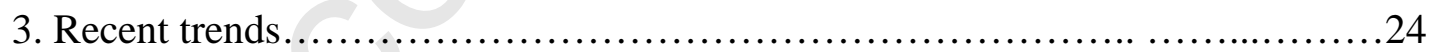

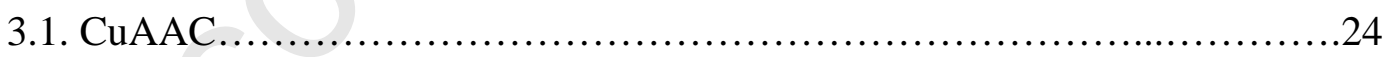

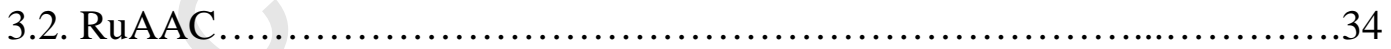

3.3. Applications of the CuAAC "click" reactions................................. 36

4. Conclusions and outlook............................................... 37

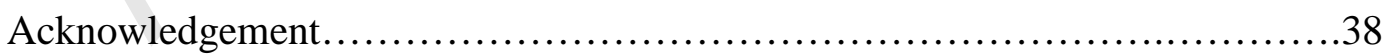

Notes and references................................................. 38 


\begin{abstract}
This review is focused on the mechanistic aspects and recent trends of the metalcatalyzed azide-alkyne cycloaddition (MAAC) so-called "click" reactions with catalysts based on various metals ( $\mathrm{Cu}, \mathrm{Ru}, \mathrm{Ag}, \mathrm{Au}, \mathrm{Ir}, \mathrm{Ni}, \mathrm{Zn}, \mathrm{Ln})$, although $\mathrm{Cu}(\mathrm{I})$ catalysts are still the most used ones. These MAAC reactions are by far the most common click reactions relevant to the "green chemistry" concept. First developed by the Fokin-Sharpless and Meldal group with $\mathrm{Cu}(\mathrm{I})$ in 2002, they have then been extended to $\mathrm{Ru}(\mathrm{II})$ catalysts by the Fokin group in 2005 and finally to many other metal catalysts. Mechanistic investigations are essential to reaction improvements and subsequent applications, and indeed as shown in this review the proposed mechanisms have been multiple during the last decade based on theoretical computations and experimental search of intermediates. New trends (since 2012) are also presented here often representing both exciting approaches for various applications and new challenges for further mechanistic investigations.
\end{abstract}

\title{
TOC :
}

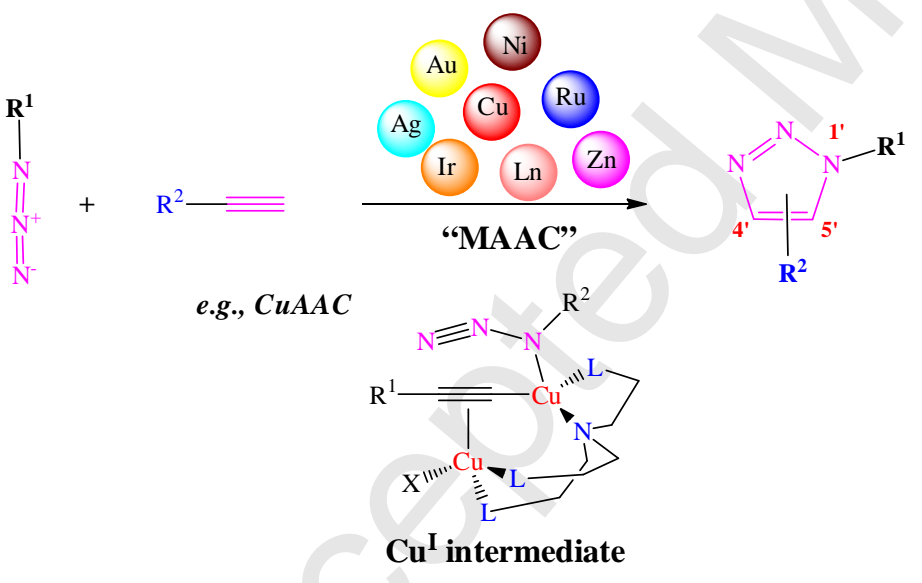




\section{Introduction}

The concept of "click chemistry" proposed by Kolb, Finn and Sharpless in 2001 [1] has revolutionized molecular engineering including applications to organic and medicinal chemistry [2-11], polymer science and materials science [12-21]. Among the various "click" reactions responding to the requirements of this concept, the most generally used one is the copper(I)-catalyzed reaction between terminal alkynes and azides (CuAAC) selectively yielding 1,4-disubstituted 1,2,3-triazoles, that was reported independently by the Sharpless-Fokin [22] and the Meldal groups in 2002 [ $23,24]$. This reaction is the catalyzed version of the 1,3 dipolar cycloaddition, known in the former decades as the Huisgen reaction that had already been first disclosed in the XIXth century [25]. The advantages of the $\mathrm{Cu}(\mathrm{I})$ catalyzed "click" reaction are that (i) it is regioselective, whereas the non-catalyzed Huisgen reaction lacks regioselectivity, producing both the 1,4- and 1,5-disubstituted isomers, (ii) it proceeds at milder temperature than the non-catalyzed reaction (iii) it fulfills the requirements of "green chemistry" in so far as it can occur in aqueous or alcoholic medium, (iv) the catalyst reported by Sharpless and Fokin is simple and inexpensive; it consists in $\mathrm{CuSO}_{4} \cdot 5 \mathrm{H}_{2} \mathrm{O}+$ sodium ascorbate, the later reagent being fine for the reduction of $\mathrm{Cu}$ (II) to $\mathrm{Cu}(\mathrm{I})$, but not to $\mathrm{Cu}(0)$ [22]. The only drawback is the need of large quantities of this catalyst mixture that is slow. Indeed, various nitrogen ligands accelerate the $\mathrm{Cu}(\mathrm{I})$ catalysis of the "click" reaction and allow using $1 \%$ or a few \% $\mathrm{Cu}$ (I) catalyst [20,26]. Recently we reported that using a recyclable dendritic nanoreactor in water only, it was possible to decrease the $\mathrm{Cu}(\mathrm{I})$ amount using the $\mathrm{CuSO}_{4} \cdot 5 \mathrm{H}_{2} \mathrm{O}+$ sodium ascorbate catalyst to $1 \mathrm{ppm}$ or only a few ppm with various applications to biomedical targets [27a]. Disubstituted alkynes cannot be used for the $\mathrm{CuAAC}$ reaction, because deprotonation of the terminal alkyne to give $\mathrm{Cu}$ (alkynyl) intermediate species is mandatory in this reaction [26]. With pentamethylcyclopentadienyl-ruthenium catalysts, however, the Fokin group showed that the other isomer, i.e. 1,5-disubstituted triazole is regioselectively formed in the RuAAC reaction even with disubstituted alkynes according to a different mechanism [28]. Ruthenium catalysis is versatile, because other ruthenium catalysts reacted with terminal alkynes via a key ruthenium-acetylide species to yield the 1,4-disubstituted triazoles [29]. Since the early reports, a variety of transition-metal catalysts have been used for the reactions between mono- or disubstituted alkynes and azides (vide infra). For the $\mathrm{Cu}(\mathrm{I})$ catalyzed reaction, a variety of mechanisms involving $\mathrm{Cu}(\mathrm{I})$-aryl intermediates have been proposed in which the key-step species contains either mononuclear [35] or binuclear copper species [30-38]. Theoretical studies of the RuAAC reaction have also been reported [28,39-41]. Given this mechanistic variety and the large number of transition-metals catalysts used for the MAAC reactions $(\mathrm{M}=$ transition metal), it is essential and timely to address the mechanistic problems by reviewing the state of knowledge in the literature, conduct theoretical calculations on MAAC reactions and compare these results with those reported in the literature. 


\section{MAAC reactions with various metal catalysts}

\subsection{The $\mathrm{CuAAC}$ reactions}

With over 2000 publications in hardly more than a decade, the CuAAC reaction is illustrious and undoubtedly has been a breakthrough in organic synthesis and $\mathrm{Cu}(\mathrm{I})$ catalysis [2-24,42]. Although a large number of $\mathrm{Cu}(\mathrm{I})$ catalysts are efficient in catalyzing this reaction [21,24,26], the conventional Sharpless-Fokin catalyst $\left(\mathrm{CuSO}_{4} /\right.$ sodium ascorbate) [22] is by far the most used one in spite of the large required catalyst amount, slow rate, difficulty to remove copper after the reaction, and sometimes the detrimental effects on rates and yield observed in the presence of chlorides, bromides and iodides [43]. For instance, low efficiency was observed for CuAAC of 2-azidopyridines [44]. Thus experimental protocols such as adding podand-like ionic liquids (ILs) [45], simple thermal heating [46], ultrasoundassistance [47], and the combination of both ultrasounds and ILs [48] were used to accelerate the reaction rates of the Sharpless-Fokin catalyst .

Concerning the optimization of " $\mathrm{X}$ " ligands in the $\mathrm{Cu}(\mathrm{I})(\mathrm{X})$ catalysts, Zhang et al. compared various $\mathrm{Cu}(\mathrm{I})$ sources $\left(\mathrm{CuCl}, \mathrm{CuBr}, \mathrm{CuI}, \mathrm{CuSO}_{4} \cdot 5 \mathrm{H}_{2} \mathrm{O} / \mathrm{NaAsc}\right.$ and $\left.\left[(\mathrm{CuOAc})_{2}\right]_{\mathrm{n}}\right)$ that catalyze the $\mathrm{CuAAC}$ reaction of 6 tetrazolo- $[1,5-a]$ pyridines toward the synthesis of 1-(pyridin-2-yl)-1,2,3-triazoles, and the results showed that copper(I) acetate was the most efficient catalyst [49]. The nitrogen ("L") ligands accelerate the $\mathrm{CuAAC}$ reaction are amines, pyridines, and triazoles, in particular tridentate ligands [26,50-52]. $N$-heterocyclic carbenes (NHC) that reported by Nolan's group to be excellent ligands, providing high reaction rates and yield for the $\mathrm{CuAAC}$ reaction (vide infra). Interestingly, internal alkynes were also successfully used, which suggested that a different mechanism than that implying copper-acetylide intermediates was involved [33,53]. Bertrand's mesoionic carbenes were also efficient [54,55] even with sterically hindered azide and alkynes [55]. With various ligands and $\mathrm{Cu}(\mathrm{I})$ catalysts, a large variety of solvents have been used, and the reaction is compatible with aqueous solvents [21,22]. 

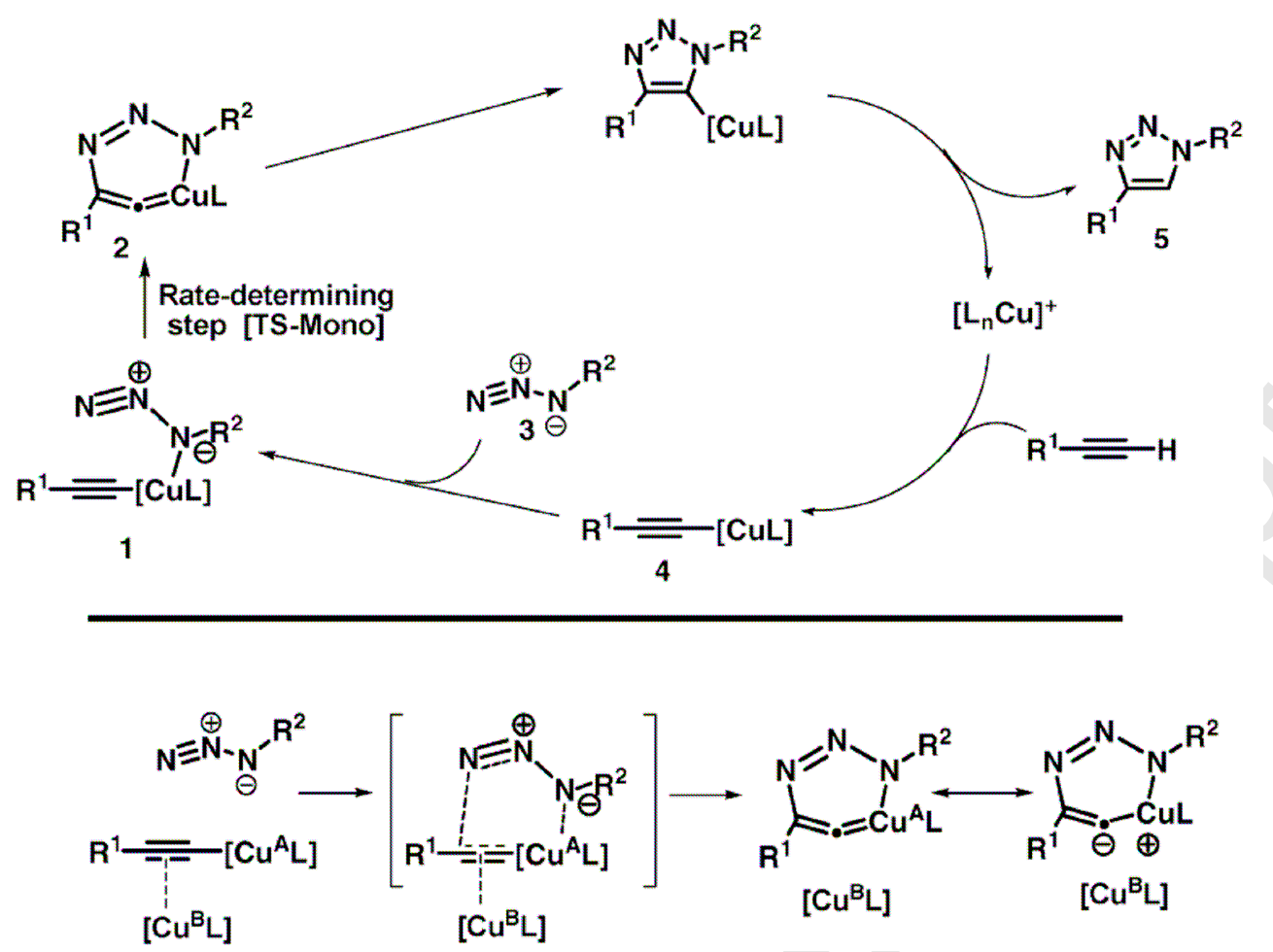

Fig. 1: The CuAAC mechanisms (Sharpless-type catalysis) proposed by Fokin and coworkers from their DFT calculations. Top: proposed mononuclear mechanism. Bottom: proposed dinuclear mechanism. Reprinted with permission from ref. 57. Copyright 2007, American Chemical Society.

Noticing the fact that the $\mathrm{Cu}(\mathrm{I})$ species accelerated the rate of the AAC reactions by 7 8 orders of magnitude compared to purely thermal cycloaddition reactions observed without metal catalysts, Sharpless and coworkers then proposed a stepwise mechanism involving a mononuclear $\mathrm{Cu}$-acetylide intermediate based on DFT studies (top of Fig. 1) [31]. In a latter study, however, Fokin and Finn also pointed out the possibility that two $\mathrm{Cu}$ centers were involved in the transition state of the cycle [32], for which the following detailed kinetic studies confirmed the possibility of a $\sigma, \pi$ bimetallic $\mathrm{Cu}(\mathrm{I})$ intermediate $[26,50,56]$. Subsequent DFT calculations, carried out in the same group [22b,57], supported this hypothesis by showing that the complexation of the alkyne unit by a second metal center (bottom of Fig. 1) reduces the activation energy barrier by $4-6 \mathrm{kcal} / \mathrm{mol}$, depending on the nature of the ligand on the $\mathrm{Cu}^{\mathrm{B}}$ atom indicated in Fig. 1 [57]. The effect of $\pi$-complexation of the $\sigma$-alkynyl-Cu(I) species enhances the reactivity of the alkynyl ligand by decreasing electron density on the sp carbon atoms, thus facilitating the azide attack. In fact the $\mu^{2}$ coordination mode of the alkyne to $\mathrm{Cu}^{\mathrm{B}}$ was quite distorted and dependent on the ligand nature. Concomitantly to the DFT investigation on binuclear processes of Fokin and coworkers [57], Straub published a computational investigation on copper acetylide complexes showing the same trend, i.e., di- and tetra-nuclear species display higher reactivity in the $\mathrm{CuAAC}$ reaction than do their mononuclear relatives [58a]. According to this study, the complexation of a supplementary copper atom reduces the $\mathrm{Cu}=\mathrm{C}=\mathrm{C}$ double bond character and therefore the ring strain in the metallocyclic 
intermediate. Following previous work [58b], Straub's group also recently presented the first molecular copper acetylide complex that featured high activity in CuAAC with added acetic acid even at $-5{ }^{\circ} \mathrm{C}$. The relationship between the "click" reactivity and the aggregation of acetylide-copper species different from dinuclear intermediates contributes to the mechanistic interpretation of this reaction. Indeed, complexes with acetylide ligands that bind copper species may be resting states of the catalyst in such click reaction mixtures that are not acidic [58c].

Following these pioneering computational works, several theoretical mechanistic investigations on the CuAAC reactions have been carried out, considering various copper systems, most of them multinuclear, and leading basically to similar qualitative conclusions [34,58-62]. A recent investigation pointed out the possibility for a concerted $v s$. stepwise nature of the mechanism, however, depending on the ligand nature [63]. The most recent experimental mechanistic study by Fokin's group unambiguously demonstrated the participation of a dinuclear copper intermediate in the case of a $\mathrm{CuAAC}$ reaction in which a mixture of $\mathrm{Cu}(\mathrm{I})(\operatorname{aryl})$ complex and $\left[\mathrm{Cu}(\mathrm{I})(\mathrm{MeCN})_{4}\right]^{+}$were used (Figure 2). Their study revealed that monomeric copper acetylide complexes were not reactive toward organic azides, except in the presence of exogenous copper catalyst [38]. Furthermore, direct injection by time-of-flight mass spectrometry (TOF-MS) for crossover experiments with an isotopically enriched exogenous copper source showed that two copper centers were involved within the cycloaddition process yielding the 1,4-substituted 1,2,3-triazoles. This mechanism was also recently confirmed by ESI-MS upon utilizing a mixture of an approach of neutral reactant and the strategy by Angelis's group that involves ion tagging and characterized the putative dinuclear copper intermediates [64].

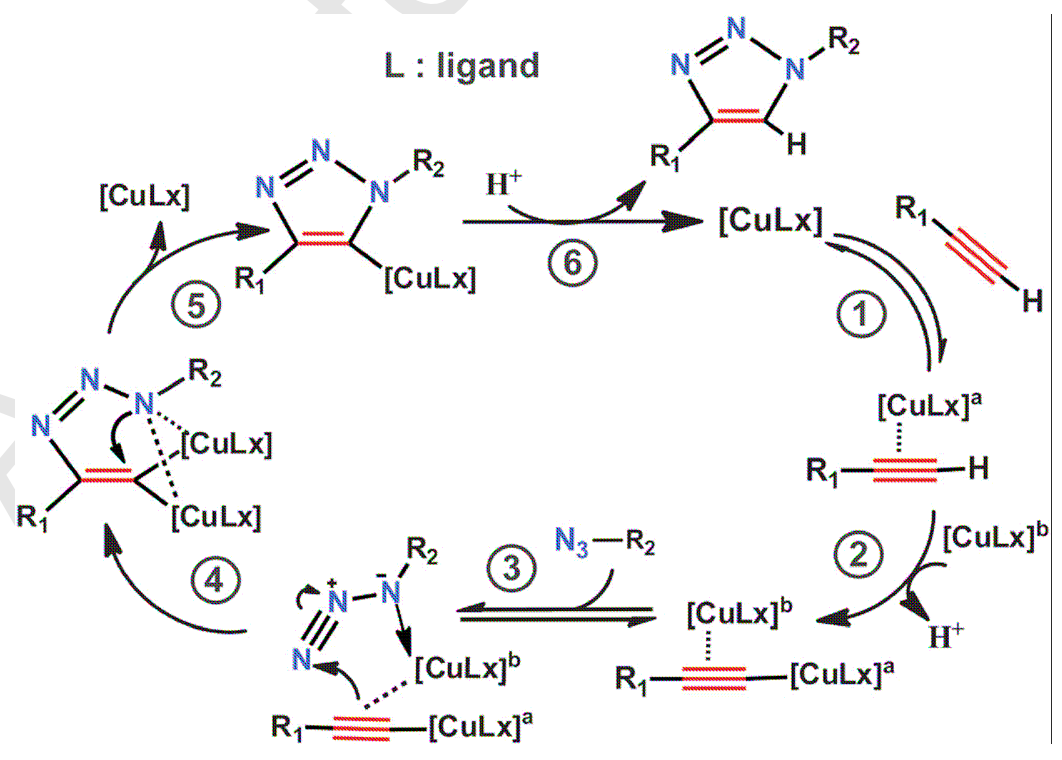

Fig. 2 Fokin's proposed mechanism for the CuAAC reaction with two copper centers. Reproduced with permission from ref. 38. Copyright 2013, American Association for the Advancement of Science. 
The CuAAC reaction is also working well with the mononuclear mechanism as shown by efficient intradendritic catalysis that cannot accommodate two metals at the active site for obvious steric reasons. Intradendritic catalysis with the $\mathrm{Cu}$ catalytic center located either at the dendrimer core or activated by the triazole ligand located on the dendrimer tether is so efficient that sometimes down to a ppm amount of $\mathrm{Cu}$ is enough to catalyze the $\mathrm{CuAAC}$ reaction in water at ambient temperature [27a]. In the case of the active $\mathrm{Cu}(\mathrm{I})$ tren catalyst, a dendrimer was constructed around the tren ligand with $\mathrm{Cu}$ at the metallodendrimer core, emphasizing the monometallic mechanism. In such cases, the proposed mechanism based on DFT calculations [27b] involves the following intermediates (Figure 3):

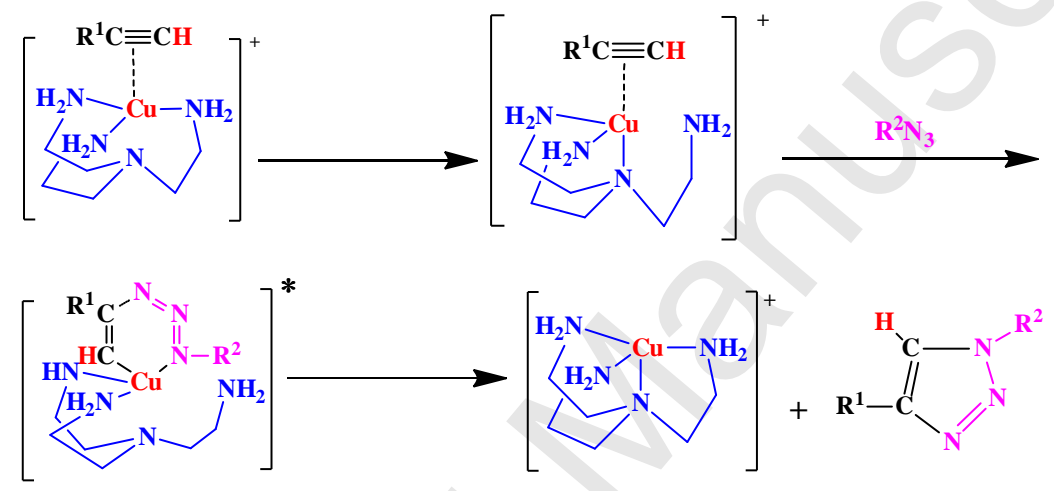

Fig. 3. Computed intermediates and transition state involved in the mechanism of $\mathrm{Cu}(\mathrm{I})$ (tren)-catalyzed $\mathrm{CuAAC}$ reactions.

With a NHC-Cu(I) catalyst, however, DFT calculations by Nolan's group confirmed that a different mechanism was operating taking into account the reactivity of internal alkynes [33]. The following research from this group reported that, with the version of the NHC ligands bearing $\mathrm{N}$-adamantyl substituents, the $\mathrm{Cu}$-iodide catalyst was always superior to other $[\mathrm{Cu}(\mathrm{NHC}) \mathrm{X}]$ complexes in water or under neat conditions [65]. Based on the fact that the transformations involved both terminal and internal alkynes, these authors proposed a multiple mechanistic pathways for AAC reaction that suggested that the alkyne (or acetylide following deprotonation) might bind either end on or side on to $\mathrm{Cu}$ (Fig. 4) [66]. Moreover, the addition of aromatic nitrogen donors to the reagent mixture increased the AAC reaction activity, as reported by Gautier's group [67]. Furthermore, Nolan's group also pointed out the importance of NHC salts formation in the investigation of the cationic bis-carbene complexes for AAC. Indeed, the positive role of the second NHC ligand for the deprotonation of the terminal alkynes favors the generation of a $[\mathrm{Cu}]$-acetylide species that plays a key role for AAC [68a]. 


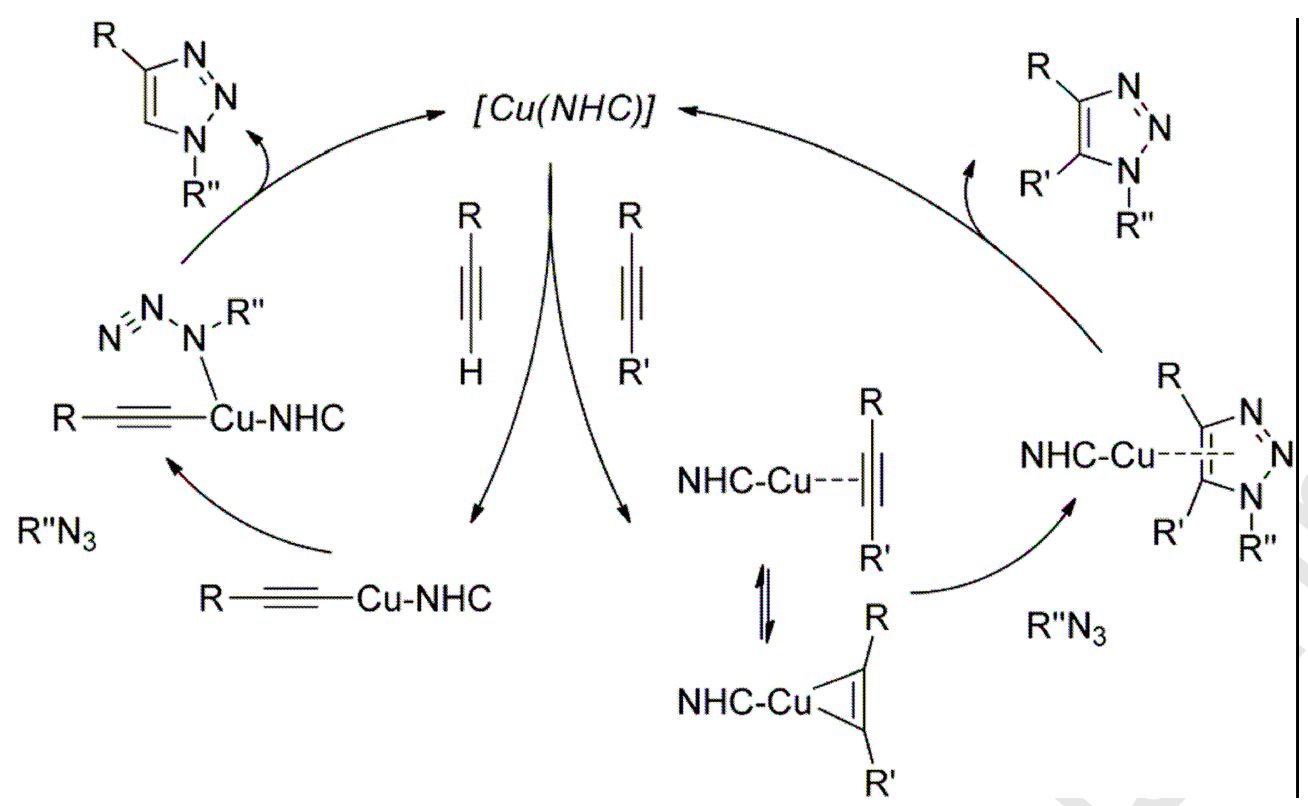

Fig. 4 Nolan's proposed multiple mechanistic pathways for the [3+2] cycloaddition of azides to alkynes. Reproduced with permission from ref. 66. Copyright 2013, Royal Society of Chemistry.

Recently, the Bertrand group compared the role of the anionic ligand in each individual step of the AAC reaction catalyzed by $\mathrm{LCuX}$ by examining the kinetic profiles on these stoichiometric reactions [68b]. The $\mathrm{X}$ ligands covered a broad range of basicity ( $\mathrm{X}=\mathrm{Cl}$, OAc, $\mathrm{OPh}, \mathrm{O} t-\mathrm{Bu}, \mathrm{OTf}$ ), and the L ligand was Bertrand's cyclic (alkyl)(amino)carbene (CAAC). In these cases, the steps are the metallation of the terminal alkyne, the formation of the $\sigma, \pi$-alkyne bis(copper) complex, the cycloaddition producing the metallated triazole, and the protolysis of the latter that regenerates the active catalytic species and produces the final triazole. Phenyl acetylene and benzyl azide were used as substrates. The results remarkably pointed out the Janus role of the $\mathrm{X}$ ligands. Basic $\mathrm{X}$ ligands favored the metallation, but disfavor the formation of the dinuclear intermediate, opposite to non-nucleophilic ligands. Acetate was a good compromise and very efficient for the protodemetallation step. That the dinuclear $\mathrm{Cu}$ species can be disfavored in the CuAAC mechanism is also an interesting result at variance with other studies [68b].

In the CuAAC reactions, one of the interesting ways to generate $\mathrm{Cu}(\mathrm{I})$ appeared recently is by $\mathrm{Cu}$ (II) photoreduction simply activated using light to induce the click reactions. Tasdelen, Yagci and Ramil et al. have reviewed these applications, especially toward biomolecular systems and macromolecular syntheses [69], The mechanisms of photoinduced CuAAC "click" reactions involved the direct (i) and indirect (ii) reduction pathways of $\mathrm{Cu}$ (II) to $\mathrm{Cu}$ (I). The photo-click chemistry using visible light requires a radical-generating photoinitiator that assists photoreduction of $\mathrm{Cu}$ (II) to reactive $\mathrm{Cu}$ (I) species for the CuAAC reaction (Fig. 5, route a) as demonstrated by Bowman's group [70]. For example, upon irradiation at 350-520 nm, the presence of an additional photoinitiator is not necessary when the solvent contains at least $15 \mathrm{wt} \%$ of methanol that serves for the photoreduction process [71]. Another 
technique consists in the direct photolysis of the $\mathrm{Cu}$ (II) complex to generate $\mathrm{Cu}(\mathrm{I})$ by $\mathrm{UV}$ light irradiation, because many $\mathrm{Cu}$ (II) complexes such as $\mathrm{CuCl}_{2} / \mathrm{PMDETA}$ [70b,70d,70e,72], $\mathrm{Cu}(\mathrm{AP})_{2}$-PMDETA [70c], $\mathrm{Cu}$ (II)-PAC complex (PAC = polynuclear aromatic compound) [73], $\mathrm{Cu}(\mathrm{II}) /$ carboxylate complex [74], and copper(II)-DMEDA complex [75] are sensitive to UV light or sunlight. Here the ligand is involved, i.e. it absorbs the UV light, promoting intramolecular electron transfer from the $\pi$-system of the ligand to the central $\mathrm{Cu}$ ion (Fig. 5, route b). During this process, $\mathrm{Cu}$ (II) is reduced to $\mathrm{Cu}(\mathrm{I})$ and the ligand is transformed into a radical species [76]. Interestingly, recently doping small amounts of $\mathrm{Cu}$ into the $\mathrm{ZnS}$ quantum dots (QDs) shell partially quenched the QD core (CdSe) luminescence, making QDs photoactivated vectors for the release of catalytically active $\mathrm{Cu}^{+}$ions for $\mathrm{CuAAC}$ [77]. On light irradiation, the QDs photo-oxidized with $\mathrm{S}$ was oxidized to $\mathrm{SO}_{\mathrm{x}}{ }^{\mathrm{y}-}$, causing $\mathrm{Cu}$ to form a complex with the azide that acted as a sacrificial electron acceptor allowing the click reaction to occur.

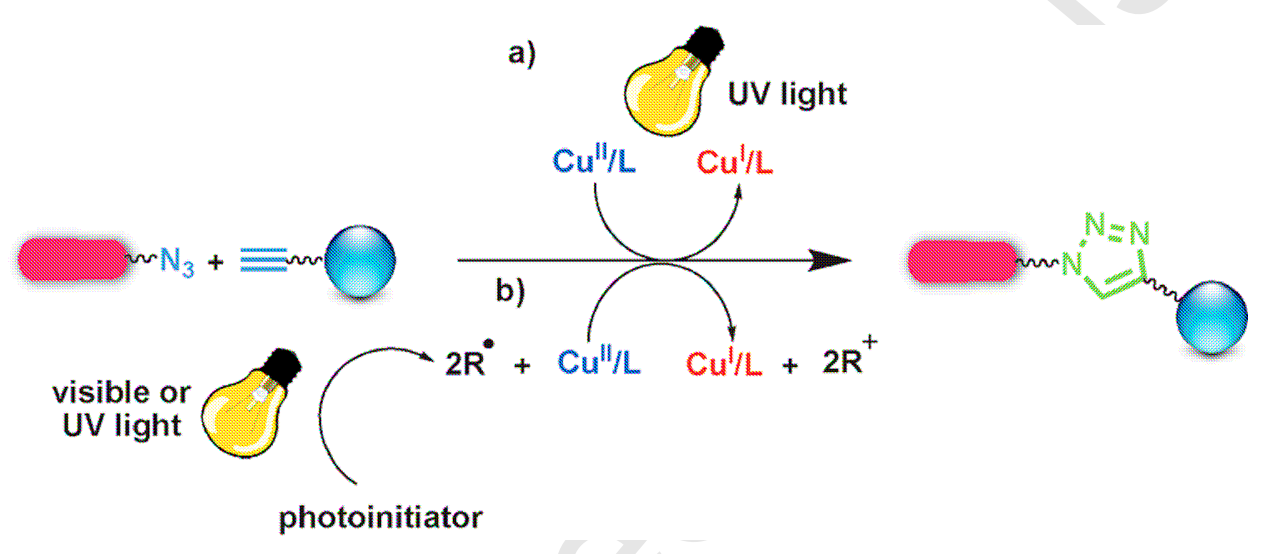

Fig. 5 Photoinduced CuAAC click reaction pathways. Reprinted with permission from ref. 69a. Copyright 2013, Wiley-VCH.

The other interesting ways to generate catalytic active species $\mathrm{Cu}(\mathrm{I})$ by using $\mathrm{Cu}(0)$ NPs is through comproportionation of $\mathrm{Cu}(0)$ and $\mathrm{Cu}(\mathrm{II})$ in the native oxide layer on the $\mathrm{Cu}$ surface [78]. In Alonso's proposed mechanism for the CuNP-catalyzed AAC, $\mathrm{Cu}(\mathrm{I})$ acetylides appeared as the true intermediate species [79]. The in-situ generation of $\mathrm{CuCl}$ was postulated after acetylene deprotonation, with the concomitant formation of triethylammonium chloride (in the presence of $\mathrm{LiCl}$ derived from CuNPs preparation), and the action of the latter on the CuNPs. The reaction of the nascent $\mathrm{CuCl}$ with the acetylide species would furnish the corresponding copper(I) acetylide (Fig. 6) [80]. From this point of view, the reaction mechanism followed the original stepwise pathway that was proposed by Noodleman, Sharpless and Fokin et al [31]. 


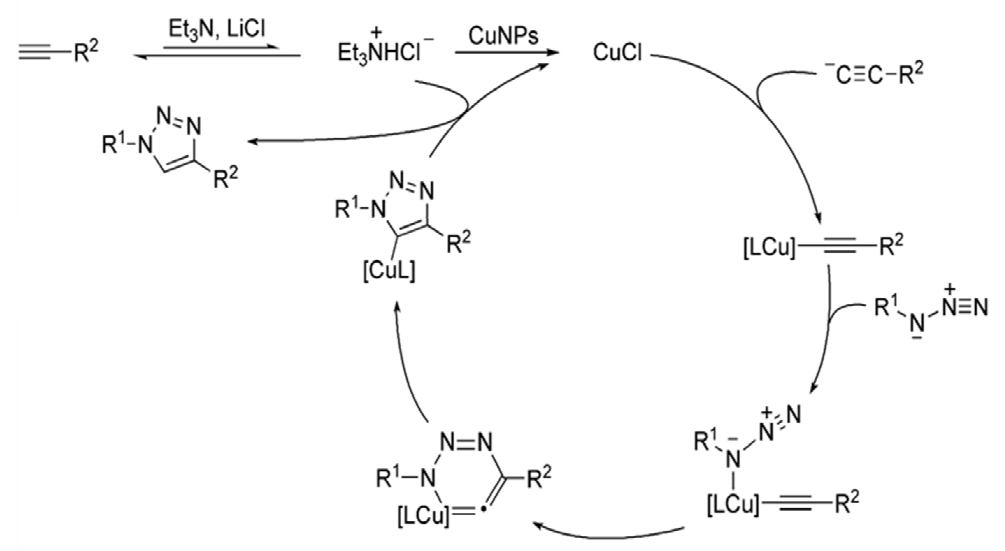

Figure 6. Reaction mechanism proposed for the CuNPs-catalysed 1,3-dipolar cycloaddition of terminal alkynes and azides. Reproduced with permission from ref. 80. Copyright 2010, WILEY-VCH.

\subsection{The RuAAC reactions}

Apart from copper, the most frequently used catalysts for the MAAC reactions are ruthenium-based catalysts, the reaction being then abbreviated as RuAAC. Among all the $\mathrm{Ru}$ catalysts, the most investigated ones are the pentamethylcyclopentadienyl ruthenium chloride-based (noted $[\mathrm{Cp} * \mathrm{RuCl}]$ ) complexes), although Fokin's group also observed that the steric encumbrance imparted by the $\mathrm{Cp}^{*}$ ligand is detrimental to the reaction [81]. These complexes catalyzed the regioselective RuAAC reaction of terminal alkynes forming, unlike CuAAC catalysts, 1,5-disubstituted 1,2,3-triazoles, and also unlike the CuAAC catalysts, they reacted with internal alkynes providing trisubstituted 1,2,3-triazoles [28,39,40,82]. The $\mathrm{Cp} * \mathrm{RuCl}$ based catalysts provided multiple application that were recently developed (vide infra) [81, 83-87]. 


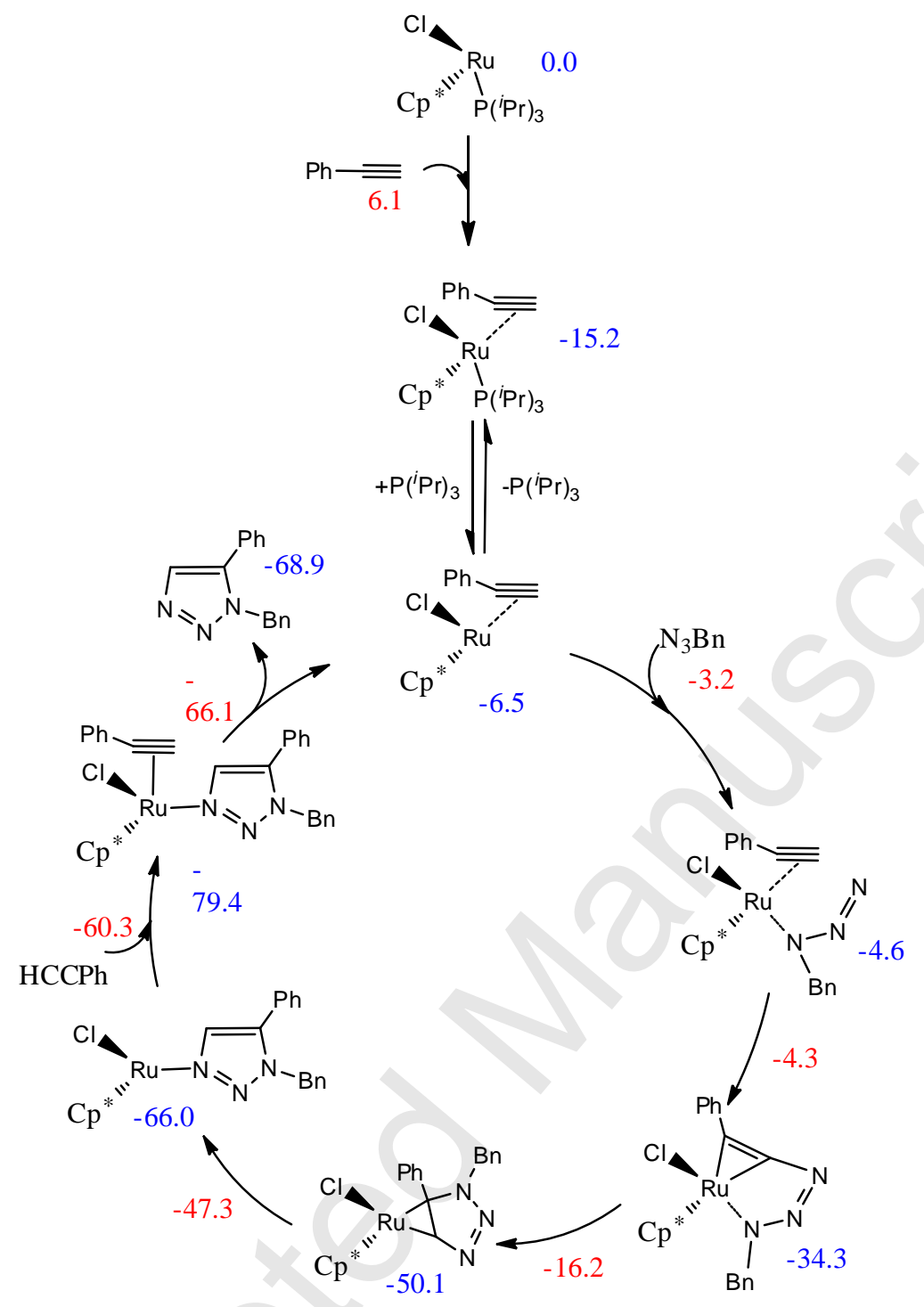

Fig. 7 Activation of the precatalyst and catalytic mechanism of the RuAAC of phenylacetylene with benzylazide. Numbers colored in blue and in red are computed relative free energies of intermediate and transition states, respectively (in $\mathrm{kcal} / \mathrm{mol}$ ). Reproduced with permission from ref. 88. Copyright 2012, American Chemical Society.

The first mechanistic investigation was proposed by Lin, Jia, Fokin and coworkers based on DFT calculations [39]. The firstly formed azide-alkyne Ru complex was suggested to lead to a 6-membered ruthenacycle intermediate, followed by reductive elimination and formation of the triazole product. Subsequent calculations by Poater, Nolan and coworkers [88] found a somewhat different pathway but confirmed the key ruthenacycle intermediate. Their computed mechanism is reproduced in Fig. 7. More recently, Boz and Tüzün published a detailed DFT study in which various terminal and internal alkynes as well as $\mathrm{Cp}$ and $\mathrm{Cp}^{*}$ ligands were considered [41]. They investigated the various possible mechanisms ensuing from the four possible configurations of the azide-alkyne Ru precursor complex. This detailed investigation 
allowed them to evaluate the interplay between the various electronic and steric effects. In any case the formation of a key 6-membered ruthenacycle intermediate is confirmed. Their computed regioselectivities (particularly in the case of internal alkynes) reproduce the experimental ones.

Given the richness of ruthenium catalysis, other families of ruthenium catalysts were disclosed. The Jia group first reported the RuAAC of terminal alkynes with $100 \%$ selectivity to lead to 1,4-disubstituted 1,2,3-triazoles using the catalyst $\left[\mathrm{RuH}_{2}(\mathrm{CO})\left(\mathrm{PPh}_{3}\right)_{3}\right][29,89]$. Then they compared a family of Ru catalysts that do not contain $\mathrm{Cp}$ ligands for the RuAAC reaction of terminal alkynes to selectively yield 1,4-disubstituted 1,2,3-triazoles [29], and the most efficient catalyst was $\left[\mathrm{RuH}\left(\eta^{2}\right.\right.$ $\left.\left.\mathrm{BH}_{4}\right)(\mathrm{CO})\left(\mathrm{PCy}_{3}\right)_{2}\right]$. Both the experimental results and the DFT calculations indicated that the active species in the reactions was $\left[\mathrm{Ru}(\mathrm{C} \equiv \mathrm{CR})_{2}(\mathrm{CO})\left(\mathrm{PR}_{3}^{\prime}\right)_{2}\right]$ (Fig. 8). In their proposed mechanism, the authors indicated that the $\mathrm{Ru}$-acetylide species 1 first formally underwent a cycloaddition reaction with an azide to give the species [Ru(triazolyl)], 2 (Fig. 8) resulting from initial coordination of the azide to the $\mathrm{Ru}$ center in 3 via the internal nitrogen atom (Fig. 9). Then, with a terminal alkyne metathesis of the $\mathrm{Ru}-\mathrm{C}$ bond occurred via a four-centered transition state yielding the 1,4-disubstituted 1,2,3-triazole, which regenerates the starting catalyst. The complete mechanism of this catalytic cycle proposed by Jia, Lin, Fokin, and coworkers [29] from a detailed DFT analysis of the mechanism with propyne, methylazide and $\left[\mathrm{Ru}(\mathrm{CCMe})_{2}(\mathrm{CO})(\mathrm{PMe})_{2}\right]$ is shown in Fig. 9. These authors showed also that the formation of the 1,5-triazole is highly disfavored. This is in line with Boz and Tüzün's theoretical work (see above) that indicated the importance of the electronic and steric effects for the regioselectivity, both thermodynamic and kinetic parameters playing a crucial role in the reactions [41].

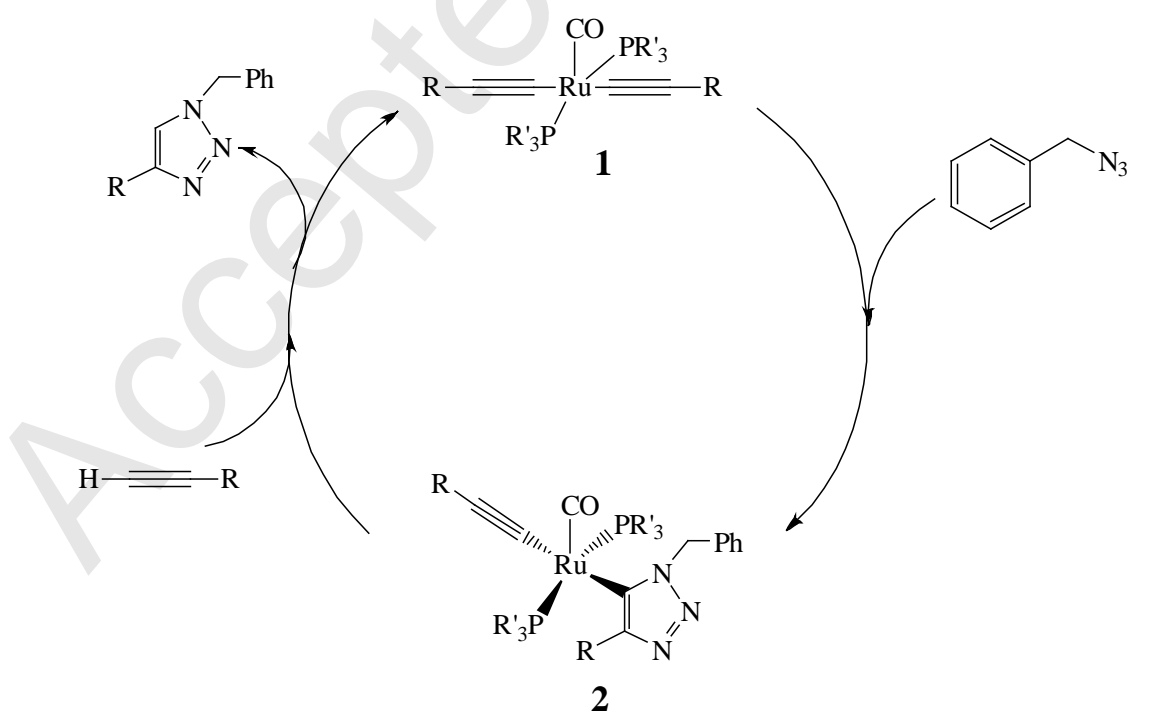

Fig. 8 Proposed catalytic cycle of RuAAC reaction catalyzed by $\left[\mathrm{RuH}\left(\eta^{2}-\right.\right.$ $\left.\mathrm{BH}_{4}\right)(\mathrm{CO})\left(\mathrm{PCy}_{3}\right)_{2}$ ]. Reproduced with permission from ref. 29. Copyright 2012, American Chemical Society. 


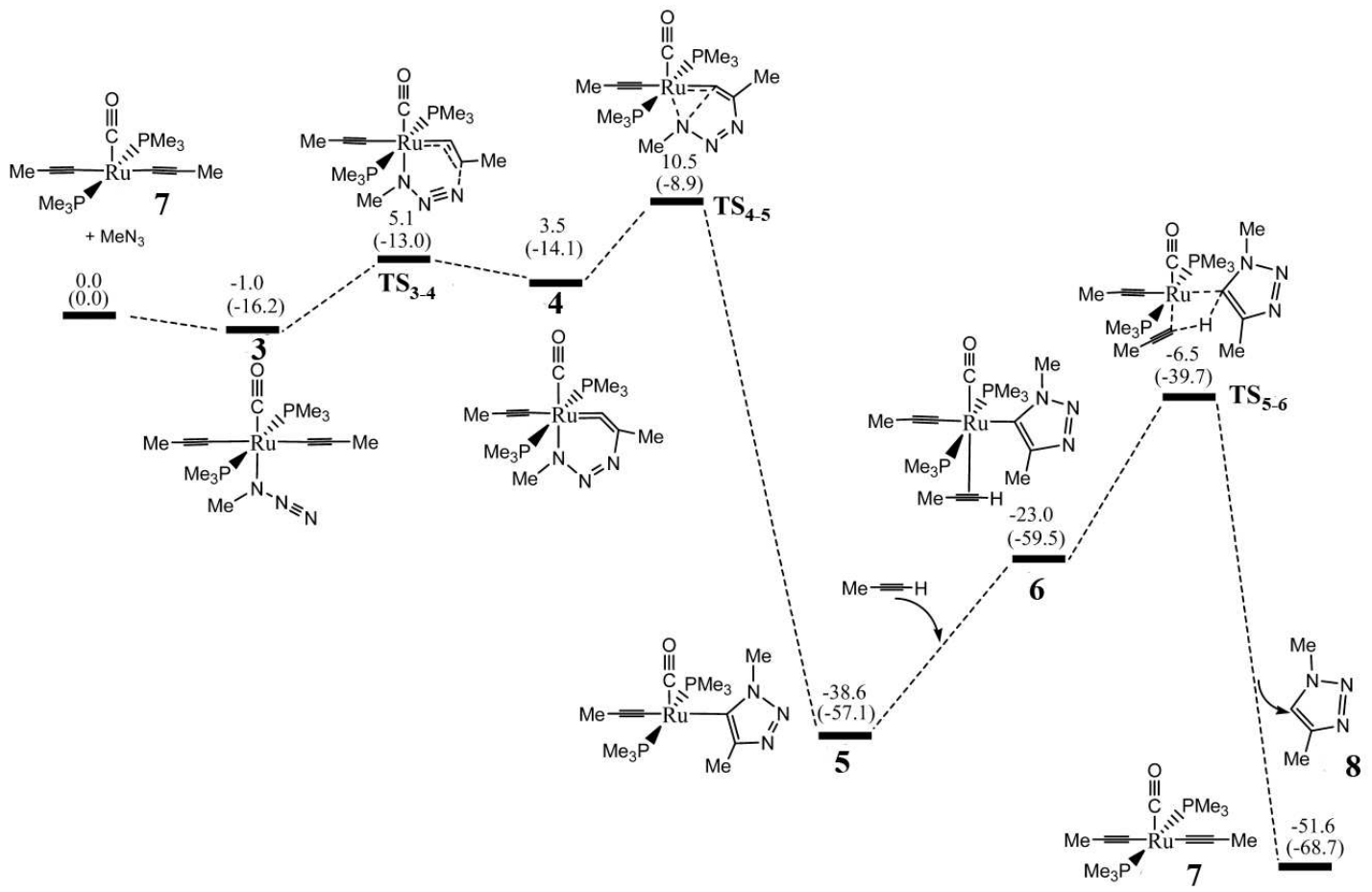

Fig. 9 DFT free energy profile (in $\mathrm{kcal} / \mathrm{mol}$ ) for the proposed mechanism of the formation of 1,4-triazole catalyzed by a Ru complex lacking cyclopentadienyl ligand. Reproduced with permission from ref. 29. Copyright 2012, American Chemical Society.

Lo's group presented the first case of ruthenium azido complexes catalyzing the cycloaddition reaction of terminal alkynes with alkyl azides [90,91]. The new ruthenium azido complexes were synthesized from the mother $\mathrm{TpRu}$ complex $\left[\mathrm{Ru}(\mathrm{Cl})(\mathrm{Tp})\left(\mathrm{PPh}_{3}\right)_{2}\right], \quad \mathrm{Tp}=\mathrm{HB}(\mathrm{pz})_{3}, \quad \mathrm{pz}=$ pyrazolyl $)$, yielding first $\left[\mathrm{Ru}\left(\mathrm{N}_{3}\right)\left(\mathrm{PPh}_{3}\right)\left[\mathrm{Tp}\left({ }^{t} \mathrm{BuNC}\right)\right][90]\right.$, then the amine-substituted ruthenium azido complex $\left[\mathrm{Ru}\left(\mathrm{N}_{3}\right)\left(\mathrm{Tp}\left(\mathrm{PPh}_{3}\right)\left(\mathrm{EtNH}_{2}\right)\right]\right.$ [91]. Although the detailed mechanism could not be established, the authors speculated a similar mechanism to previous proposed by Fokin et al [28]. As shown in Fig. 10, the displacement of the spectator ligands $\left(\mathrm{EtNH}_{2}, \mathrm{PPh}_{3}\right)$ produced the activated intermediate $\mathbf{A}$ that was then converted to the intermediate $\mathbf{B}$ via the oxidative coupling of an alkyne and an azide. After that, ligand substitution occurred in $\mathbf{B}$ leading to the release of the aromatic triazole product and regenerating the catalyst. Interestingly, in both cases, the $\mathrm{N}_{3}$ ligand in the ruthenium azido complex did not couple the terminal alkyne in the substrate, because reaction energy for convertion of $\mathbf{A}$ to $\mathbf{B}$ is much smaller than that for convertion of $\mathbf{A}$ to $\mathbf{C}$ (DFT-computed free energies $-45.9 \mathrm{kcal} / \mathrm{mol}$ vs $34.9 \mathrm{kcal} / \mathrm{mol}$, respectively) [91]. 


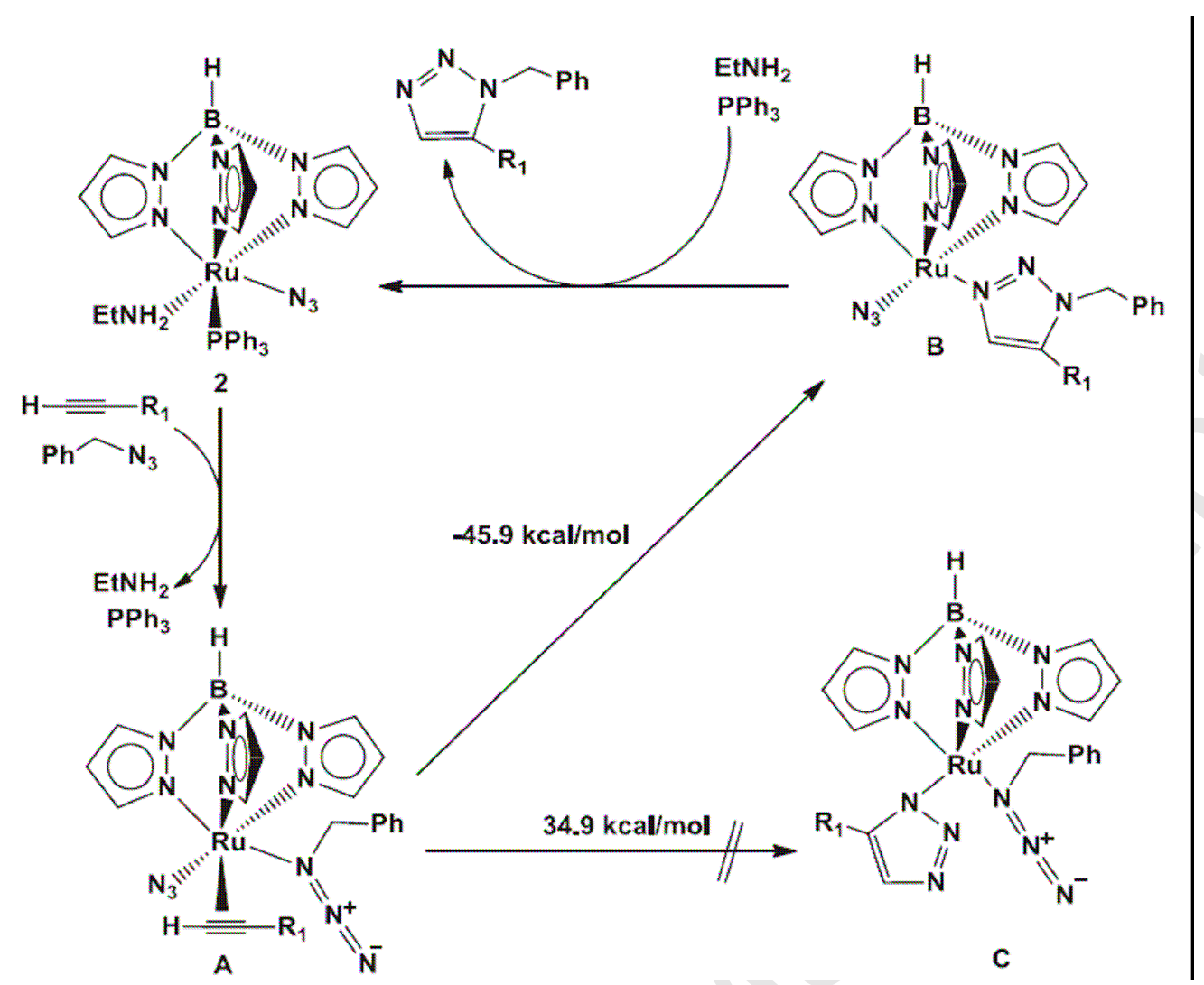

Fig. 10 Proposed mechanism of the RuAAC catalysis by ruthenium azido complexes. Reprinted with permission from ref. 91. Copyright 2014, Elsevier B.V.

\subsection{The AgAAC reactions}

In a seminal report McNulty's group published the first example $\mathrm{Ag}(\mathrm{I})$ catalyst of the AAC reaction without copper at room-temperature (r.t.) [92]. Silver(I) salts alone were not efficient to promote the AAC reactions, but when AgOAc reacted with the $\mathrm{P}, \mathrm{O}$-ligand 2-diphenylphosphino- $N, N$,-diisopropylcarboxamide, the $\mathrm{P}, \mathrm{O}$ ligandsilver(I) complex catalyzed the AAC reaction very well. Further experiments indicated that silver acetylide intermediate activated the formation of an acetylideazide species toward cyclization [93]. Thus a reaction mechanism for homogeneous $\mathrm{Ag}(\mathrm{I})$-catalyzed AAC reaction was proposed (Fig 11). First of all, the loss of acetate from the 18-electron species 9 yield the active 14-electron catalyst I, forming the ligated silver(I) acetylide II, the electrophilicity of which is modulated by the hemilabile amide substituent. The nucleophilic reaction of the azides on II gives the species IIIA. The hemilabile ligand in IIIA intervenes by amide complexation generating a coordinatively saturated species that transfers the charge via the filled $d$ orbitals to the $\pi^{*}$ orbitals of the acetylide resulting in cyclization. The reaction occurs via the intermediate metallacycle (IIIB). Then the nitrogen atom migrates to carbon transporting two electrons to form the triazole $\mathbf{I V}$, forming $\mathbf{3}$ by protonation, and the active catalyst $\mathbf{I}$ is regenerated.

Ortega-Arizmendi et al. also reported an "abnormal" NHC complex, Ag(I)-aNHC, that catalyzed the ACC reactions [94]. In this case, silver chloride by itself catalyzed 
the cycloaddition of various alkynes and azides in good yield, however with side reactions. Further introduction of the aNHC ligand avoided side reactions and facilitated the purification of the final products. Hybrid AgNP catalysts were also developed. For example, Salam and co-workers recently reported that the AgNP/graphene oxide (Ag/GO) based composite catalyzed multi-component reactions and one-pot click reaction (Fig. 12). In their approach, the catalysts were very stable and showed no silver leaching or aggregation, and were reused at least 5 times without loss of catalytic activity [95]. However when the AAC reaction is said to be catalyzed by Ag-based catalysts or other metal catalysts, caution is appropriate, because trace amount of copper contaminants could be enough to catalyze the AAC reactions. Indeed, Connell et al. found that the successful cycloaddition of an azide and terminal alkyne catalyzed by the isolated complex $\left.\left[\mathrm{Ag}_{2}\left(\mathbf{L}^{\mathbf{1}}\right)_{2}\right]\left(\mathrm{BF}_{4}\right)_{2}\right]$ was actually catalyzed by trace amounts of copper in the catalyst [96]

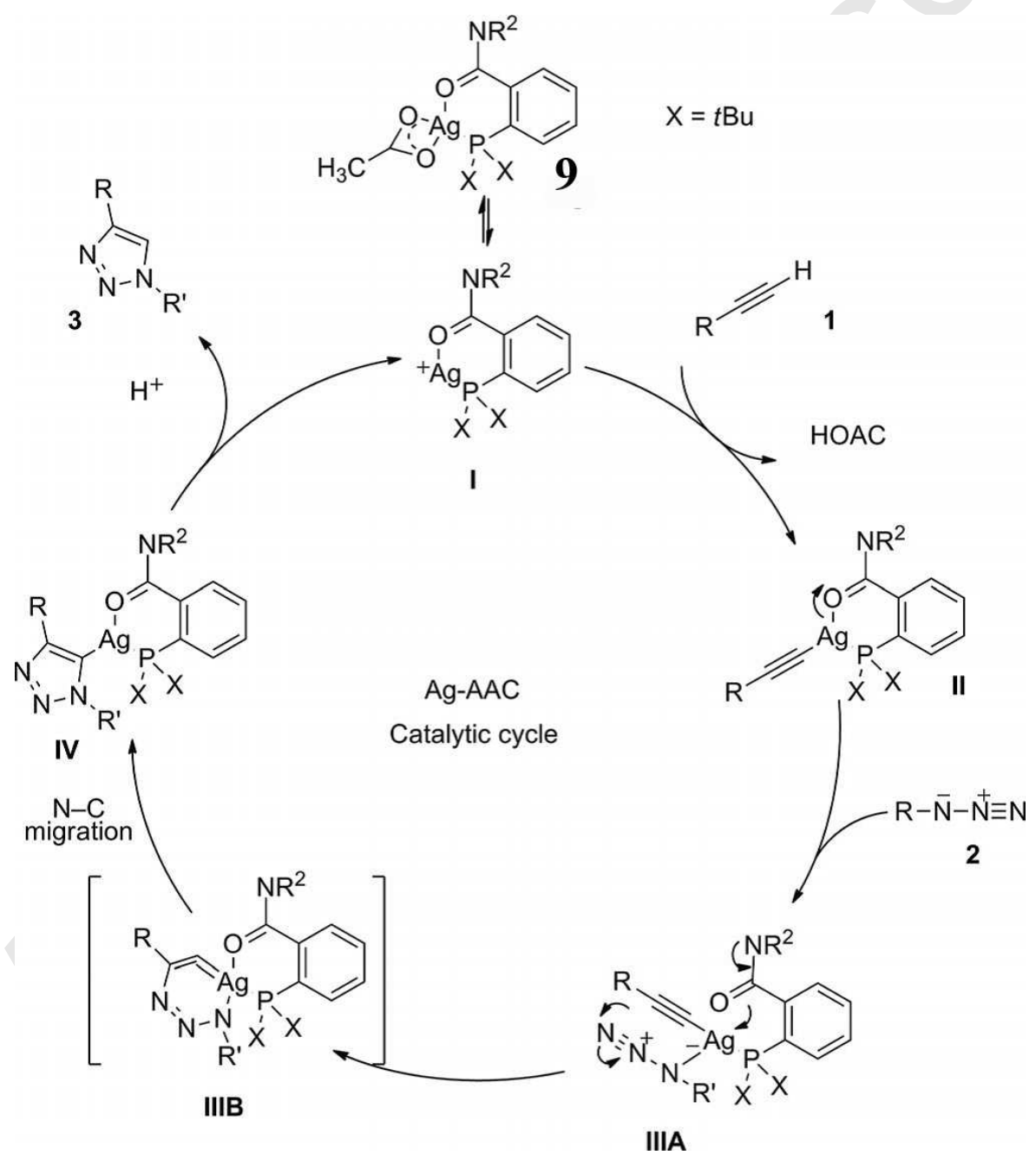

Fig. 11 Proposed catalytic cycle for the homogeneous Ag(I)-catalyzed AAC reaction. Reproduced with permission from ref. 93. Copyright 2012, WILEY-VCH. 


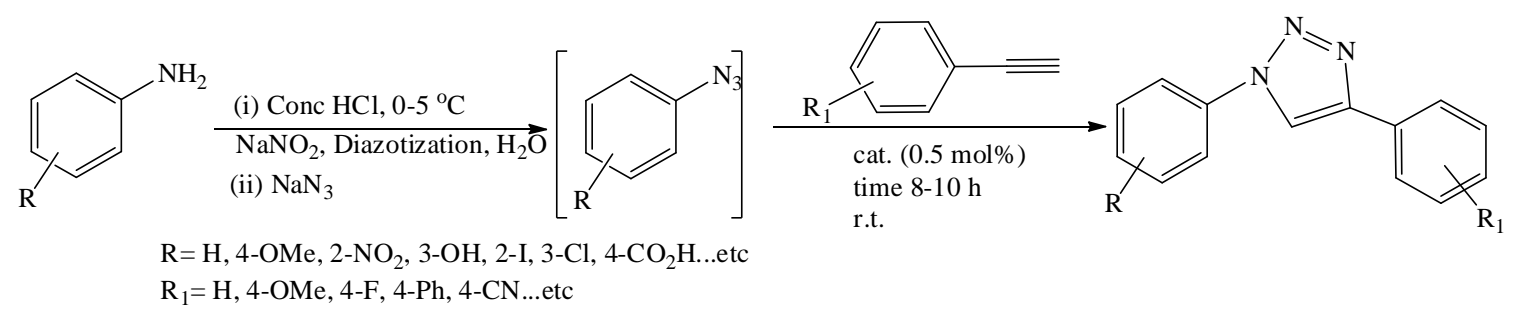

Fig. 12 One-pot AAC reaction catalyzed by Ag/GO. Reproduced with permission from ref. 95. Copyright 2014, Royal Society of Chemistry.

Ferretti et al recently reported that silver(I) oxide nanoparticles $\left(\mathrm{Ag}_{2} \mathrm{O}\right.$ NPs) catalyzed $\mathrm{AAC}$ reactions in anhydrous toluene [97]. Although the $\mathrm{Ag}_{2} \mathrm{O}$ catalyst was less efficient than the conventional $\mathrm{Cu}^{\mathrm{I}}$ catalyst that was generated from the $\mathrm{Cu}(0)$ and $\mathrm{CuO}$ under the same condition, the $\mathrm{Ag}_{2} \mathrm{O}$ NPs are somewhat effective, robust and reusable, especially in the presence of a small amount of water. In this case, substituent effects were noticed, and substrates containing electron-withdrawing groups onto the azide moiety gave mixtures of regioisomeric cycloadducts, which was a limitation. One should recall here that the uncatalyzed Huisgen reaction that yields such mixtures of isomeric cycloadducts works under ambient or mild conditions when substrates possess electron-withdrawing groups [25]. Sarma's group then compared various silver sources in AAC reactions conducted in $\mathrm{H}_{2} \mathrm{O}$ /ethylene glycol (EG) under ambient conditions without exclusion of air [98]. The ligands and solvents played a critical role in their approach. Upon optimization the combinations of $\operatorname{AgN}(\mathrm{CN})_{2}$ as a catalyst and DIPEA as a base/ligand gave the best results. It was proposed that this ligand played the same role as the tertiary amine in CuAAC reactions in the intermediate step. Various 1,4-disubstituted-1,2,3-triazoles were synthesized in high isolated yield under these very mild conditions, showing that $\operatorname{AgN}(C N)_{2} / D I P E A$ is a highly effective catalytic system for the AAC reactions. 


\subsection{The AuAAC reactions}

(a)

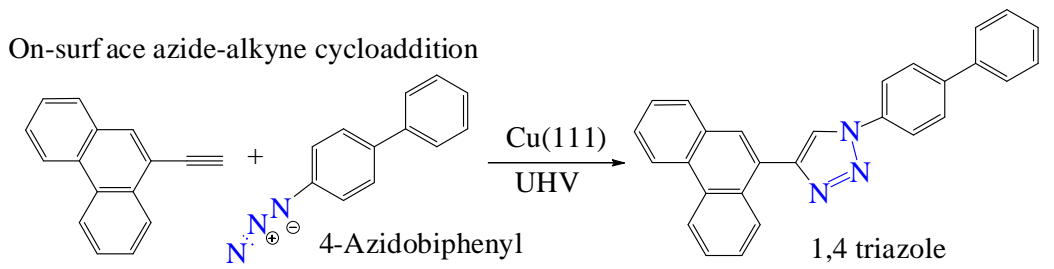

9-Ethynylphenanthrene

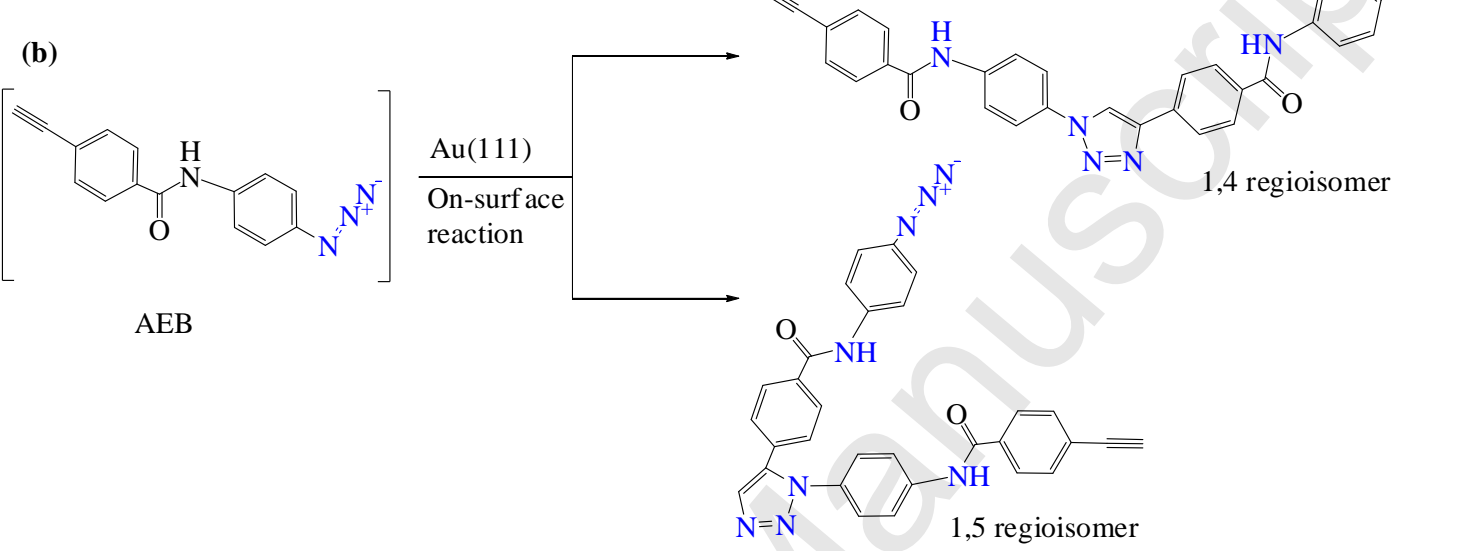

Fig. 13 (a) On $\mathrm{Cu}(111)$ surface catalyzed AAC. (b) Proposed on-surface AAC reaction of $\mathrm{N}$-(4-azidophenyl)-4-ethynylbenzamide (AEB) and possible regioisomeric dimers 2 and 3. Reproduced with permission from ref. 100 and 101, respectively. Copyright 2013, American Chemical Society.

"On-surface" chemistry was a viable method to synthesize covalent nanostructures under ambient temperature at the surface under ultra-high-vacuum (UHV) conditions [99]. This method has also been used to explore the mechanism of AAC reaction and guide the catalyst design. Bebensee et al. recently reported the fully regioselective AAC reaction on a $\mathrm{Cu}(111)$ surface leading to 1,4-triazoles (Fig. 13a) resulting from copper acetylide formation subsequent to $\mathrm{C}-\mathrm{H}$ activation and bonding of the alkynyl group to the $\mathrm{Cu}(111)$ surface. The reaction proceeded with a very low yield. Therefore XPS showed that significant degradation of the azide upon adsorption occurred on the surface, though the reaction proceeded readily; especially the intact reactants were available on the surface [100]. Using on-surface chemistry under UHV, Arado et al. explored the MAAC reaction on $\mathrm{Au}(111)$ (Fig. 13b). By combining cryogenic scanning tunneling microscopy (STM) and DFT studies, they confirmed Bebensee's results on $\mathrm{Cu}(111)$ (vide supra) according which the MAAC reaction occurred on the [100] surface. However, the difference between these two examples is that $\mathrm{Au}(111)$ is not catalytically involved in $\mathrm{C}-\mathrm{H}$ activation of alkyne. It only played a role as a twodimensional (2D) surface to place the two partners of the reaction, which provided the observed selectivity. The successful control of the regioselectivity of the MAAC by 
surface constraint together with the careful design of the reactants provided the effective well-defined nanostructure without the requirement of a catalyst or additional thermal activation [101]. Recently another particular case using a heterogeneous reusable $\mathrm{Au} / \mathrm{TiO}_{2}$ nanostructure to efficiently catalyze the AAC reaction was highlighted (Fig. 14a). The authors proposed a mechanism in three steps (Fig. 14b): (i) a gold atom (I) reduced the electron density on the alkyne, enabling facile nucleophilic attack by the azide; (ii) a six member intermediate II, then intermediate III formed (iii) gold was removed to afford 1,4-disubstituted 1,2,3triazoles and complete the reaction cycle [102].

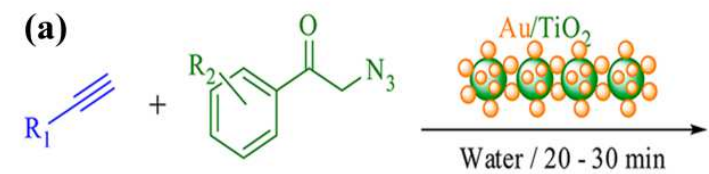

$\mathrm{R}_{1}=$ phenyl, 2-methoxyphenyl, cyclohexenyl, COOEt

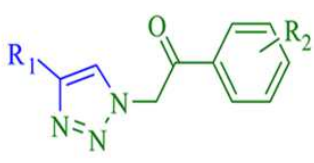

$86-97 \%$

(b)

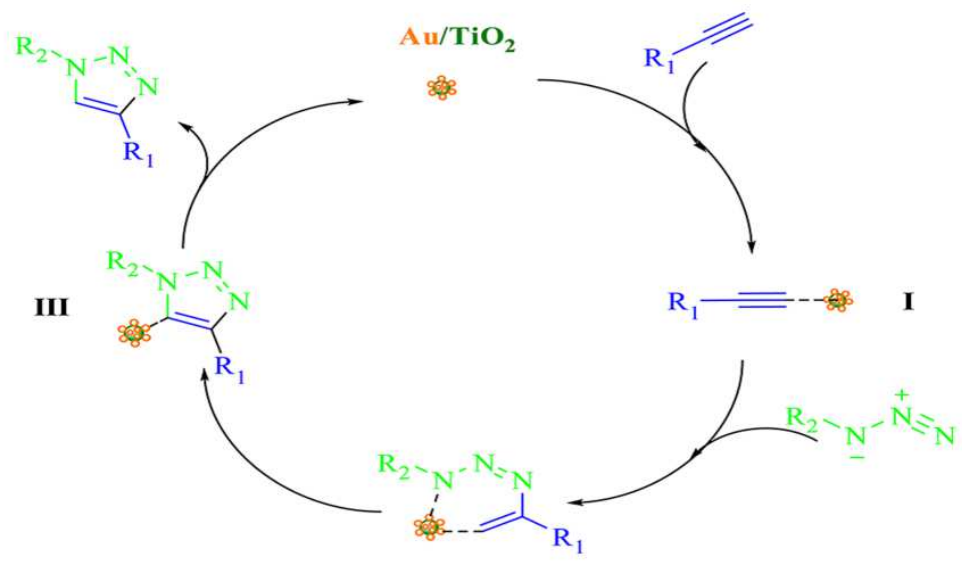

II

Fig. 14 (a) Titania-supported gold nanosphere-catalyzed 1,2,3-triazole synthesis. (b) Plausible mechanism for the formation of triazole. Reproduced with permission from ref. 102. Copyright 2013, American Chemical Society.

\subsection{The IrAAC reactions}

The Iridium-catalyzed intermolecular AAC (IrAAC) has also proved to be a valuable complement to the well-known CuAAC and RuAAC reactions. The dimeric iridium complex $[\operatorname{Ir}(\mathrm{cod}) \mathrm{OMe}]_{2}$ catalyzed the direct formation of new 1,4,5-trisubstituted triazoles [103]. [ $\mathrm{Ir}(\mathrm{cod}) \mathrm{OMe}]_{2}$ catalyzed the AAC reaction bromoalkynes producing 1,5-disubstituted 4-bromo-1,2,3-triazoles under mild conditions (Fig. 15). The electronic features of the alkyne component strongly affected the reaction yield, i.e. the arylalkynes that are electron rich showed the optimized reactivity, while the bromoalkynes that are electron deficient provided a low yield of the corresponding 4bromotriazoles. This catalyst was used to prepare 1,4,5-trisubstituted triazoles 
subsequent to Pd-catalyzed Suzuki-Miyaura reactions with appropriate arylboronic acids. Ding et al. compared various Ir complexes in the IrAAC of electron-rich internal alkynes and showed that the use of $[\operatorname{Ir}(\operatorname{cod}) \mathrm{Cl}]_{2}$ optimized the reaction [104]. The increase of steric hindrance on the alkyne did not affect the reaction efficiency, but an electronic effect was also observed, i.e. electron-deficient alkynes led to moderate or good efficiency, while electron-rich and normal alkynes showed low reactivity except the aryloxy alkyne and selenyl alkyne.

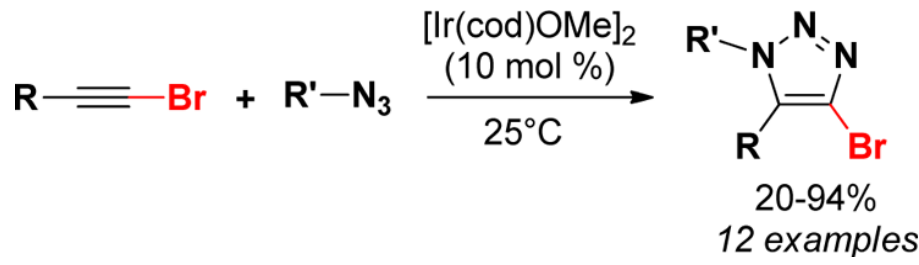

Fig. 15 Synthesis of 1,4,5-trisubstituted triazoles catalyzed by a dimeric iridium complex. Reprinted with permission from ref. 103. Copyright 2013, American Chemical Society.

These differences in the regioselectivities of addition of thioalkynes and bromoalkynes to azides have been elegantly rationalized through DFT calculations by Lin, Jia and coworkers [105]. Their major findings are summarized in Fig. 16. Both mechanisms start with the precoordination of the alkyne and azide on the metal center of $[\operatorname{Ir}(\mathrm{cod}) \mathrm{X}]$. In the case of thioalkynes, a metallabicyclic Ir-carbene intermediate, stabilized by the $\pi$-donor effect of the ${ }^{2} \mathrm{RS}$ substituent is formed. In the case of bromoalkynes this $\pi$-donor effect is much weaker, and the metallabicyclic intermediate cannot be stabilized. Rather, a six-member metallacycle intermediate is formed and, depending on the $\pi$-donating ability of the $\mathrm{R}$ substituent, the 4 - or the 5bromotriazole is formed preferentially, as sketched in Fig. 16. 

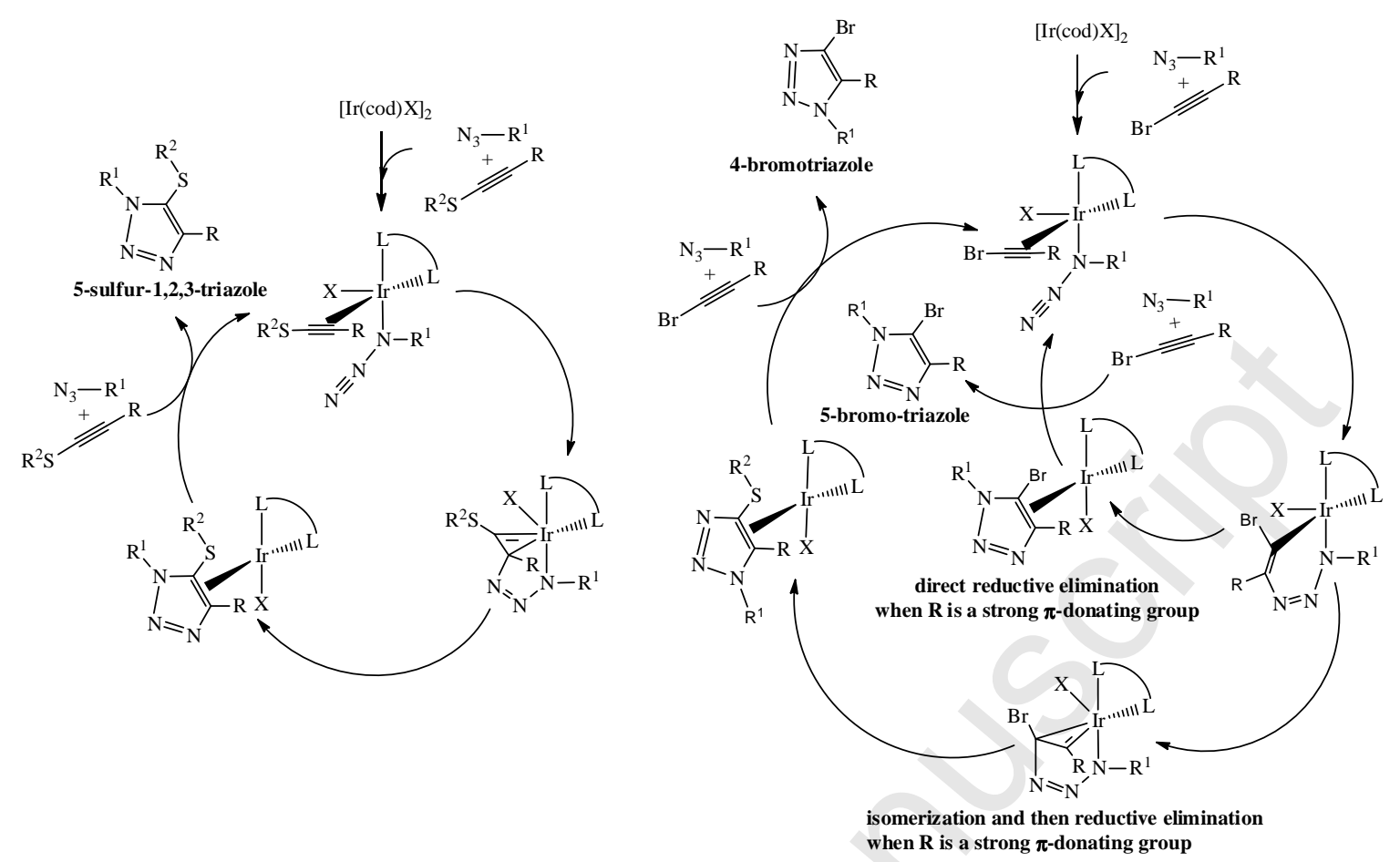

Fig. 16. The different IrAAC mechanisms proposed in the case of the addition of thioalkynes and bromoalkynes to azides in the presence of the $[\operatorname{Ir}(\operatorname{cod}) \mathrm{X}]_{2}(\mathrm{X}=\mathrm{Cl}$ or OMe) dimer. Reproduced with permission from ref. 105. Copyright 2014, American Chemical Society.

\subsection{The NiAAC reactions}

Rao's group recently demonstrated that the Raney $\mathrm{Ni}$, without additional reducing agent, efficiently catalyzed acetylene azide cycloaddition reactions to form 1,2,3triazoles [106]. In their methodology, the Raney nickel catalyzed combinatorial NiAAC with excellent yield. (Fig. 17a) To explore the NiAAC reaction pathway, deuteration experiments were conducted (Fig. 17b) in the presence of $\mathrm{Ni}(0)$ indicating that, unlike the copper-acetylide formation in CuAAC, the cycloaddition went through a metallocycle [107]. Thus in their proposed mechanism, the reaction starts on the Raney nickel surface by acetylene complexation leading to the $\pi$-complex 11 (Fig. 17b). Then the reaction proceeds AAC leading to $\mathbf{1 3}$ via $\mathbf{1 2}$, and the Ni-acetylene species led to AAC in the orientation shown in 14. The authors suggested that stereoelectronic features of the azide and alkyne favor the transition states $\mathbf{1 2}$ or $\mathbf{1 4}$ leading to the 1,4-product preferred to 1,5. 
(a)

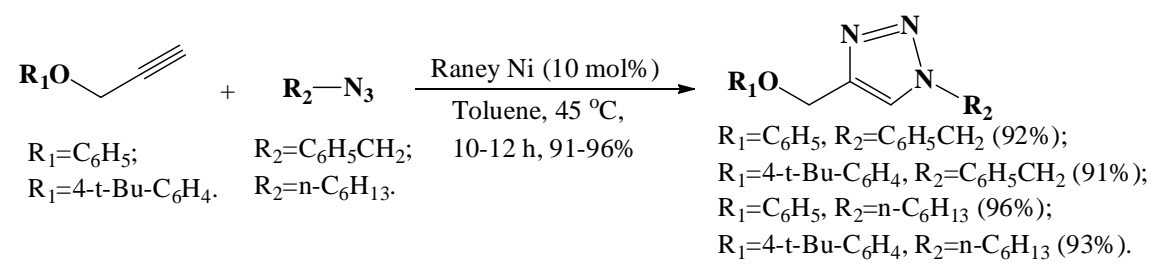

(b)

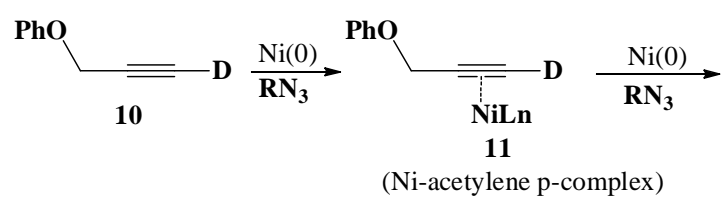
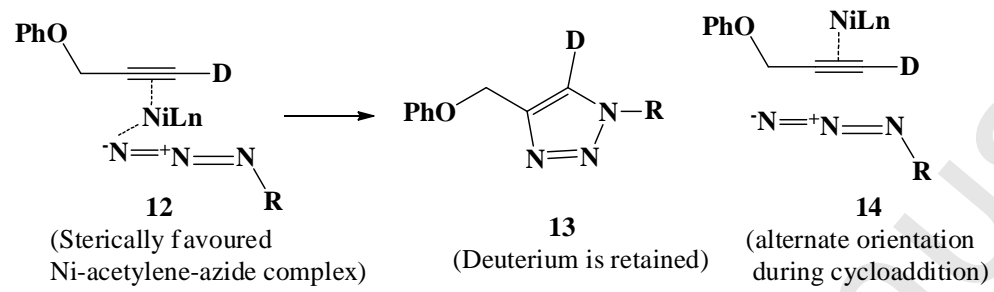

Fig 17 (a) Combinatorial cycloaddition of two aryl propargyl ethers to benzyl and $n$ hexyl azides catalyzed by Raney Ni, and (b) Proposed mechanism for the NiAAC. Reproduced with permission from ref. 106. Copyright 2014, Royal Society of Chemistry.

\subsection{The $\mathrm{ZnAAC}$ reactions}

For the ZnAAC reactions, pioneering contribution by Chen's group showed that heterogeneous zinc-on-charcoal $(\mathrm{Zn} / \mathrm{C})$ catalyzed the cycloaddition of aryl/aliphatic azides and aryl alkynes (including internal alkynes) in DMF at $50{ }^{\circ} \mathrm{C}$ without exclusion of air (63\%-94\% yield) (Fig. 18) [108]. In this case, no electronic effect was observed, both electron-rich and electron-poor azides generating similar good reaction yield. The catalyst was recovered and reused for at least five times without significant decrease of activity. When ZnNPs were alloyed with CuNPs to form the catalysts for multicomponent 1,2,3-triazole synthesis/triazole alkynylation, the presence of $\mathrm{Zn}$ resisted the oxidation of $\mathrm{Cu}$ by sacrificial formation of $\mathrm{ZnO}$ that played a role in controlling the formation of alkynylated triazoles [108].

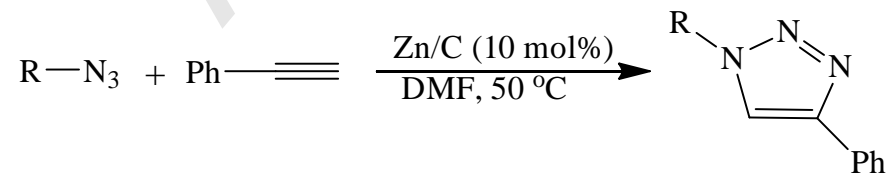

Fig. $18 \mathrm{Zn/C-catalyzed} \mathrm{AAC} \mathrm{reactions.} \mathrm{Reproduced} \mathrm{with} \mathrm{permission} \mathrm{from} \mathrm{ref.} 108$. Copyright 2010, WILEY-VCH.

On the other hand, Greaney's group also described a mild method for the regioselective formation of 1,5-substituted 1,2,3-triazoles upon using $\mathrm{ZnEt}_{2}$ at r.t 
[109a]. In their approach, the base $N$-methylimidazole (NMI) was needed to help the formation of the zinc acetylide species in order to promote reactivity and continue screening. The 4-position of the triazole was substituted via the aryl-zinc intermediate towards further coupling. The proposed mechanism for this reaction is summarized in Fig. 19. The initial metallation of the alkyne mediated by the amine base formed the zinc acetylide 16. Then the reversible pre-coordination between the azide and zinc acetylide occurred before the [3+2]-cycloaddition, after which the aryl-zinc intermediate 15 formed, then was utilized to lead to 1,4,5-trisubstituted 1,2,3triazoles. Based on these experimental results, Lan's group then reported their DFT calculations towards the mechanism and regioselectivity research of this ZnAAC using frontier molecular orbital (FMO) theory and distortion-interaction energy analysis [109b]. B3LYP-D3BJ calculations showed that ethynylzinc complexes bearing alkyl substituents showed a reactivity analogous to that of ethyl(phenylethynyl)zinc and a lower regioselectivity. B3LYP calculations gave a higher regioselectivity, however, because of a lower distortion energy in the transition state and led to a lower activation energy for 1,5-substituted product generation, as explained by the distortion-interaction analysis. Furthermore, the FMO analysis revealed that the binding of $\mathrm{N}$-methylimidazole to zinc increased the energy of the HOMO of ethyl(phenylethynyl)zinc, which increased its reactivity.

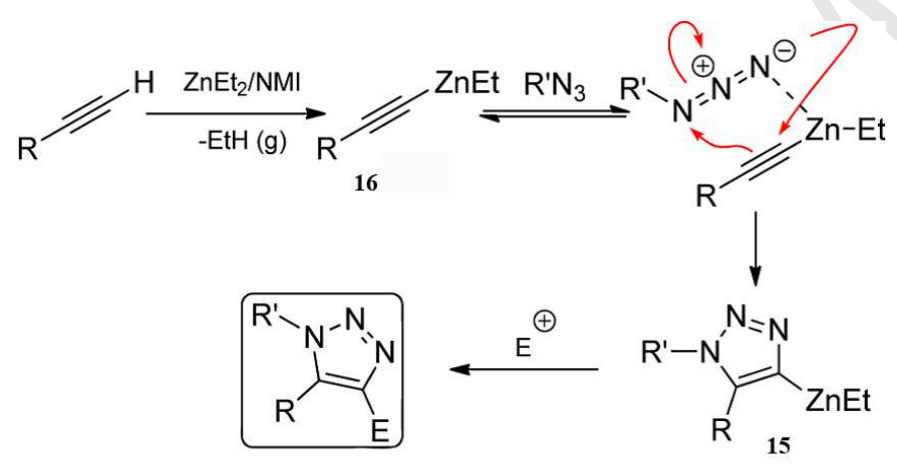

Fig. 19 Proposed mechanism explaining the reactivity in the system mediated by $\mathrm{ZnEt}_{2}$. Reproduced with permission from ref. 109a. Copyright 2013, American Chemical Society.

\subsection{The LnAAC reactions}

Recently, a seminal example of rare earth-metal-catalyzed AAC reaction with terminal alkynes leading to 1,5-disubstituted 1,2,3-triazoles was described by Zhou's group [110]. The authors chose $\left[\mathrm{Sm}\left\{\mathrm{N}\left(\mathrm{SiMe}_{3}\right)_{2}\right\}_{3}\right]$ as the catalyst after compared examination of the rare-earth metal catalysts $\left[\mathrm{Ln}\left\{\mathrm{N}\left(\mathrm{SiMe}_{3}\right)_{2}\right\}_{3}\right], \mathrm{Ln}=\mathrm{Sm}, \mathrm{Nd}, \mathrm{Y}, \mathrm{Gd}$. Optimization of the reaction conditions showed that the presence of $10 \mathrm{~mol} \% n$ $\mathrm{BuNH}_{2}$ improved the yield (Fig. 20a). By comparison, they suggested that the involvement of an acetylide intermediate complex was essential for the efficiency and selectivity. The proposed mechanism is shown in Fig. 20b. First activation of the C-H bond of the terminal alkyne produced the Ln acetylide $\mathbf{A}$ and $\mathrm{HN}\left(\mathrm{SiMe}_{3}\right)_{2}$. Then 1,1- 
insertion of the azide in the Ln-C bond of $\mathbf{A}$ gave the species $\mathbf{C}$ and $\mathbf{D}$, and the antinucleophilic attack of the nitrogen atom to the $\pi$-coordinated alkyne led to the triazolate $\mathbf{E}$. Then, the protonation of $\mathbf{E}$ with another alkyne molecule afforded $\mathbf{1 7}$ and regenerated $\mathbf{A}$ (path a). In an alternative pathway, path $\mathrm{b}$ was suggested based on the presence of amine additives that were favorable to the cycloaddition.

(a)

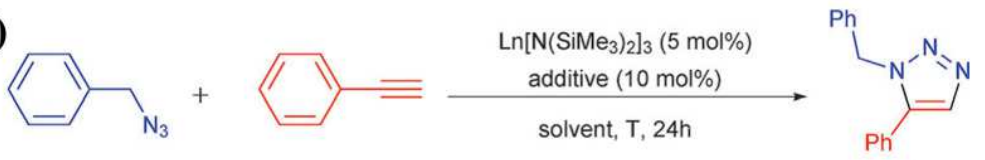

(b)

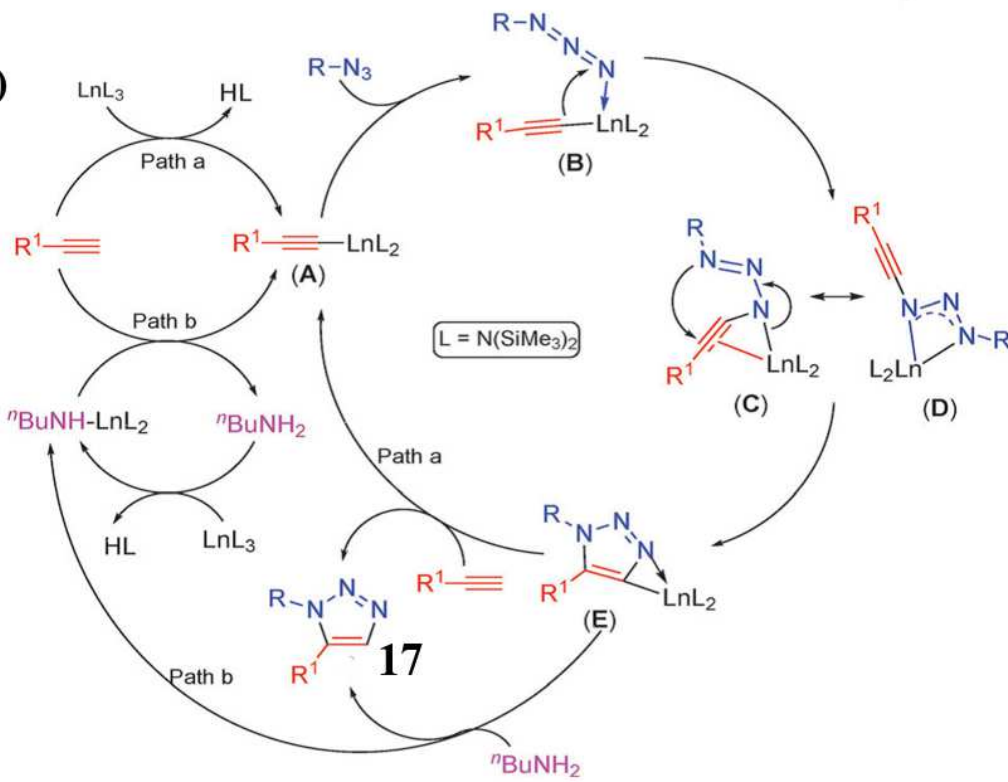

Fig. 20 (a) $\left[\mathrm{Ln}\left\{\mathrm{N}\left(\mathrm{SiMe}_{3}\right)_{2}\right\}_{3}\right]$-catalyzed cycloaddition of terminal alkynes with azides $(\mathrm{Ln}=\mathrm{Sm}, \mathrm{Nd}, \mathrm{Y}, \mathrm{Gd})$. (b) Reaction pathway for $\left[\mathrm{Ln}\left\{\mathrm{N}\left(\mathrm{SiMe}_{3}\right)_{2}\right\}_{3}\right]$-catalyzed cycloaddition between terminal alkynes and azides. Reproduced with permission from ref. 110. Copyright 2013, Royal Society of Chemistry.

We have computationally explored this proposed mechanism by DFT calculations considering the complex $\left[\mathrm{Y}\left\{\mathrm{N}\left(\mathrm{SiH}_{3}\right)_{2}\right\}_{3}\right]\left(\mathrm{YL}_{3}\right)$ as the simplified precatalyst, acetylene and hydrogen azide [27b]. The induction part of the mechanism (path a in the left side of Fig. 20b) that corresponds to the formation of the acetylide intermediate and a protonated ligand is computed to proceed with a rather low free energy barrier $(7.0 \mathrm{kcal} / \mathrm{mol})$. The computed $\mathbf{B}$ to $\mathbf{E}$ transit of Fig. $20 \mathrm{~b}$ was a single step process and the rate-determining one, with a transition state that is $13.7 \mathrm{kcal} / \mathrm{mol}$ above B (Fig. 21). These results confirmed the proposed mechanism of Zhou's group (path a in Fig. 20b), although the pathway from $\mathbf{B}$ to $\mathbf{E}$ was computed to be a single step. Likewise, Li's group also recently computationally investigated the same catalytic process that was performed considering the pre-catalyst model $\left[\mathrm{SmL}_{2} \mathrm{~S}(\mathrm{CCPh})\right](\mathrm{L}=$ acetylide $)$ and benzyl azide [111]. In their case, the observed 1,5 isomer was produced from the formation of an intermediate that resulted from the azide coordination on $\left[\mathrm{SmL}_{2} \mathrm{~S}(\mathrm{CCPh})\right]$ through its substituted nitrogen atom. This 
computed result was different from ours, indicating that only the 1,4-trz isomer was formed in this pathway though a similar mechanism, but with a higher energy barrier.

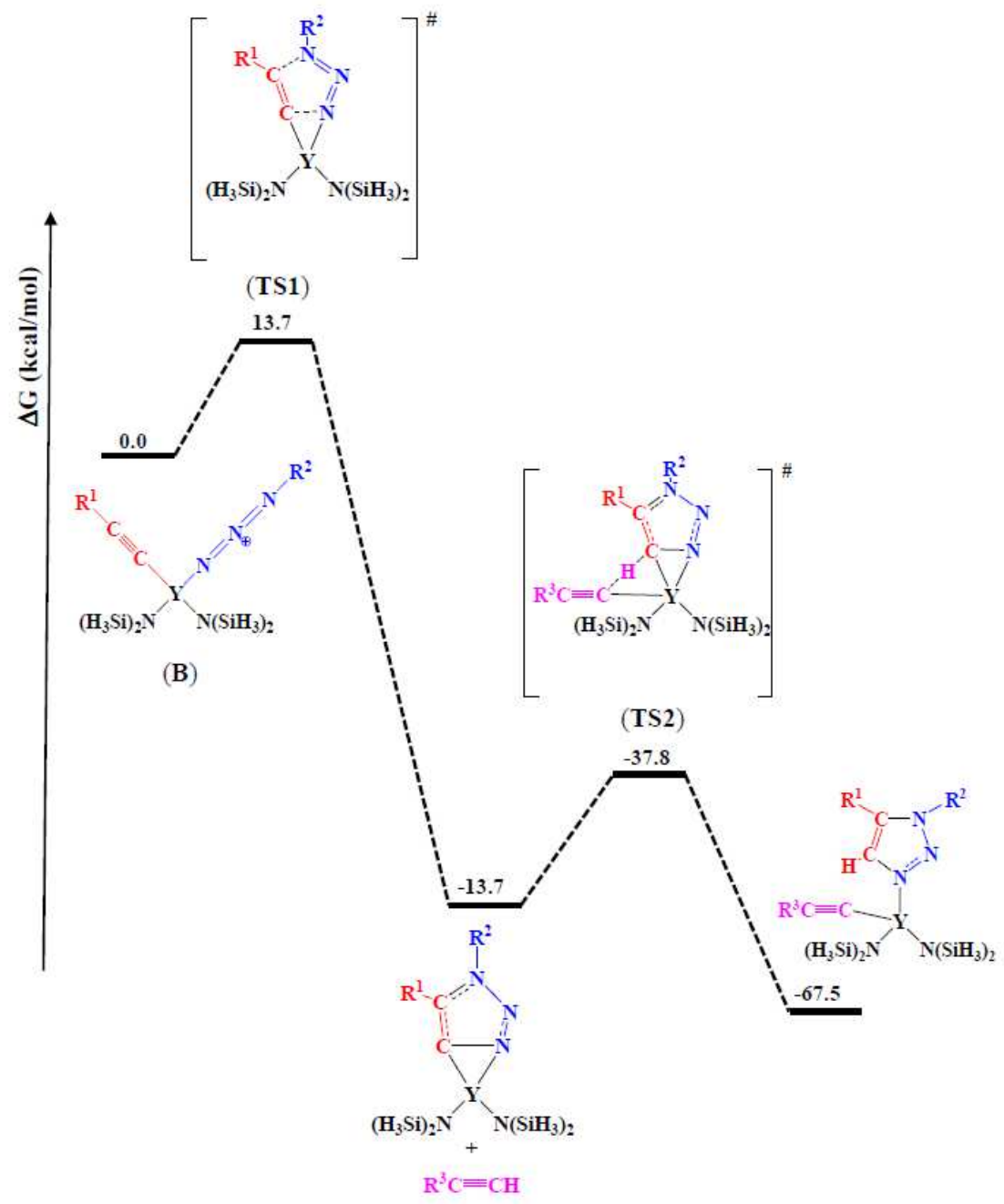

(E)

Fig. 21 DFT free energy profile (in $\mathrm{kcal} / \mathrm{mol}$ ) computed for the mechanism of the formation of 1, 5-triazole catalyzed by a rare-earth complex reported in ref. $110\left(\mathrm{R}^{1}=\right.$ $\mathrm{R}^{2}=\mathrm{H}$; relative free energy values).

\section{Recent trends}

Following the basic features that characterize the MAAC reactions including the state of the art in the mechanistic understanding with various metals, recent trends essentially in CuAAC and RuAAC have appeared that are gathered in this section.

\subsection{CuAAC}

$\mathrm{N}$-heterocyclic carbenes (NHCs) have become an increasingly used class of "L" ligands in organometallic chemistry and click catalysis [112]. Following the seminal work by Nolan's group [33], the $\mathrm{Cu}(\mathrm{I})$ complexes of NHC ligands were continuously very efficient catalysts for the click cycloaddition reaction between azides and alkynes $[38,113]$. Lal et al. compared the catalytic activity of NHC and phosphine complexes 
for the CuAAC formation of 5-iodo-1,2,3-triazoles (Fig. 22). The experimental/computational-DFT results suggested that iodoalkynes might be prone to dehalogenation under copper catalysis conditions. Two distinct mechanistic pathways that proceed through a copper(III) metallacycle or by direct $\pi$-activation of the starting iodoalkyne are likely to be competitive with these catalysts [112a]. Other carbene ligands that were recently used with success in catalysis of click reactions include abnormal N-heterocyclic carbenes (aNHCs) [55,114], mesoionic carbenes (MIC) and ring-expanded carbenes (RE-NHCs) [115]. With copper(I) complexes of triazolylidene ligands (Fig. 23a) [116] the halide-free complexes $[\mathrm{Cu}(a \mathrm{NHC})]\left[\mathrm{BF}_{4}\right]$, 20-23, are more efficient than the halide-containing complexes 18 and 19 in catalyzing $\mathrm{CuAAC}$ reactions. The complex $[\mathrm{CuCl}(a \mathrm{NHC})]$ (Fig. 23b) catalyzed $\mathrm{CuAAC}$ reactions in excellent yield at r.t. within short reaction time under solventfree conditions [117]. With the complex [Cu(I)(MIC)], addition of a phenanthroline derivative generated a highly active catalyst that surpassed the performances of a "normal" NHC complex, which was taken into account by the combination of a greater electron-donating character of the carbene ligand and a less crowded environment of the catalytic center [118]. Beside the NHC ligands, $\mathrm{Cu}(\mathrm{I})$ complexes bearing one or two $\alpha$-diimine ligands [119], hybrid nitrogen-sulfur ligand-supported $\mathrm{Cu}(\mathrm{I}) /(\mathrm{II})$ complexes [120] were also highly efficient. Other recently reported useful systems include $\mathrm{Cu}$ (II) complexes supported by mixed NN, NO, and NS 1,2,3-triazole based ligands utilized together with sodium ascorbate [121], $\mathrm{Cu}(\mathrm{I})$ complexes with pyridyl and thioether hybridized 1,2,3-triazole ligands [122], $\mathrm{Cu}(\mathrm{I})$ complexes containing sulfur-based ligand [123], $\mathrm{Cu}(\mathrm{I})$ complexes with new chiral phosphine ligand [124], dinuclear $\mathrm{Cu}(\mathrm{I})$ complex $\left(\mathrm{Cu}_{2}(\mathrm{pip})_{2}\right)$ with (2-picolyliminomethyl)pyrrole anion ligand [125], and binuclear $\mathrm{Cu}(\mathrm{I})$ complex of $\left(N^{\prime} 1 \mathrm{E}, N^{\prime} 2 \mathrm{E}\right)-N^{\prime} 1, N^{\prime} 2-$ bis(phenyl(pyridin-2-yl)methylene)oxalohydrazide ligand [126]. On the other hand, $\mathrm{Cu}$ (II) species without deliberate addition of a reducing agent for $\mathrm{CuAAC}$ reactions have also been investigated. The mechanistic studies indicated that the real catalytic $\mathrm{Cu}(\mathrm{I})$ species were generated in a short induction period via reducing $\mathrm{Cu}$ (II) salts by alcoholic solvents [127], sodium azide [46,128], or thiobenzanilide [129] especially in the three-component 1,3-dipolar cycloaddition for 1,4-disubstituted 1,2,3-triazoles synthesis. For instance, the recently reported 2-pyrrolecarbaldiminato- $\mathrm{Cu}$ (II) complexes efficiently catalyzed three-component 1,3 -dipolar cycloaddition reaction of benzyl halides and sodium azide with terminal alkynes in water at r.t., leading to the synthesis of several regioselective 1,4-disubstituted 1,2,3-triazoles in 55-97\% yield [130]. On the other hand, the direct use of $\mathrm{Cu}(\mathrm{I})$ complexes to catalyze threecomponent reactions of $\mathrm{N}$-tosylhydrazones, terminal alkynes and azides to efficiently synthesize 1,4,5-trisubstituted 1,2,3-triazoles with good to excellent yield has also recently been explored by Wang's group [131]. 

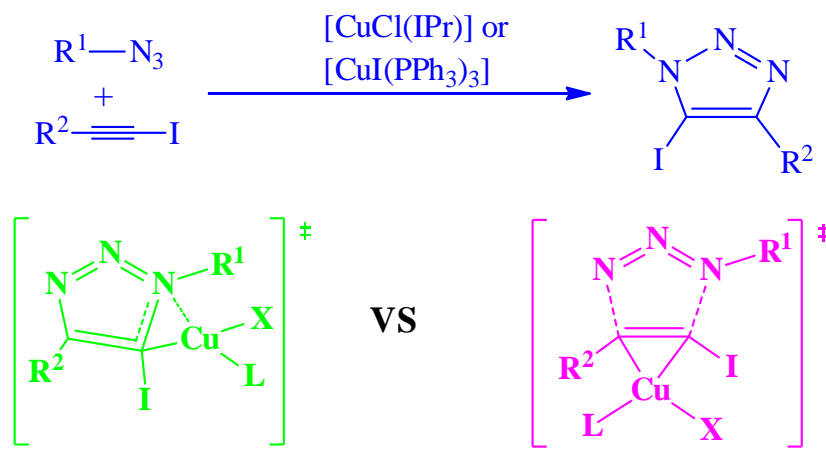

VS

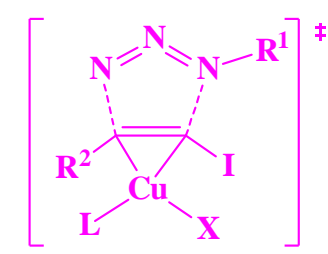

Fig. 22 NHC or phosphine-containing copper(I) complexes for the synthesis of 5iodo-1,2,3-triazoles. Reproduced with permission from ref. 112a. Copyright 2014 American Chemical Society.

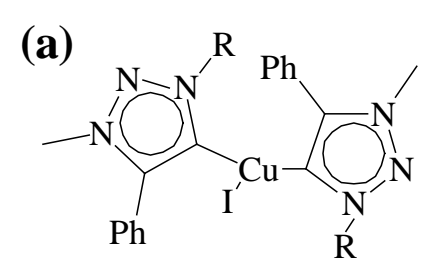

$18 \mathrm{R}=\mathrm{Bn}$

$19 \mathrm{R}=2-($ methylthio)phenyl

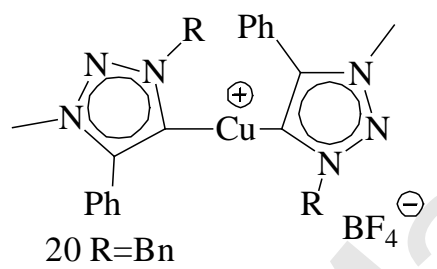

$21 \mathrm{R}=\mathrm{Ph}$

$22 \mathrm{R}=2$-(methylthio)phenyl

$23 \mathrm{R}=$ mesityl (b)

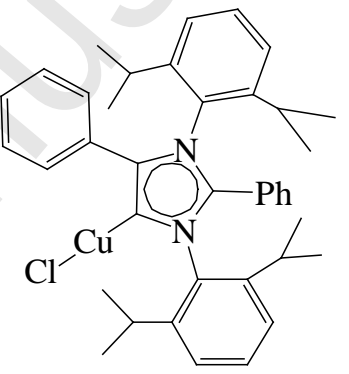

Fig. 23 (a) Copper(I)-triazolylidene complexes. (b) aNHC coordinated copper(I) chloro complex. Reproduced with permission from ref. 116 and 117, respectively. Copyright 2013, WILEY-VCH.

From the above examples and many others, the catalysts for CuAAC reactions are usually homogeneous catalysts. Although they are often very efficient, their preparation often is tedious and/or expensive. Together with the difficulties in handling and recycling the catalysts, the applications toward the click reactions using homogeneous catalysts are somehow limited. To solve these problems, considerable interest and efforts have been devoted to develop suitable supports, especially in the field of the heterogenization of homogeneous catalysts. For example, Varma's group reported a recyclable heterogeneous copper catalyst on chitosan for CuAAC reactions in water [132]. The chitosan-supported catalyst was simply obtained by stirring an aqueous suspension of chitosan in water with copper sulfate. The catalyst was very efficient in catalyzing CuAAC in water at r.t. (Fig. 24); it was recycled and reused at least 5 times without losing its activity and changing morphology. Pourjavadi and coworkers recently reported the immobilization of copper ions $\left(\mathrm{CuSO}_{4}\right)$ in a graphene oxide/poly(vinyl imidazole) nanocomposite $(\mathrm{GO} / \mathrm{Pim} / \mathrm{Cu})$ as highly efficient, robust and recyclable catalysts for one-pot three-component cycloadditions in water in the presence of NaAsc as the reductant [133]. Moreover, they also successfully reduced the amount of catalysts to $0.002 \%$ mol with $93 \%$ isolated yield of product in water at $50^{\circ} \mathrm{C}$ for $20 \mathrm{~h}$. 


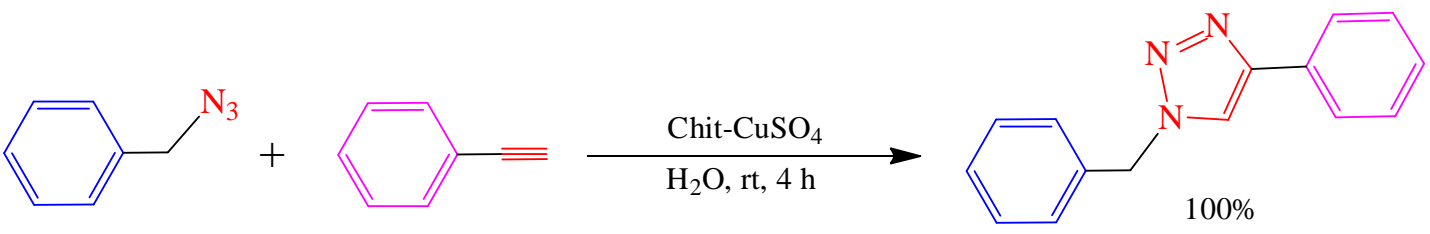

Fig. 24 Chit-CuSO 4 catalyzed dipolar cycloaddition of benzyl azide and phenyl acetylene $($ Chit $=$ chitosan $)$. Reproduced with permission from ref. 132. Copyright 2013, Royal Society of Chemistry.

Immobilizing $\mathrm{Cu}(\mathrm{II})$ on silica-type materials, such as SBA-15, to build up heterogeneous catalysts, has also been achieved [134]. For example, Roy's group recently reported $\mathrm{Cu}(\mathrm{II})$-anchored functionalized mesoporous SBA-15 for one-pot CuAAC reaction [134a]. In a typical synthesis procedure shown in Fig. 25, 2pyridine-carboxaldehyde was added to a mixture of 3-amino propyl-functionalized

SBA-15 in super dry ethanol. The reaction mixture was then stirred at $60^{\circ} \mathrm{C}$ for $24 \mathrm{~h}$ to yield SBA-15 supported imine material. Then, reaction of $\mathrm{Cu}(\mathrm{OAc})_{2}$ with SBA-15 yielded the catalyst Cu@PyIm-SBA-15. This catalyst in low amount $(0.1 \mathrm{Cu}$ mol\%), showed a good activity and reusability for the one-pot click reaction between azides formed in situ from the corresponding amines and acetylenes in water at $0^{\circ} \mathrm{C}$ to r.t., providing a wide variety of 1,4-disubstituted 1,2,3-triazoles. The electron paramagnetic resonance (EPR) spectrum of the fresh and used catalyst suggested that copper remained in +2 oxidation state throughout the reaction which was taken into account by $\mathrm{Cu}^{2+}$ as catalyst, though such evidence does not prove the absence of active $\mathrm{Cu}(\mathrm{I})$ species [135]. Nasr-Esfahani reported copper immobilization on nanosilica triazine dendrimer $\left(\mathrm{Cu}(\mathrm{II})-\mathrm{TD} @ \mathrm{nSiO}_{2}\right.$, Fig. 26a), and excellent yield via a one-pot three-component reaction of alkynes and sodium azide with organic halides or $\alpha$-bromo ketones at r.t. (Fig. 26b). Sodium ascorbate was then needed to reduce $\mathrm{Cu}$ (II) to $\mathrm{Cu}(\mathrm{I})$ [136], and the synthesis of 1,4-disubstituted 1,2,3-triazoles and bisand tris-triazoles proceeded in a single-step operation. $\mathrm{Cu}(\mathrm{I})$ catalytic species were also reported upon immobilization onto solid supports for CuAAC reactions, such as silica cuprous sulfate (CDSCS) doped with $\mathrm{Cu}(\mathrm{I})$ [137], $\mathrm{Cu}(\mathrm{I})$ on modified poly(styreneco-maleic anhydride) [138], $\mathrm{Cu}(\mathrm{I})$ onto triazole functionalized $\mathrm{Fe}_{3} \mathrm{O}_{4}$ [139] and $\mathrm{CuBr}$ on graphene oxide/ $\mathrm{Fe}_{3} \mathrm{O}_{4}[140]$. 

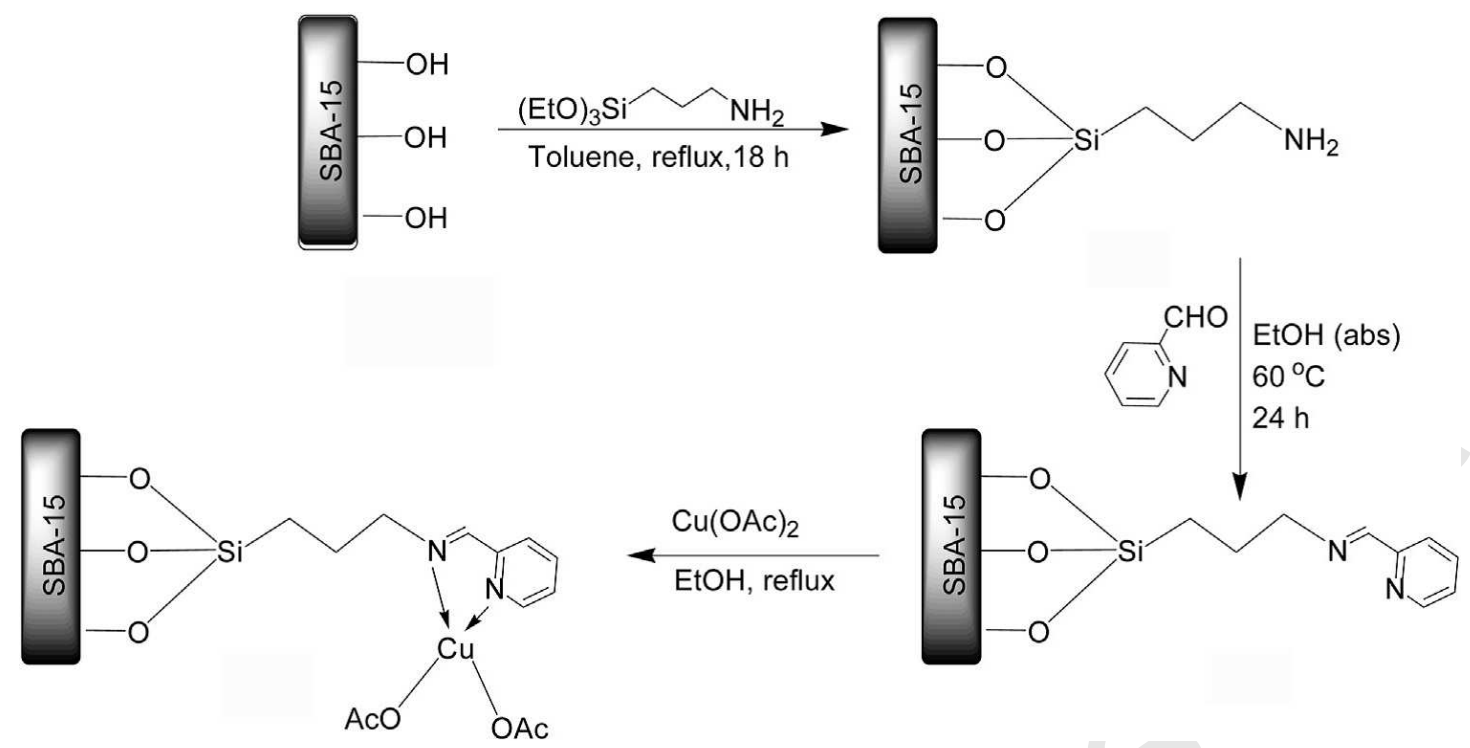

Fig. 25 Synthesis of the Cu@PyIm-SBA-15 catalyst. Reproduced with permission from ref. 134a. Copyright 2014, Elsevier B.V.

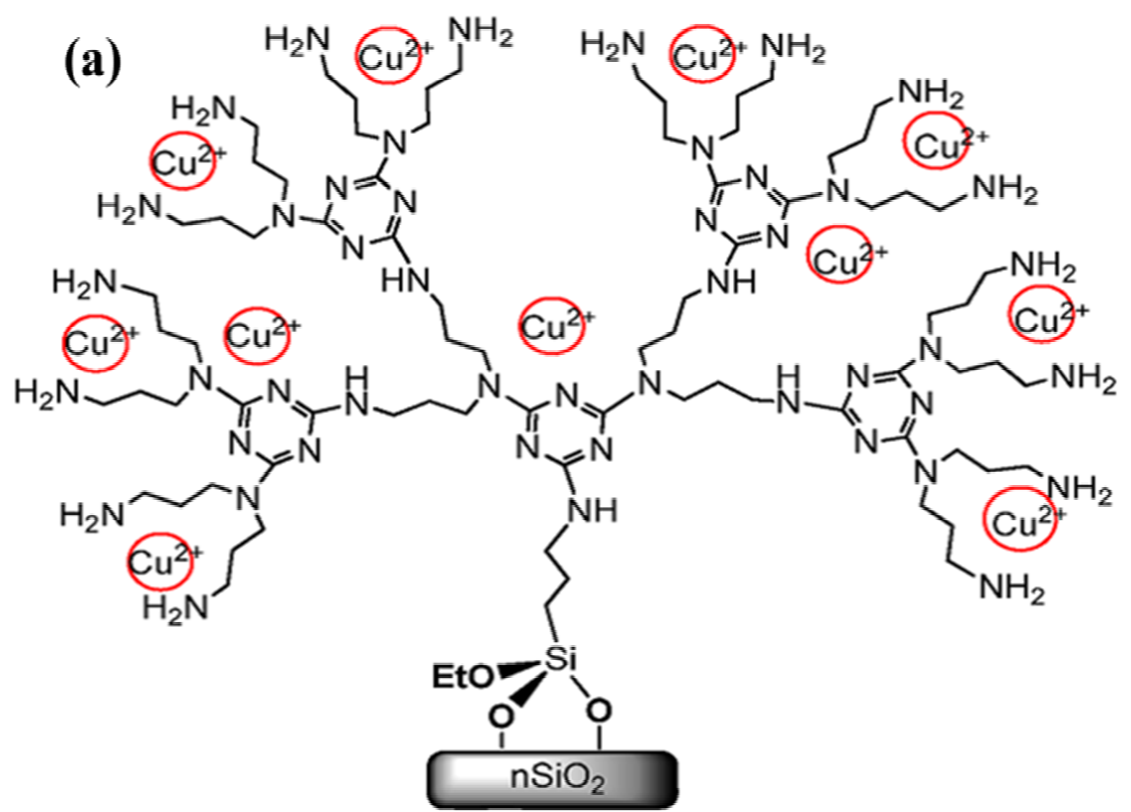

(b)

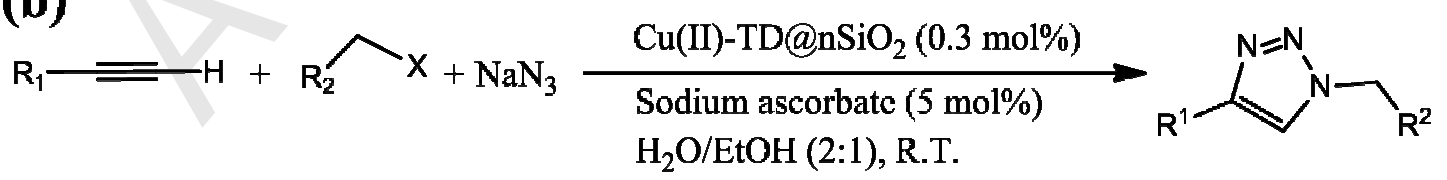

Fig. 26 (a) Structure of $\mathrm{Cu}(\mathrm{II})-\mathrm{TD} @ \mathrm{nSiO}_{2}$, (b) $\mathrm{Cu}(\mathrm{II})-\mathrm{TD} @ \mathrm{nSiO}_{2}$-catalyzed threecomponent synthesis of 1,4-disubstituted 1,2,3-triazoles from alkyl/benzyl halides. Reproduced with permission from ref. 136. Copyright 2014, American Chemical Society. 
$\mathrm{Cu}_{2} \mathrm{O}$, another $\mathrm{Cu}(\mathrm{I})$ source, is also used for the $\mathrm{CuAAC}$ reactions, though in some cases a stabilizer such as PVP was used to enable the formation of the well-defined and small copper(I) oxide [141]. Bai and Chen's group demonstrated the safe and high efficient synthesis of triazole drugs by using a $\mathrm{Cu}_{2} \mathrm{O}-\mathrm{NP}$ catalyst in aqueous/organic solvents $\left(\mathrm{CH}_{3} \mathrm{CN}\right.$ and $\left.\mathrm{H}_{2} \mathrm{O}\right)$ for the key AAC stage (Fig. 27) [142]. In their study, $\mathrm{Cu}_{2} \mathrm{O}-\mathrm{NP}$ was more efficient than $\mathrm{CuSO}_{4} / \mathrm{NaAsc}$, which was explained by the fact that the $\mathrm{Cu}_{2} \mathrm{O}-\mathrm{NP}$ catalyst was dispensed in both organic solvent and water, while the $\mathrm{CuSO}_{4} / \mathrm{NaAsc}$ system required higher ratio of water. The in situ generated $\mathrm{Cu}_{2} \mathrm{O}$ together with $\mathrm{HOAc}$ exhibited better catalytic efficiency than isolated $\mathrm{Cu}_{2} \mathrm{O}$ combined with HOAc [143]. The $\mathrm{Cu}$ (II) species in $\mathrm{Cu}(\mathrm{OAc})_{2} \bullet \mathrm{H}_{2} \mathrm{O}$ was also reduced to $\mathrm{Cu}$ (I) by $\mathrm{NH}_{2} \mathrm{NH}_{2} \bullet \mathrm{H}_{2} \mathrm{O}$ that could in situ generate $\mathrm{Cu}_{2} \mathrm{O}-\mathrm{NPs}$ and HOAc to efficiently catalyze $\mathrm{CuAAC}$ reactions in water at r.t. with relatively short reaction times. However, drawbacks are obvious, because of the unrecoverable and unreusable properties of small molecular organic acids. In order to overcome these problems, the authors latter on combined $\mathrm{Cu}_{2} \mathrm{O}$ and carboxymethylpullulan (CMP) for high-yield $\mathrm{CuAAC}$ reactions in water with a relatively short reaction times, and CMP still remained in water enabling easy recoverability and reusability [144]. Very recently, $\mathrm{Cu}_{2} \mathrm{O}$ supported on graphene nanosheet [145] served as recyclable and reusable heterogeneous catalyst with excellent catalytic activity for CuAAC. More importantly, an excellent performance was also obtained for bulk CuAAC reactions via meltrheology with trivalent azide- and alkyne-functionalized polyisobutylenes (PIB) at r.t. (Fig 28), which was useful for designing self-healing materials. Additionally, special rhombic dodecahedra $\mathrm{Cu}_{2} \mathrm{O}$ bounded by the $\{110\}$ facets was also a promising heterogeneous catalyst for multicomponent AAC reactions [146].

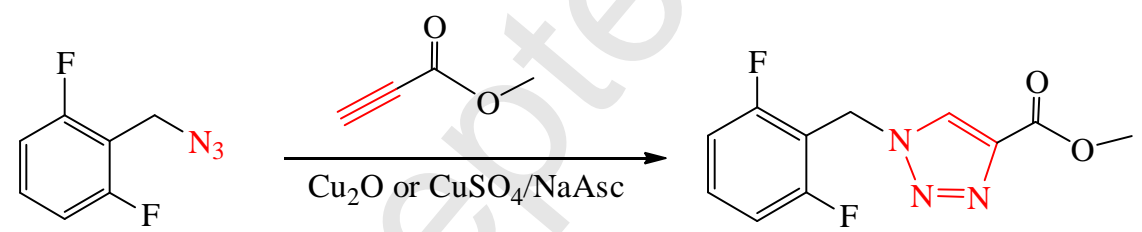

Fig. 27 AAC reactions catalyzed by $\mathrm{Cu}_{2} \mathrm{O}-\mathrm{NP}$ and $\mathrm{CuSO}_{4} / \mathrm{NaAsc}$. Reproduced with permission from ref. 142. Copyright 2013, Elsevier B.V. 


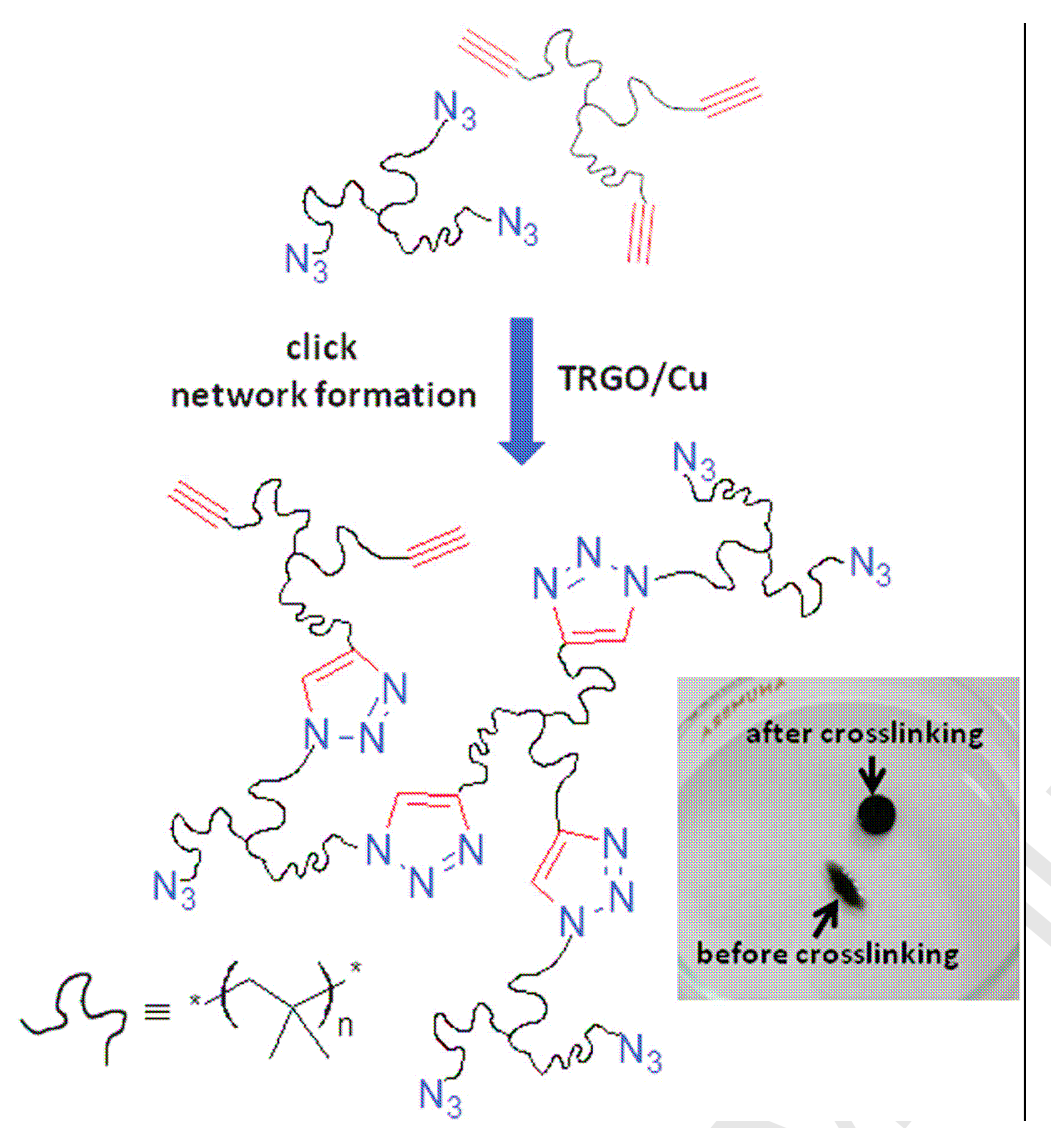

Fig. 28 Schematic illustration of the bulk CuAAC reaction of PIB-azide and PIBalkyne with $\mathrm{TRGO} / \mathrm{Cu}(\mathrm{I})$ at $20^{\circ} \mathrm{C}$ via melt rheology. Reprinted with permission from ref. 145a. Copyright 2014, Royal Society of Chemistry.

Copper nanoparticles (CuNPs) have attracted interest for the $\mathrm{CuAAC}$ reactions due to their large surface area, tunable morphology and sustainable catalytic activities. For CuNP-catalyzed AAC, Scaiano et al. successively proved that catalysis occurred at the surface of the CuNPs by standard bench scale techniques with single-molecule spectroscopy [78a]. Following the seminal report on the use of CuNPs to catalyze the CuAAC reaction by Fokin et al. [31], efforts have been devoted to design highlyefficient and low-cost heterogeneous CuNPs catalysts for this reaction. However, in most cases, strategies had to be developed in order to prevent CuNPs agglomeration [147], enabling the stability of small CuNPs and high activity toward CuAAC. For example, agarose was a cheap and degradable polysaccharide for the stabilization of active CuNP (CuNPs@agarose) in the size range of 4-8 nm in water under low catalyst loading and mild reaction conditions [148]. The 3-aminopropylsilica support was able to stabilize smaller CuNPs with the size in the range of $1-4.5 \mathrm{~nm}$, leading to very high catalytic activity (productivity up to $1689 \mathrm{~mol} / \mathrm{mol}$ ) in continuous-flow click reaction between phenyl acetylene and benzyl azide [149]. A more recent case showed fluorescent aggregates of hexarylbenzene derivatives serving both as reactors and stabilizers for the preparation of 9-17 nm-sized CuNPs with efficient catalysis of CuAAC reactions in excellent yield under solvent-free conditions [150]. 
On the other hand, Sureshan's group also successfully developed a simple methodology to generate naked CuNPs or their clusters as catalysts $\left(\mathrm{CuSO}_{4} \cdot 5 \mathrm{H}_{2} \mathrm{O}+\right.$ $\mathrm{N}_{2} \mathrm{H}_{4} \bullet \mathrm{H}_{2} \mathrm{O}$ ) that did not require stabilizers, solid support, or special conditions for solvent-free CuAAC reactions at r.t. (Fig. 29) [151]. Interestingly, Cravotto's group successfully adopted ball-mill-based mechanochemical activation of metallic copper powder that facilitated solvent-free CuAAC reactions. This new, efficient, facile and eco-friendly procedure has afforded the corresponding 1,4-disubstituted 1,2,3-triazole derivatives in high yield and purities [152].

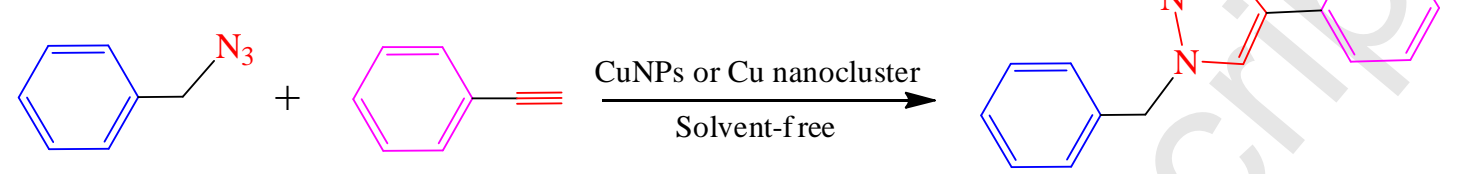

Fig. 29 CuNPs or their clusters catalyzed solvent-free AAC reaction. Reproduced with permission from ref. 151. Copyright 2012, Elsevier B.V.

Alonso and Yus et al have also investigated the use of CuNPs for multicomponent CuAAC reactions [80]. They showed that the nanostructured CuNPs supported on active carbon (CuNPs/C) catalyst displayed much higher catalytic activity than commercial bulk copper catalysts in the one-pot synthesis of 1,2,3-triazoles from inactivated alkenes. Their sequence involved two click steps including first the azidosulfenylation of the olefin, then the reaction of the in situ generated organic azide with the terminal alkyne (Fig. 30b) [153]. Other recently reported nanostructured $\mathrm{Cu}$ catalysts for three-component $\mathrm{CuAAC}$ reactions included CuNPs [154], heterogeneous porous $\mathrm{Cu}(0)$ [155], and CuNPs on silica coated maghemite nanoparticles (CuNPs/mag silica) [156].

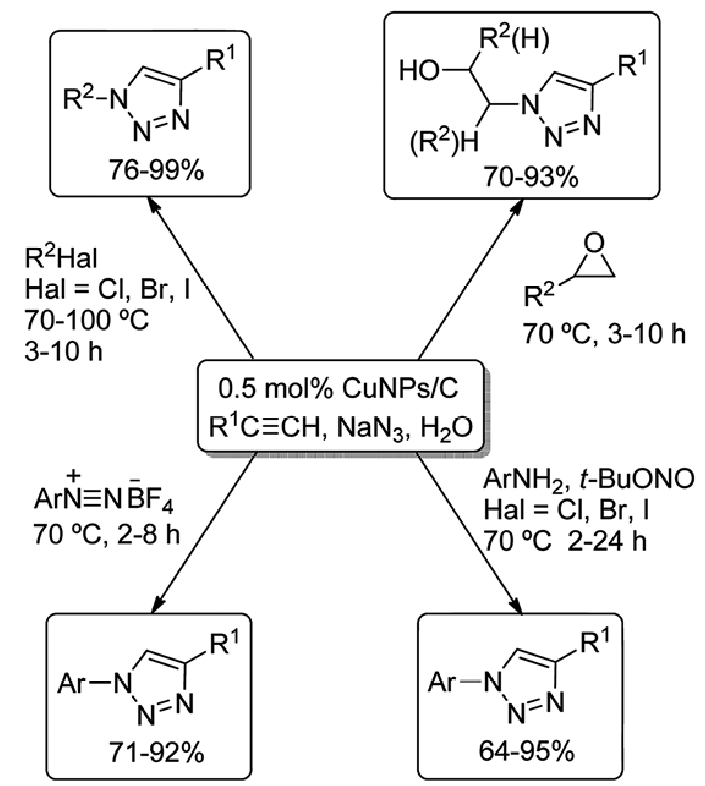

Fig. 30 Multicomponent synthesis of 1,2,3-triazoles from various azide precursors catalyzed by $\mathrm{CuNPs} / \mathrm{C}$ in water. Reproduced with permission from ref. 153. Copyright 


\section{3, American Chemical Society.}

Since Lipshutz's seminal study involving nickel oxide NPs in the CuAAC reaction [157], essentially $\mathrm{Cu}-\mathrm{M}$ bimetallic alloys ( $\mathrm{M}=$ metal or its oxides NPs, mainly Fe and $\mathrm{Ni}$ ) have been explored in the AAC reaction. Among these various bimetallic alloyed nanostructures for $\mathrm{AAC}, \mathrm{Cu}$ is known for its catalytic efficiency, while $\mathrm{M}$ is known for its magnetic nature or other catalytic efficiencies except for AAC. In the case of the CuFe system, although Nageswar's group showed the successful multicomponent synthesis of 1,4-disubstituted $1,2,3$-triazoles in water at $70{ }^{\circ} \mathrm{C}$ catalyzed by magnetically separable $\mathrm{CuFe}_{2} \mathrm{O}_{4}$ [158], low efficiency of $\mathrm{CuFe}_{2} \mathrm{O}_{4}$ NP-catalyzed benzyl azide and phenylacetylene cycloaddition in water at r.t. was also observed [159]. To alleviate this limitation, they then synthesized bimetallic CuFe NPs by using presynthesized FeNP-reducted $\mathrm{CuSO}_{4}$. Here, the presence of FeNPs served both as the electron source to reduce $\mathrm{Cu}$ (II) into $\mathrm{Cu}(\mathrm{I})$ and the support for $\mathrm{Cu}(\mathrm{I})$ species to prevent their liberation as soluble ions, enabling a heterogeneous mechanism for the CuAAC reaction. Likewise, Fulop's group also recently showed that iron powder was a readily available copper scavenger for continuous-flow CuAAC [160]. By contrast, in the case of the $\mathrm{CuNi}$ bimetallic alloy nanostructures, heterogeneous $\mathrm{Cu}-\mathrm{Ni} / \mathrm{C}$ catalysts have independently been reported by Lipshutz's [157] and Tang's group [161]. In the former case, $\mathrm{Cu}-\mathrm{Ni} / \mathrm{C}$ mediated both group 10 and group 11 crosscouplings [157], whereas in the latter case, transformation of waste polymer materials into valuable metal/carbon heterogeneous composites was highlighted. In this approach, the $\mathrm{Cu} / \mathrm{Ni}$ molar ratios (initial catalytic substances were $\mathrm{Ni}_{2} \mathrm{O}_{3}$ and $\mathrm{CuCl}$ ) played a crucial role in the formation of the microstructures and for the catalytic functions. Although $\mathrm{Cu}-\mathrm{Ni} / \mathrm{C}-0.5$ was used to catalyze a $\mathrm{CuAAC}$ reaction with high yield (97\%), the reaction time was longer compared to those of previous reports $[157,162]$, which was attributed to the amorphous nature of carbon covering the $\mathrm{Cu}$ particles in $\mathrm{Cu}-\mathrm{Ni} / \mathrm{C}-0.5$, leading to insufficient catalysis [161]. On the other hand, Mandal's group also showed that chain-like bimetallic magnetic CuNi nanoalloy in the presence of polymers (PVP or PEG) is a stabilizing/structure-directing agent for CuAAC reactions with good to excellent yield in water and in DMF at r.t. XPS and zeta potential analysis confirmed that $\mathrm{Cu}(\mathrm{I})$ on the alloyed NPs surface was responsible for the catalytic activity, while the magnetic reusability was attributed to $\mathrm{Ni}$ [163]. This novel unsupported $\mathrm{Cu}$ based nanocatalyst was highlighted for its advantages of both homogeneous and heterogeneous catalysis while avoiding their drawbacks, and it was called pseudo-homogeneous catalyst. Moreover, a new bimetallic catalyst derived from nickel and copper supported on magnetite was a good catalyst for the multicomponent reaction of terminal alkynes, sodium azide, and benzyl bromide derivatives, because of the positive and synergetic effect of the metallic species [164].

The use of microwaves was a valuable assistance in CuAAC reactions upon considerably shortening reaction times, and it improved yield [20,127c,165]. Perics's group reported the synthesis of tris(triazolyl)methane ligands [166] with $\mathrm{CuCl}$ for 
CuAAC of benzyl azide with representative alkynes. For instance with tris(aryltriazolyl)methanol-CuCl (see the ligands in Fig. 31), both $24(\mathrm{R}=\mathrm{H})$ and the electron-poor ligand $25\left(\mathrm{R}=\mathrm{CF}_{3}\right)$ gave high conversions. However, the ligand 26 bearing the electron-rich 4-methoxyphenyl substituents provided a very poor catalyst in all solvents except in water. Upon taking the advantage of microwave irradiation, a quantitative reaction was observed for the CuAAC of organyl bromide and sodium azide in acetonitrile/water at $100^{\circ} \mathrm{C}$ in 40 min [166c]. Other recent examples include MW-assisted of $\mathrm{Cu}-\mathrm{NHC}$-catalyzed cycloaddition of azido-disubstituted alkynes [112b], MW-assisted CuAAC of fast 2D assembling of iron oxide NPs on a selfassembled monolayer (SAM) of organic molecules [167], recoverable and recyclable $\mathrm{Cu} / \mathrm{SiO}_{2}$ composite for eco-friendly multicomponent synthesis of 1,2,3-triazoles [168], "copper-in-charcoal" catalyzed triazole click reactions [169], palladium and copper-supported on charcoal as heterogeneous multi-task catalysts for sequential Sonogashira-click and click-Heck reactions [170], Cu/porous glass catalyst for $\mathrm{CuAAC}$ in water [165c], CuNPs supported on nano- $\mathrm{Fe}_{3} \mathrm{O}_{4}$-glutathione $(\mathrm{Cu} /$ nanoFGT) for one-pot multicomponent synthesis of 1,2,3-triazoles [171], and $\mathrm{Fe}_{3} \mathrm{O}_{4}$ supported $\mathrm{CuBr}$ catalysts for one-pot and scale-up synthesis of 1,2,3-triazoles (Fig. 32) [172]. When CuNPs are used, it is indeed assumed that surface oxidation of $\mathrm{Cu}(0)$ to catalytically active $\mathrm{Cu}(\mathrm{I})$ species occurs upon MW irradiation.

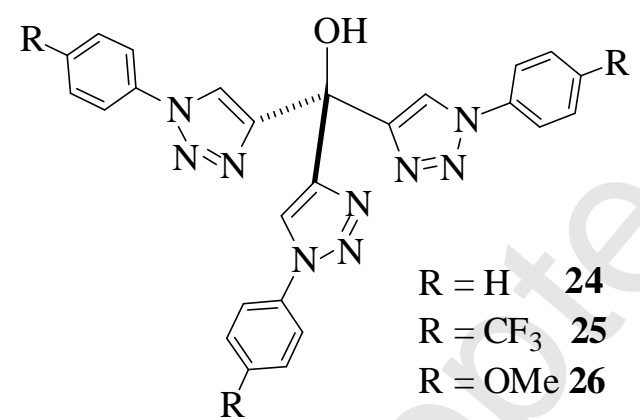

Fig. 31 Tris(aryltriazolyl)methanol ligands. Reproduced with permission from ref. 166c. Copyright 2009, American Chemical Society.

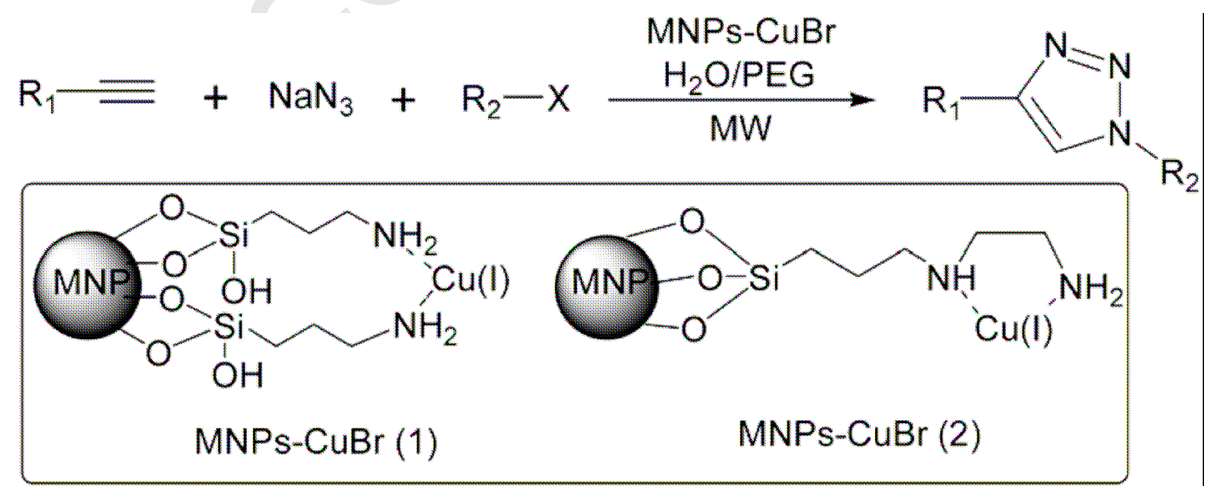

Fig. 32 MNPs-CuBr catalyzed one-pot synthesis of 1,4-disubstituted 1,2,3-triazoles in water under microwave irradiation conditions. Reprinted with permission from ref. 172. Copyright 2013, Royal Society of Chemistry. 
Concerning the CuAAC reaction using the conventional Sharpless-Fokin catalyst $\mathrm{CuSO}_{4} .5 \mathrm{H}_{2} \mathrm{O}+\mathrm{Na}$ Asc. for multiple applications, the shortcoming as already mentioned above is its large quantity, together with the toxicity of copper, limiting the potential for large applications in electronics, biomedicine and biological chemistry. Thus, new $\mathrm{Cu}(\mathrm{I})$ catalysts are on the "top-wanted" list. Our group recently developed the catalyst $[\mathrm{Cu}($ hexabenzyl)tren $][\mathrm{Br}]$ that was easily synthesized, toluene soluble, efficient, easy to separate from products and recyclable [35]. In this approach, reactions achieved TONs of the order of $10^{4}$ reached upon recharging substrates with only $0.1 \mathrm{~mol} \%$ amount of catalyst. The latter was active for "click" reactions between azides and alkynes in toluene or water, and the system recharged at least 10 times. A key advantage of this catalyst [35] compared to Sharpless catalyst is the tremendeous ligand acceleration of the reaction.

Other recent well-defined supramolecular catalytic approaches for the CuAAC reactions such as polymer-supported catalysts of $\mathrm{Cu}(\mathrm{I})$-poly(styrene-co-maleimide) (CuI-SMI) for the one-pot three-component click synthesis of 1,4-disubstituted- $1 \mathrm{H}$ 1,2,3-triazoles [138], polymer-anchored PS-C22-CuI for three-component synthesis of 1,4-disubstituted 1,2,3-triazoles under aerobic conditions in water [173], polymersupported catalyst Amberlyst A-21-CuI for the synthesis of 1,4-disubstituted-1H1,2,3-triazoles in $\mathrm{CH}_{2} \mathrm{Cl}_{2}$ at r.t. [174], $\mathrm{Cu}(\mathrm{I})$-incorporated microporous Schiff base network polymer for $\mathrm{CuAAC}$ in $\mathrm{MeCN}$ at r.t. [175], supramolecular material of polymer supported $\mathrm{Cu}(\mathrm{I})$ catalyst, $(\mathrm{Cu}(\mathrm{I})$-poly(2-aminobenzoic acid), $\mathrm{Cu}(\mathrm{I})-\mathrm{pABA})$, showed excellent yield toward AAC reactions at r.t. in aqueous media [176]. The combined use of two polymer supported reagents (polystyrene-1,5,7triazabicyclo[4,4,0]dec-5-ene/Cu and polystyrene-2-iodoxybenzamide) enabled the reliable $\mathrm{CuAAC}$ in the presence of an oxidant agent [177], $\mathrm{CuI}$ onto dimethylaminografted cross-linked polystyrene (CuI@A-21) for azide-alkyne click polymerization [178], and metal-organic framework ( $\left.\mathrm{Cu}-\mathrm{MOF}, \mathrm{Cu}(\mathrm{PTZ})(\mathrm{NSA})_{0.5} \cdot \mathrm{H}_{2} \mathrm{O}\right)$ for the solvent-free CuAAC [179], were also successfully achieved.

In addition, some of the abnormal 1,2,3-triazoles, for example $N$-carbamoyl 1,2,3triazoles [180a], and 1,4,5-trisubstituted 5-dialkylamino-1,2,3-triazole [180b] were also successfully synthesized to fill the gap.

Interestingly, the Rennes-Valparaiso groups discovered that organometallic Schiffbase copper complexes were excellent precatalysts for the CuAAC reactions, including with regenerated polymethylmethacrylate supports [181].

\subsection{RuAAC}

Recent applications of $\mathrm{Cp} * \mathrm{RuCl}$-based catalysts included the synthesis of 4haloisoxazoles and 5-halotriazoles [81], thiolactoside glycoclusters [83], one-step synthesis of triazoles [84], palladium-based metallocene complexes [85], 1,2,3triazole peptides [86], 5-TTF-1,2,3-triazoles [87], 1,5-substitued 1,2,3-triazole amino acids [182], 5-amino-1,2,3-triazole-4-carboxylic acid [183a], and fluorinated 1,4,5substituted 1,2,3-triazoles [183b].

RuAAC reactions catalyzed by $\mathrm{Ru}(\mathrm{II})$ complexes and RuNPs were also reported. In 
the former case, our group reported the simple and efficient synthesis of magnetically recyclable magnetic NP-supported pentamethylcyclopentadienyl $\mathrm{Ru}$ (II) catalyst (see Fig. 33a) for RuAAC reactions to yield the fully selective construction of 1,5disubstituted 1,2,3-triazoles [184].

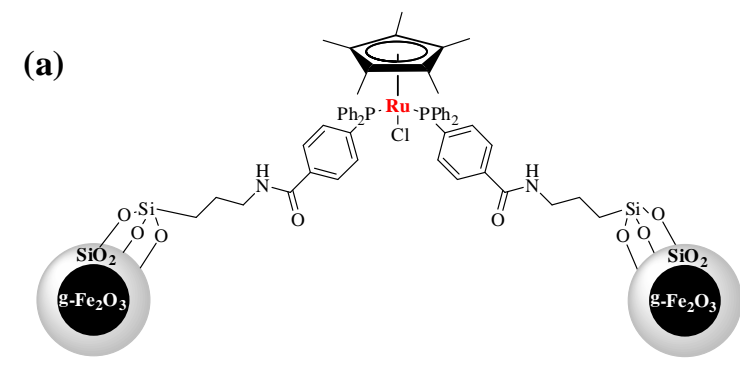

(b)

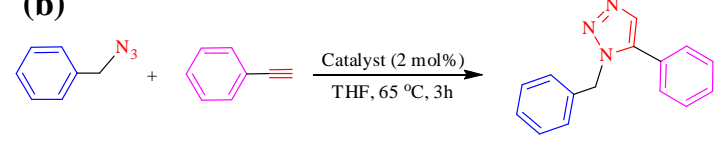

Fig. 33 (a) Magnetically recyclable $\mathrm{Cp} *\left(\mathrm{PPh}_{3}\right)_{2} \mathrm{Ru} / \mathrm{SiO}_{2} / \gamma-\mathrm{Fe}_{2} \mathrm{O}_{3}$ catalyst. (b) Catalytic performance of magnetic catalyst in cycloaddition of phenylacetylene and benzyl azides. Reproduced with permission from ref. 184. Copyright 2013, Royal Society of Chemistry.

The catalyst provided excellent yield and almost 100\% selectivity for the target product and was reused five times by simple magnetic separation with only a minimum decrease in catalytic activity and selectivity, (Fig. 33b) and little change in the morphology and size of the NPs.

A +3 metal oxidation state of polymer supported ruthenium complex was first demonstrated by Molla et al. who reported the synthesis of 1,4-disubstituted 1,2,3triazoles in water with excellent yield via multicomponent coupling in aqueous medium at r.t [185]. On the other hand, Lee's group synthesized the RuNP catalyst using the co-precipitation method. The RuNP catalyst exhibited good results in terms of reactivity in the RuAAC reactions, but the size effect strongly influenced the catalytic activity of these RuNP catalysts, because the size of the catalyst was sensitive to parameters such as the $\mathrm{pH}$ of the medium and the type and concentration of the surfactant [186].

MW-assistance promoted RuAAC reactions [82,84,87], as recently exemplified by Johansson et al who reported one-pot RuAAC reactions to synthesize 1,5disubstituted $1 H-1,2,3$-triazoles involving two steps under microwave heating (Fig. 34). First of all, the organic azide was formed in situ by treating the primary alkyl halide with sodium azide in DMA under microwave heating, then the catalyst [RuClCp* $\left.\left(\mathrm{PPh}_{3}\right)_{2}\right]$ was added, and a second microwave irradiation was applied to yield the cycloaddition product [187]. 


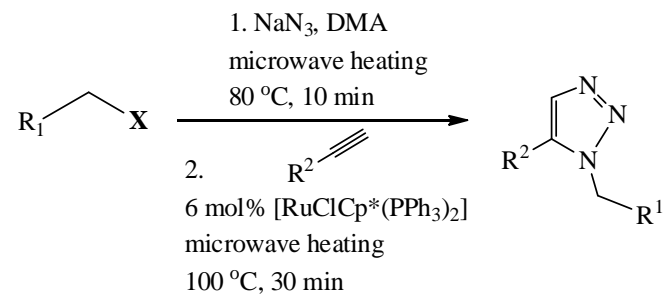

Fig. 34 Sequential one-pot RuAAC reaction under microwave heating. Reproduced with permission from ref. 187. Copyright 2011, American Chemical Society.

\subsection{Applications of the CuAAC “click" reactions}

The CuAAC reaction is considered as the most robust and straightforward synthetic procedure for various organic syntheses [188], especially in building novel structures, including natural products modifications [189], the synthesis of porphyrin based derivatives [190], the iterative click construction of dendrimers that are terminated with various functional groups [191], and polymers [192]. In the case of the dendrimer the "click" synthesis of a water soluble dendrimer that contained 9 intradendritic triazole rings and terminated by 27 triethylene glycol (TEG) termini was reported and used as nanoparticle stabilizer and catalyst template. This dendrimer has recently been employed as an amphiphilic micellar nanoreactor, stabilizer and activator for part-permillion $\mathrm{Cu}(\mathrm{I})$ catalyst of "click" chemistry in water under ambient conditions, due to its coordination and encapsulation abilities of $\mathrm{Cu}(\mathrm{I})$-ions and hydrophobic $\mathrm{Cu}(\mathrm{I})$ catalysts, respectively [27a]. The "click" synthesis of polycondensation metallopolymers containing redox-robust bis(ethynyl)biferrocene (biFc) and di(azido) poly(ethylene glycol) was also achieved [193]. This polymer showed intriguing properties; the biFc unit provided a class-II mixed-valence polyelectrolyte and electrochrome properties, while the presence of PEG in the polymer improved the water solubility and biocompatibility. The triazole linkers between biFc and PEG units facilitated redox sensing of transition-metal cations. Moreover, this easy available polymer was an excellent template for the stabilization of catalytically active AuNPs and PdNPs for 4-nitrophenol reduction and Suzuki-Miyaura reaction, respectively.

The easy accessible click approach of various material constructions has a great impact in materials science [194a,b]. The excellent reviews on click chemistry in materials science by Bowman's group [194a] and Diaz [194b] cover this area. Veige's click functionalization of inorganic complexes (inorganic click) by reaction of $\mathrm{PPh}_{3} \mathrm{AuN}_{3}$ with alkynyl- or $p$-substituted alkynyl gold complexes led to bi- and polymetallic triazoles [194c-g], and the functionalization of gold nanoparticles has also proved to be an effective method for the construction of novel nanostructures [195]. The functionalization of carbon-based nanomaterials has long attracted the interest of researchers. For example, $\mathrm{CuAAC}$ functionalizations of $\mathrm{C}_{60}$ derivatives have been achieved [196] and improved their solubility. Recent examples include the preparation of fullerene sugar balls [197], $\mathrm{C}_{60}$-containing polymers [198], viral 
nanoparticle (VNP)- $\mathrm{C}_{60}$ conjugates [199], supramolecular interactions between molecular tweezers and macrocycles, functionalization of $\mathrm{C}_{70}$ fullerenes [200], and biotinylation of fullerene vesicle via CuAAC and conjugation with avidin [201]. Functionalized graphene and partially reduced graphene oxide (rGO) functionalized on the surface provide possibilities for improving the electrical strength recovery and utilization in devices. Functionalized rGO surface covalently immobilized with metal nanoparticles such as AuNPs and AgNPs, through the organic linkers is a good tool for achieving controllable transport in memory devices [202] and electron transfer in photocatalysis [203]. Click formation of 1,2,3-triazoles on the surface of rGO combined with localized surface plasmon resonance (LSPR) effect of the AuNPs allowed the observation of a fivefold photocurrent enhancement for triazole linkers. This showed that the triazoles linker between rGO and AuNPs were very efficient for charge separation and electron transfer [203].

In the field of biology, click chemistry has also been extensively used with various successful biological, chemical and medicinal applications [204] including nucleic acid ligation [205], bioconjugation for protein modification [206], drug design [207], gel syntheses for biomedical applications [208], chemical modification of biological molecules [209], and biomolecular labeling [210] activity-based protein profiling (ABPP) [211].

\section{Conclusions and outlook}

The MAAC reactions are of considerable use in synthesis with applications in materials science and biomedicine, and they remain by far the most prominent example of "click" chemistry. Therefore considerable research has been devoted to extend the variety of metal catalysts and to mechanistically understand the different MAAC reactions with the help of theoretical calculations, characterizations of intermediates and optimization of reaction parameters. In this field as in many others the theoretical calculation and experimental progress are intimately connected in order to improve the reaction efficiency, simplify procedures and apply them to industry in particular by decreasing catalytic amounts. Thus both mechanistic advances and recent trends of AAC "click chemistry" have been reviewed here. The multiple new advances are inspiring for theoretical chemists to rationalize the mechanisms of new routes. In turn, the theoretical advances guide and lead chemists to imagine new reaction improvements.

The CuAAC reaction remains the most currently used MAAC reaction, and the review has highlighted a multitude of reported improvements including the use of excellent $\mathrm{Cu}(\mathrm{I})$ ligands, copper metal and CuNPs in various forms to make this click reaction more practical and more easily applicable. The very practical initial Sharpless-Fokin catalyst $\mathrm{CuSO}_{4}+\mathrm{NaAsc}$ remains most often used, and with the use of optimized ligands researches have led to considerable decrease of the catalytic amounts down to the ppm permitting industrial applications. Some theoretical calculations have converged to the identification of a bimetallic $\square \square \square$ intermediate in a bimetallic mechanism. On the other hand, studies showed that in the presence of 
very low amounts of catalyst a monometallic mechanism was occurring in catalytically efficient $\mathrm{Cu}(\mathrm{I})$-centered dendrimers with positive dendritic effect for the smaller substrates and in extraordinarily efficient dendrimer-mediated $\mathrm{Cu}(\mathrm{I})$ catalysis. The complete change of regioselectivity provided by the RuAAC reaction discovered by Fokin's group has been perfectly rationalized mechanistically, but Nolan's introduction of the NHC ligands in the RuAAC reactions showed alternative results and mechanistic features. Many more metals are active in MAAC reactions and some of them including lanthanides have been mechanistically rationalized based on theoretical calculations. Indeed, the quality of modern theoretical calculations with DFT methods now allows confident mechanistic approaches with excellent determination of reaction energetics, for both thermodynamic and kinetic sides.

In conclusion calculations and experimental research have brought MAAC at the forefront of "green chemistry" with mild, environmentally benign and useful synthetic methods that are now applicable to industry. Further work including computational and experimental research is required, however, to push MAAC towards multicomponent "one-pot" syntheses [212] for industrial production and to design multi-task catalysts based on bimetallic or multi-metallic systems for tandem reactions.

\section{Acknowledgement}

Financial support from the China Scholarship Council (CSC) of the People's Republic of China (grant to C.W.), the Universities of Bordeaux and Rennes 1 and the Centre National de la Recherche Scientifique (CNRS) are gratefully acknowledged.

\section{Notes and references}

[1] H. C. Kolb, M. G. Finn, K. B. Sharpless, Angew. Chem., Int. Ed. 40 (2001) 20042012.

[2] H. C. Kolb, K. B. Sharpless, Drug Discov. Today 8 (2003) 1128-1137.

[3] A. E. Speers, G. C Adams, B. F. Cravatt, J. Am. Chem. Soc. 125 (2003) 46864687.

[4] H. Nandivana, X. Jiang, J. Lahann, Adv. Mater. 19 (2007) 2197-2208.

[5] J. M. Baskin, J. A. Prescher, S. T. Laughlin, N. J. Agard, P. V. Chang, I. A. Miller, A. Lo, J. A. Codelli, C. R. Bertozzi, Proc. Nat. Acad. Sci. 104 (2008) 16793-16797.

[6] G. C. Tron, T. Pirali, R. A. Billington, P. L. Canonico, G. Sorba, A. A. Genazzani, Med. Res. Rev. 28 (2008) 278-308.

[7] C. D. Hein, X. -M. Liu, D. Wang, Pharmaceut. Res. 25 (2008) 2216-2230.

[8] C. A. DeForest, B. D. Polizzotti, K. S. Anseth, Nat. Mater. 8 (2009) 659-664.

[9] A. H. El-Sagheer, T. Brown, Chem. Soc. Rev. 39 (2010) 1262-1271.

[10] S. G. Agalave, S. R. Maujan, V. S. Pore, Chem. Asian J. 6 (2011) 2696-2718.

[11] N. P. Grimster, B. Stump, J. R. Fotsing, T. Weide, T. T. Talley, J. G. Yamauchi, A. Nemecz, C. Kim, K. Y. Ho, K. B. Sharpless, P. Taylor, V. V. Fokin, J. Am. Chem. Soc. 134 (2012) 6732-6740.

[12] P. Wu, A. K Felman, A. K. Nugent, C. J. Hawker, A. Scheel, B. Voit, J. Pyun, J. 
M. J. Fréchet, K. B. Sharpless, V. V. Fokin, Angew. Chem., Int. Ed. 43 (2004) 39283932.

[13] N. V. Tsarevsky, B. S. Sumerlin, K. Matyjaszewsski, Macromol. 38 (2005) 3558-3561.

[14] W. H. Binder, R. Sachsenhofer, Macromol Rapid. Commun. 28 (2007) 15-54.

[15] D. Fournier, R. Hoogenboom, U. S. Schubert, Chem. Soc. Rev. 36 (2007) 13691380 .

[16] J. -F. Lutz, Angew. Chem., Int. Ed. 46 (2007) 1018-1025.

[17] W. H. Binder, R. Sachsenhofer, Macromol. Rapid. Commun. 29 (2008) 952-981.

[18] G. Franc, A. Kakkar, Chem. Commun. 42 (2008) 5267-5276.

[19] B. S. Sumerlin, A. P. Vogt, Macromol. 43 (2010) 1-13.

[20] P.L. Golas, K. Matyjaszewski, Chem. Soc. Rev. 39 (2010) 1338-1354.

[21] L. Liang, D. Astruc, Coord. Chem. Rev. 255 (2011) 2933-2945.

[22] (a) V. V. Rostovtsev, L. G. Green, V. V. Fokin,, K. B. Sharpless, Angew. Chem., Int. Ed. 41 (2002) 2596-2599; (b) V. V. Fokin, K. Matyjaszewski, CuAAC: the quintessential click reaction, in: Organic Chemistry-Breakthroughs, Perspectives, Wiley-VCH Verlag GmbH \& Co. KGaA, 2012, pp. 247-277.

[23] C. W. Tornøe, C. Christensen, M. Meldal, J. Org. Chem. 67 (2002) 3057-3064.

[24] M. Meldal, C. W. Tornøe, Chem. Rev. 108 (2008) 2952-3015.

[25] R. Huisgen, Angew. Chem., Int. Ed. Engl. 2 (1963) 565-598.

[26] J. E. Hein, V. V. Fokin, Chem. Soc. Rev. 39 (2010) 1302-1315.

[27] (a) C. Deraedt, N. Pinaud, D. Astruc, J. Am. Chem. Soc. 136 (2014) 12092-

12098; (b) D. Ikhlef, C. Wang, S. Kahlal, B. Maouche, D. Astruc, J.-Y. Saillard,

Comp. Theo. Chem. 1073 (2015) 131-138.

[28] L. Zhang, X. G. Chen, P. Xue, H. H. Y. Sun, I. D. Williams, K. B. Sharpless, V. V. Fokin, G. C. Jia, J. Am. Chem. Soc. 127 (2005) 15998-15999.

[29] P. N. Liu, J. Li, F. H. Su, K. D. Ju, L. Zhang, C. Shi, H. H. Y. Sung, I. D. Williams, V. V. Fokin, Z. Y. Lin, G. C. Jia, Organometallics 31 (2012) 4904-4915.

[30] V. D. Bock, H. Hiemstra, J. H. van Maarseven, Eur. J. Inorg. Chem. (2005) 5168.

[31] F. Himo, T. Lovell, R. Hilgraf, V. V. Rostovssev, L. Noodleman , K. B. Sharpless, V. V. Fokin, J. Am. Chem. Soc. 127 (2005) 210-216.

[32] V. O. Rodionov, V. V. Fokin, M. G. Finn, Angew. Chem., Int. Ed. 44 (2005) 2210-2215.

[33] S. Diez-Gonzalez, A. Correa, L. Cavallo, S. P. Nolan, Chem. Eur. J. 12 (2006) 7558-7564.

[34] D. Cantillo, M. Avalos, R. Babiano, P. Cintas, J. L. Jimenez, J. C. Placios, Org. Biomol. Chem. 9 (2011) 2952-2958.

[35] L. Liang, J. Ruiz, D. Astruc, Adv. Syn. Catal. 353 (2011) 3434-3450.

[36] D. Astruc, L. Liang, A. Rapakousiou, J. Ruiz, Acc. Chem. Res. 45 (2012) 630640.

[37] R. Berg, B. F. Straub, Beilstein J. Org. Chem. 9 (2013) 2715-2750.

[38] B. T. Worrell, J. A. Malik, V. V. Fokin, Science 340 (2013) 457-460.

[39] B. C. Boren, S. Narayan, L. K. Rasmussen, L. Zhang, H. T. Zhao, Z. Y. Lin, G. 
C. Jia, V. V. Fokin, J. Am. Chem. Soc. 130 (2008) 8923-8930.

[40] D. R. Hou, T. C. Kuan, Y. K. Li, R. Lee, R. W. Luang, Tetrahedron 66 (2010) 9415-9420.

[41] E. Boz, N.S. Tuzun, J. Organomet. Chem. 724 (2013) 167-176.

[42] N. V. Sokolovaab, V. G. Nenajdenko, RSC Adv. 3 (2013) 16212-16242.

[43] R. M. Moorman, M. B. Collier, B. H. Frohock, M. D. Womble, J. M. Chalker, Org. Biomol. Chem. 13 (2015) 1974-1978.

[44] (a) B. Chattopadhyay, C. I. Rivera Vera, S. Chuprakov, V. Gevorgyan, Org. Lett. 122010 2166-2169; (b) S. Gu, H. Xu, N. Zhang, W. Chen, Chem.-Asian J. 5 (2010) 1677-1686.

[45] M. Javaherian, F. Kazemi, M. Ghaemi, Chin. Chem. Lett. 25 (2014) 1643-1647.

[46] Y. Jiang, D. Kong, J. Zhao, W. Zhang, W. Xu, W. Li, G. Xu, Tetrahedron Lett. 55 (2014) 2410-2414.

[47] M. F. Mady, G. E.A. Awad, K. B. Jørgensen, Eur. J. Med. Chem. 84 (2014) 433443.

[48] S. Marullo, F. D’ Anna, C, Rizzo, R. Noto, Ultrason. Sonochem. 23 (2015) 317323.

[49] Q. Zhang, X. Wang, C. Cheng, R. Zhu, N. Liu, Y. Hu, Org. Biomol. Chem. 10 (2012) 2847-2854.

[50] A. N. Semakin, D. P. Agababyan, S. Kim, S. Lee, A. Yu. Sukhorukov, K. G. Fedina, J. Oh, S. L. Ioffe, Tetrahedron Lett. 56 (2015) 6335-6339.

[51] D. Wang, M. Zhao, X. Liu, Y. Chen, N. Li, B. Chen, Org. Biomol. Chem. 10 (2012) 229-231.

[52] D. Wang, N. Li, M. Zhao, W. Shi, C. Ma, B. Chen, Green Chem. 12 (2010) 2120-2123

[53] S. Diez-Gonzales, D. Edwin, S. P. Nolan, Chem. Commun. 39 (2008) 47474749.

[54] G. Gisado-Barrios, J. Bouffard, B. Donnadieu, G. Bertrand, Angew. Chem., Int. Ed. 49 (2010) 4759-4752.

[55] T. Nakamura, T. Terashima, K. Ogata, S. Fukusawa, Org. Lett. 13 (2011) 620623.

[56] V. O. Rodionov, S. I. Presolski, S. Gardinier, Y. -H. Lim, M. G. Finn, J. Am. Chem. Soc. 129 (2007) 12696-12704.

[57] M. Ahlquist, V. V. Fokin, Organometallics 26 (2007) 4389-4391.

[58] (a) B. F. Straub, Chem. Commun. 37 (2007) 3868-3870. (b) R. Berg, J. Straub, E. Schreiner, S. Mader, F. Rominger, B. F. Straub, Adv. Synth. Catal. 354 (2012) 34453450; (c) A.Makarem, R. Berg, F. Rominger, B. F. Straub, Angew. Chem. Int. Ed. 54 (2015) 7431-7435.

[59] B. F. Straub, M. Bessel, R. Berg in : P. Comba (Ed.), Modeling of Molecular Properties, Wiley-VCH, 2011, pp 207-214.

[60] C. Özen, N. Ș. Tüzün, J. Mol. Gr. Modell. 34 (2012) 101-107.

[61] E. Haldón, M. Besora, I. Cano, X. C. Cambeiro, M. A. Pericàs, F. Maseras, M. C. Nicasio, P. J. Pérez, Chem. Eur. J. 20 (2014) 1-13.

[62] S. Calvo-Losada, M. S. Pino, J. J. Quirante, J. Mol. Model. 20 (2014) 2187- 
2194.

[63] S. Calvo-Losada, M. S. Pino-González, J. J. Quirante, J. Phys. Chem. 119 (2014) 1243-1258.

[64] C. Iacobucci, S. Reale, J. -F. Gal, F. D. Angelis, Angew. Chem. Int. Ed. 54 (2015) 3065-3068.

[65] S. Díez-González, E. C. Escudero-Adan, J. Benet-Buchholz, E. D. Stevens, A. M. Z. Slawin, S. P. Nolan, Dalton Trans. 39 (2010) 7595-7606.

[66] J. D. Egbert, C. S. J. Cazin, S. P. Nolan, Catal. Sci. Technol. 3 (2013) 912-926.

[67] (a) M.-L. Teyssot, A. Chevry, M. Traikia, M. El-Ghozzi, D. Avignant, A. Gautier, Chem. -Eur. J. 15 (2009) 6322-6326; (b) M. -L. Teyssot, L. Nauton, J. -L. Canet, F. Cisnetti, A. Chevry, A. Gautier, Eur. J. Org. Chem. (2010) 3507-3519.

[68] (a) S. Díez-González, S. P. Nolan, Angew. Chem., Int. Ed. 47 (2008) 8881-8884; (b) L. Jin, E. A. Romero, M. Melaimi, G. Bertrand, J. Am. Chem. Soc. 137 (2015) 15696-15698.

[69] (a) M. A. Tasdelen, Y. Yagci, Angew. Chem. Int. Ed. 52 (2013) 5930-5938; (b) C. P Ramil, Q. Lin, Curr. Opi. Chem. Bio. 21 (2014) 89-95; (c) S. Dadashi-Silab, S. Doran and Y. Yagci, Chem. Rev. (2016) DOI: 10.1021/acs.chemrev.5b00586.

[70] (a) B. J. Adzima, Y. H. Tao, C. J. Kloxin, C. A. DeForest, K. S. Anseth, C. N. Bowman, Nat. Chem. 3 (2011) 256-259; (b) T. Gong, B. J. Adzima, N. H. Baker, C. N. Bowman, Adv. Mater. 25 (2013) 2024-2028; (c) T. Gong, B. J. Adzima, C. N. Bowman, Chem. Commun. 49 (2013) 7950-7952; (d) M. K. McBride, T. Gong, D. P. Nair, C. N. Bowman, Polymer 55 (2014) 5880-5884; (e) A. A. Alzahrani, A. H. Erbse, C. N. Bowman, Polym. Chem. 5 (2014) 1874-1882.

[71] B. Sandmann, B. Happ, J. Vitz, M. D. Hager, P. Burtscher, N. Moszner, U. S. Schubert, Polym. Chem. 4 (2013) 3938-3942.

[72] (a) Y. Yagci, M. A. Tasdelen, S. Jockusch, Polymer 55 (2014) 3468-3474; (b) S. Dadashi-Silab, B. Kiskan, M. Antoniettib, Y. Yagci, RSC Adv. 4 (2014) 5217052173.

[73 G. Yilmaz, B. Iskin, Y. Yagci, Macromol. Chem. Phys. 215 (2014) 662-668.

[74] X. Guan, J. Zhang, Y. Wang, Chem. Lett. 43 (2014) 1073-1074.

[75] R.Beniazza, R. Lambert, L. Harmand, F. Molton, C. Duboc, S. Denisov, G. Jonusauskas, N. D. McClenaghan, D. Lastecoueres, J. -M. Vincent, Chem. Eur. J. (20) 2014 13181-13187.

[76] M. A. Tasdelen, G. Yilmaz, B. Iskin, Y. Yagci, Macromolecules 45 (2012) $56-61$.

[77] J. C. Bear, N. Hollingsworth, P. D. McNaughter, A. G. Mayes, M. B. Ward, T. Nann, G. Hogarth, I. P. Parkin, Angew. Chem. Int. Ed. 53 (2014) 1598-1601.

[78] (a) M. R. Decan, S.Impellizzeri, M. L. Marin, J. C. Scaiano, Nat. Commun. 5 (2014) 4612; (b) T. Jin, M. Yan, Y. Yamamoto, ChemCatChem 4 (2012) 1217-1229.

[79] F. Alonso, Y. Moglie, G. Radivoy, Acc. Chem. Res. 48 (2015) 2516-2528

[80] F. Alonso, Y. Moglie, G. Radivoy, M. Yus, Eur. J. Org. Chem. (2010) 18751884

[81] J. S. Oakdale, R. K. Sit, V. V. Fokin, Chem. Eur. J. 20 (2014) 11101-11110.

[82] L. K. Rasmussen, B. C. Boren, V. V. Fokin, Org. Lett. 9 (2007) 5337-5339. 
[83] A. J. Cagnoni, O. Varela, M. L. Uhrig, J. Kovensky, Eur. J. Org. Chem. (2013) 972-983.

[84] J. R. Johansson, E. Hermansson, B. Nordén, N. Kann, T. Beke-Somfai, Eur. J. Org. Chem. (2014) 2703-2713.

[85] E. Chardon, G. L. Puleo, G. Dahm, S. Fournel, G. Guichard, S. BelleminLaponnaz, ChemPlusChem 77 (2012) 1028-1038.

[86] D. S. Pedersen, A. Abell, Eur. J. Org. Chem. (2011) 2399-2411.

[87] T. Biet, T. Cauchy, N. Avarvari, Chem. Eur. J. 18 (2012) 16097-16103.

[88] M. Lamberti, G. C. Fortman, A. Poater, J. Broggy, A. M. Z. Slawin, L. Cavallo, S. P. Nolan, Organometallics 31 (2012) 756-767.

[89] (a) P. N. Liu, H. X. Siyang, L. Zhang, S. K. S. Tse, G. Jia, J. Org. Chem. 77 (2012) 5844-5849; (b) H. X. Siyang, H. L. Liu, X. Y. Wu, P. N. Liu, RSC Adv. 5 (2015) 4693-4697.

[90] Y. -H. Lo, T. -H. Wang, C. -Y. Lee, Y. -H. Feng, Organometallics 31 (2012) 6887-6899.

[91] T. -H. Wang, F. -L. Wu, G. -R. Chiang, S. -T. He, Y. -H. Lo, J. Organomet. Chem. 774 (2014) 57-60.

[92] J. McNulty, K. Keskar, R. Vemula, Chem. Eur. J. 17 (2011) 14727-14730.

[93] J. McNulty, K. Keskar, Eur. J. Org. Chem. (2012) 5462-5470.

[94] A. I. Ortega-Arizmendi, E. Aldeco-Perez, E. Cuevas-Yanez, Sci. World J. (2013) 186537.

[95] N. Salam, A. Sinha, A. S. Roy, P. Mondal, N. R. Jana, S. M. Islam, RSC Adv. 4 (2014) 10001-10012.

[96] T. U. Connell, C. Schieber, I. P. Silvestri, J. M. White, S. J. Williams, P. S. Donnelly, Inorg. Chem. 53 (2014) 6503-6511

[97] A. M. Ferretti, A. Ponti, G. Molteni, Tetrahedron Lett. 56 (2015) 5727-5730.

[98] A. A. Ali, M. Chetia, B. Saikia, P. J. Saikia, D. Sarma, Tetrahedron Lett. 56 (2015) 5892-5895.

[99] (a) A. Gourdon, Angew. Chem. Int. Ed. 47 (2008) 6950-6953; (b) D. Perepichka, F. Rosei, Science 323 (2009) 216-217.

[100] F. Bebensee, C. Bombis, S.-R. Vadapoo, J. R. Cramer, Fl. Besenbacher, K. V. Gothelf, T. R. Linderoth, J. Am. Chem. Soc. 135 (2013) 2136-2139.

[101] O. D. Arado, H. Monig, H. Wagner, J. -H. Franke, G. Langewisch, P. A. Held, A. Studer, H. Fuchs, ACS Nano 7 (2013) 8509-8515.

[102] M. Boominathan, N. Pugazhenthiran, M. Nagaraj, S. Muthusubramanian, S. Murugesan, N. Bhuvanesh, ACS Sustainable Chem. Eng. 1 (2013) 1405-1411.

[103] E. Rasolofonjatovo, S. Theeramunkong, A. Bouriaud, S. Kolodych, M. Chaumontet, F. Taran, Org. lett. 15 (2013) 4698-4701.

[104] S. Ding, G. Jia, J. Sun, Angew. Chem., Int. Ed. 53 (2014) 1877-1880.

[105] Q. Luo, G. Jia, J. Sun, Z. Lin, J. Org. Chem. 79 (2014) 11970-11980.

[106] H. S. P. Rao, G. Chakibanda, RSC Adv. 4 (2014) 46040-46048.

[107] S. Chassaing, A. S. S. Sido, A. Alix, M. Kumarraja, P. Pale, J. Sommer, Chem. -Eur. J. 14 (2008) 6713-6721.

[108] X. Meng, X. Xu, T. Gao, B. Chen, Eur. J. Org. Chem. (2010) 5409-5414. 
[109] (a) C. D. Smith, M. F. Greaney, Org. Lett. 15 (2013) 4826-4829; (b) Y. Li, X. Qi, Y. Lei, Y. Lan, RSC Adv. 5 (2015) 49802-49808.

[110] L. Hong, W. Lin, F. Zhang, R. Liu, X. Zhou, Chem. Commun. 49 (2013) 55895591.

[111] J. M. Wang, S. B. Yu, Z. M. Li, Q. R. Wang, Z.T. Li, J. Phys. Chem. A 119 (2015) 1359-1368.

[112] (a) S. Lal, H. S. Rzepa, S. Díez-Gonzalez, ACS Catal. 4 (2014) 2274-2287; (b)

Y. Xia, L. Chen, S. Lv, Z. Sun, B. Wang, J. Org. Chem. 79 (2014) 9818-9825; (c) J.

-M. Collinson, J. D. E. T. Wilton-Ely, S. Diez-Gonzalez, Chem. Commun. 49 (2013) 11358-11360; (d) E. Tasca, G. L. Sorella, L. Sperni, G. Struku, A. Scarso, Green Chem. 17 (2015) 1414-1422.

[113] F. Lazreg, A. M. Z. Slawin, C. J. Cazin, Organometallics 31 (2012) 7969-7975.

[114] S. Hohloch, C.-Y. Su, B. Sarkar, Eur. J. Inorg. Chem. (2011) 3067-3075.

[115] L. R. Collins, T. M. Rookes, M. F. Mahon, I. M. Riddlestone, M. K. Whittlesey, Organometallics 33 (2014) 5882-5887.

[116] S. Hohloch, D. Scheiffele, B. Sarkar, Eur. J. Inorg. Chem. (2013) 3956-3965.

[117] S. C. Sau, S. R. Roy, T. K. Sen, D. Mullangi, S. K. Mandal, Adv. Synth. Catal. 355 (2013) 2982-2991.

[118] S. Hohloch, B. Sarkar, L. Nauton, F. Cisnetti, A. Gautier, Tetrahedron Lett. 54 (2013) 1808-1812.

[119] J. M. Barta, S. Díez-González, Molecules 18 (2013) 8919-8928.

[120] S. -Q. Bai, L. Jiang, J. -L. Zuo, T. S. A. Hor, Dalton Trans. 42 (2013) 1131911326.

[121] D. Mendoza-Espinosa, G. E. Negrón-Silva, D. Ángeles-Beltrán, A. ÁlvarezHernández, O. R. Suárez-Castillo, R. Santillán, Dalton Trans. 43 (2014) 7069-7077.

[122] L. Jiang, Z. Wang, S. -Q. Bai, T. S. A. Hor, Dalton Trans. 42 (2013) 94379443.

[123] B. -H. Lee, C. -C. Wu, X. Fang, C. W. Liu, J. -L. Zhu, Catal. Lett. 143 (2013) $572-577$.

[124] T. Song, L. Li, W. Zhou, Z. -J. Zheng, Y. Deng, Z. Xu, L. -W. Xu, Chem. Eur. J. 21 (2015) 554-558.

[125] H. -B. Chen, N. Abeyrathna, Y. Liao, Tetrahedron Lett. 55 (2014) 6575-6576.

[126] D. P. Singh, B. K. Allam, K. N. Singh, V. P. Singh, J. Mol. Catal. A: Chem. 398 (2015) 158-163.

[127] (a) G. -C. Kuang, H. A. Michaels, J. T. Simmons, R. J. Clark, L. Zhu, J. Org. Chem. 75 (2010) 6540-6548; (b) W. S. Brotherton, H. A. Michaels, J. T. Simmons, R. J. Clark, N. S. Dalal, L. Zhu, Org. Lett. 11 (2009) 4954-4957; (c) P. Appukkuttan, W. Dehaen, V. V. Fokin, E. Van der Eycken, Org. Lett. 6 (2004) 4223-4225.

[128] S. Mohammed, A. K. Padala, B. A. Dar, B. Singh, B. Sreedhar, R. A. Vishwakarma, S. B. Bharate, Tetrahedron 68 (2012) 8156-8162.

[129] Z. Mirjafary, L. Ahmadi, M. Moradi, H. Saeidian, RSC Adv. 5 (2015) 7803878046.

[130] C. Zhou, J. Zhang, P. Liu, J. Xie, B. Dai, RSC Adv. 5 (2015) 6661-6665.

[131] Z. Zhang, Q. Zhou, F. Ye, Y. Xia, G. Wu, M. L. Hossain, Y. Zhang, J. Wang, Adv. 
Synth. Catal. 357 (2015) 2277-2286.

[132] R. B. N. Baig, R. S. Varma, Green Chem. 15 (2013) 1839-1843.

[133] A. Pourjavadia, N. Safaiea, S. H. Hosseinia, C. Bennett, Appl. Organometal. Chem. 29 (2015) 601-607.

[134] (a) S. Roya, T. Chatterjeec, M. Pramanikd, A. S. Roy, A. Bhaumik, S. M. Islam, J. Mol. Catal. A: Chem. 386 (2014) 78-85; (b) I. Jlalia, F, Gallier, N. Brodie-Linder, J. Uziel, J. Aué, N. Lubin-Germain, J. Mol. Catal. A: Chem. 393 (2014) 56-61.

[135] N. Mukherjee, S. Ahammed, S. Bhadra, B. C. Ranu, Green Chem. 15 (2013) 389-397.

[136] M. Nasr-Esfahani, I. Mohammadpoor-Baltork, A. R. Khosropour, M. Moghadam, V. Mirkhani, S. Tangestaninejad, H. A. Rudbari, J. Org. Chem. 79 (2014) 1437-1443.

[137] M. N. S. Rad, S. Behrouz, M. M. Doroodmand, A. Movahediyan, Tetrahedron 68 (2012) 7812-7821.

[138] E. Hashemi, Y. S. Beheshtiha, S. Ahmadi, M. M. Heravi, Transition Metal Chem. 39 (2014) 593-601.

[139] F. M. Moghaddam, S. E. Ayati, RSC Adv. 5 (2015) 3894-3902

[140] X. Xiong, H. Chen, Z. Tang, Y. Jiang, RSC Adv. 4 (2014) 9830-9837.

[141] F. Chahdoura, C. Pradel, M. Gómez, ChemCatChem 6 (2014) 2929-2936.

[142] J. -H. Wang, C. -W. Pan, Y. -T. Li, F. -F. Meng, H. -G. Zhou, C. Yang, Q. Zhang, C. -G. Bai, Y. Chen, Tetrahedron Lett. 54 (2013) 3406-3409.

[143] Y. Jiang, D. Kong, J. Zhao, Q. Qi, W. Li, G. Xu, RSC Adv. 4 (2014) 10101014.

[144] W. Zhang, B. Ren, Y. Jiang, Z. Hu, RSC Adv. 5 (2015) 12043-12047.

[145] (a) A. S. Nia, S. Rana, D. Dohler, X. Noirfalise, A. Belfiore, W. H. Binder, Chem. Commun. 50 (2014) 15374-15377; (b) A. S. Nia, S. Rana, D. Dohler, F. Jirsa, A. Meister, L. Guadagno, E. Koslowski, M. Bron, W. H. Binder, Chem. Eur. J. 21 (2015) 10763-10770; (c) A. S. Nia, S. Rana, D. Dohler, W. Osim, W. H. Binder, Polymer 79 (2015) 21-28.

[146] K.Chanda, S. Rej, M. H. Huang, Chem. Eur. J. 19 (2013) 16036-16043.

[147] A. Kumar, S. Aerry, A. Saxena, A. Deb, S. Mozumdar, Green Chem. 14 (2012) 1298-1301.

[148] M. Gholinejad, N. Jeddi, ACS Sustainable Chem. Eng. 2 (2014) 2658-2665.

[149] R. P. Jumde, C. Evangelisti, A. Mandoli, N. Scotti, R. Psaro, J. Catal. 324 (2015) 25-31.

[150] S. Kaur, V. Bhalla, M. Kumar, Chem. Commun. 51 (2015) 526-529.

[151] A. Pathigoolla, R. P. Pola, K. M. Sureshan, Appl. Catal. A: Gen. 453 (2013) 151-158.

[152] L. Rinaldi, K. Martina, F. Baricco, L. Rotolo, G. Cravotto, Molecules 20 (2015) 2837-2849.

[153] F. Alonso, Y. Moglie, G. Radivoy, M. Yus, J. Org. Chem. 78 (2013) 5031-5037.

[154] L. Huang, W. Liu, J. Wu, Y. Fu, K. Wang, C. Huo, Z. Du, Tetrahedron Lett. 55 (2014) 2312-2316. 
[155] (a) Y. Chen, Z. -J. Zhuo, D. -M. Cui, C. Zhang, J. Organomet. Chem. 749 (2014) 215-218; (b) C. Zhang, B. Huang, Y. Chen, D. -M. Cui, New J. Chem. 37 (2013) 2606-2609.

[156] F. Nador, M. A. Volpe, F. Alonso, A. Feldhoff, A. Kirschning, G. Radivoy, Appl. Catal. A: Gen. 4552013 39-45.

[157] B. H. Lipshutz, D. M. Nihan, E. Vinogradova, B. R. Taft, Z. V. Boskovic, Org. Lett. 10 (2008) 4279-4282.

[158] B. S. P. A. Kumar, K. H. V. Reddy, B. Madhav, K. Ramesh, Y. V. D. Nageswar, Tetrahedron Lett. 53 (2012) 4595-4599.

[159] R. Hudson, C. -J. Li, A. Moores, Green Chem. 14 (2012) 622-624.

[160] S. B. Otvos, G. Hatoss, A. Georgiades, Szabolcs Kovacs, I. M. Mandity, Z. Novakb, F. Fulop, RSC Adv. 4 (2014) 46666-46674.

[161] J. Gong, J. Liua, L. Ma, X. Wen, X. Chen, D. Wan, H. Yua, Z. Jianga, E. Borowiak-Palenc, T. Tang, App. Catal. B: En. 117 (2012) 185-193.

[162] B. H. Lipshutz, B. R. Taft, Angew. Chem. 118 (2006) 8415-8418.

[163] M. Biswas, A. Saha, M. Dule, T. K. Mandal, J. Phys. Chem. C 118 (2014) 22156-22165.

[164] J. M. Perez, R. Cano, D. J. Ramon, RSC Adv. 4 (2014) 23943-23951.

[165] (a) C.Y. Lee, R. Held, A Sharma, R. Baral, C. Nanah, D. Dumas, S. Jenkins, S. Upadhaya, W. J. Du, J. Org. Chem. 78 (2013) 11221-11228; (b) D. Ashok, D. M. Gandhi, G. Srinivas, A.V. Kumar, Med. Chem. Res. 23 (2014) 3005-3018; (c) K. Jacob, A. Stolle, Synth. Commun. 44 (2014) 1251-1257. (d) N. Mnasri, Je. L. Nyalosaso, E. Colacino, Ga. Derrien, F. Lamaty, J. Martinez, J. Zajac, C. Charnay, ACS Sustainable Chem. Eng. 3 (2015) 2516-2525.

[166] (a) P. Etayo, C. Ayats, M. A. Pericàs, Chem. Commun. 2016, DOI: 10.1039/C5CC08961A; (b) E. Ozkal, S. Ozcubukcu, C.Jimeno, M. A. Pericas, Catal. Sci. Technol. 2 (2012) 195-200; (c) E. Ozkal, P. Llanes, F. Bravo, A. Ferrali, M. A. Pericàs, Adv. Synth. Catal. 356 (2014) 857-869; (d) L. Maestre, E. Ozkal, C. Ayats, Á. Beltrán, M. M. Díaz-Requejo, P. J. Pérez, M. A. Pericàs, Chem. Sci. 6 (2015) 1510-1515; (e) D. Wang, L. Etienne, M. E. Igartua, S. Moya, D. Astruc, Chem. Eur. J. 20 (2014) 4047-4054.

[167] D. Toulemon, B. P. Pichon, C. Leuvrey, S. Zafeiratos, V. Papaefthimiou, X. Cattoen, S. Begin-Colin, Chem. Mater. 25 (2013) 2849-2854.

[168] C. S. Radatz, L. d. A. Soares, E. R. Vieira, D. Alves, D. Russowsky, P. H. Schneider, New J. Chem. 38 (2014) 1410-1417.

[169] B. R. Buckley, R. Butterworth, S. E. Dann, H. Heaney, E. C. Stubbs, ACS Catal. 5 (2015) 793-796.

[170] C. Rossy, J. Majimel, M. T.Delapierre, E. Fouquet, F. -X. Felpin, J. Organomet. Chem. 755 (2014) 78-85.

[171] R. B. N. Baig, R. S. Varma, Green Chem. 14 (2012) 625-632.

[172] X. Xiong, L. Cai, Catal. Sci. Technol. 3 (2013) 1301-1307.

[173] B. Movassagh, N. Rezaei, Tetrahedron 70 (2014) 8885-8892.

[174] R. Slimi, S. Kalhor-Monfared, B. Plancq, C. Girard, Tetrahedron Lett. 56 (2015) 4339-4344. 
[175] O. S. Taskin, S. Dadashi-Silab, B. Kiskan, J. Weber, Y. Yagci, Macromol. Chem. Phys. 216 (2015) 1746-1753.

[176] R. UlIslam, A. Taher, M. Choudhary, M. J. Witcomb, K. Mallick, Dalton Trans. 44 (2015) 1341-1349.

[177] P. M. Diz, A. Coelho, A. E. Maatougui, J. Azuaje, O. Caamano, A. Gil, E. Sotelo, J. Org. Chem. 78 (2013) 6540-6549.

[178] H. Wu, H. Li, R. T. Kwok, E. Zhao, J. Z. Sun, A. Qin, B. Z. Tang, Sci. Rep. 4 (2014) 5107.

[179] P. Li, S. Regati, H. Huang, H. D. Arman, J. C.-G. Zhao, B. Chen, Inorg. Chem. Front. 2 (2015) 42-46.

[180] (a) E. Haldon, E. Alvarez, M. C. Nicasio, P. J. Perez, Chem. Commun. 50 (2014) 8978-8981; (b) B. Wang, N. Liu, W. Chen, D. Huang, X. Wang, Y. Hu, Adv. Synth. Catal. 357 (2015) 401-407.

[181] X. Liu, N. Novoa, C. Manzur, D. Carrillo, J.-R. Hamon, New J. Chem. (2016) DOI 10.1039/c5nj02681d.

[182] N. Kann, J. R. Johansson, T. Beke-Somfai, Org. Biomol. Chem. 13 (2015) 2776-2785.

[183] (a) S. Ferrini, J. Z. Chandanshive, S. Lena, M. C. Franchini, G. Giannini, A. Tafi, M. Taddei, J. Org. Chem. 80 (2015) 2562-2572. (b) Q. Shen, E. Han, Y. Huang, Q. Chen, Y. Guo, Synthesis 47 (2015) 3936-3946.

[184] D. Wang, L. Salmon, J. Ruiz, D. Astruc, Chem. Commun. 49 (2013) 69566958.

[185] R. A. Molla, A. S. Roy, K. Ghosh, N. Salam, M. A. Iqubal, K. Tuhina, S. M. Islam, J. Organomet. Chem. 776 (2015) 170-179.

[186] A. P. Kumar, M. -W. Baek, C. Sridhar, B. P. Kumar, Y. -I. Lee, Bull. Korean Chem. Soc. 35 (2014) 1144-1148.

[187] J. R. Johansson, P. Lincoln, B. Norden, N. Kann, J. Org. Chem. 76 (2011) 2355-2359.

[188] (a) B. Chattopadhyay, V.Gevorgyan, Angew. Chem. Int. Ed. 51 (2012) 862872. (b) M. A. Tasdelen, B. Kiskan, Y. Yagci, Prog. Polym. Sci. 52 (2016) 19-78. (c) S. Dadashi-Silab, S. Doran, Y. Yagci, Chem. Rev. (2016) DOI: 10.1021/acs.chemrev.5b00586.

[189] A. Sharma, J. F. Hartwig, Nature 517 (2015) 600-604.

[190] K. Ladomenou, V. Nikolaou, G. Charalambidis, A. G. Coutsolelos, Coord. Chem. Rev. 306 (2016) 1-42.

[191] N. E. Brahmi, S. E. Kazzouli, S. Mignani, M. Bousmina, J. P. Majoral, Tetrahedron 69 (2013) 3103-3133. (b) M. Arseneault, C. Wafer, J. F. Morin, Molecules 20 (2015) 9263-9294.

[192] (a) K. Kempe, A. Krieg, C. R. Becer, U. S. Schubert, Chem. Soc. Rev. 41 (2012) 176-191. (b) G. Delaittre, N. K. Guimard, C. Barner-Kowollik, Acc. Chem. Res. 48 (2015) 1296-1307. (c) B. Yao, J. Z. Sun, A. Qin, B. Z. Tang, J. Inorg. Organomet. Polym. 25 (2015) 37-46.

[193] C. Deraedt, A. Rapakousiou, Y. Wang, L. Salmon, M. Bousquet, D. Astruc, Angew. Chem., Int. Ed. 53 (2014) 8445-8449. 
[194] (a) W. Xi, T. F. Scott, C. J. Kloxin, C. N. Bowman, Adv. Funct. Mater. 34 (2014) 2572-2590. (b) D. D. Diaz, Macromol. Symp.358 (2015) 10-20. (c) T. J. Del Castillo, S. Sarkar, K. A. Abboud, A. S. Veige, Dalton Trans. 40 (2011) 8140-8144; (d) A. R. Powers, X. Yang, T. J. Del Castillo, I. Ghiviriga, K. A. Abboud, A. S. Veige, Dalton Trans. 42 (2013) 14963-14966; (e) X. Yang, S. Wang, I. Ghiviriga, K. A. Abboud, A. S. Veige, Dalton Trans. 44 (2015) 11437-11443; (f) A. R. Powers, I. Ghiviriga, K. A. Abboud, A. S. Veige, Dalton Trans. 44 (2015) 14747-14752; (g) C. C. Beto, X. Yang, A. R. Powers, I. Ghiviriga, K. A. Abboud, A. S. Veige, Polyhedron (2015) doi.org/10.1016/j.poly.2015.08.032

[195] (a) N. Li, W. H. Binder, J. Mater. Chem. 21 (2011) 16717-16734. (b) G. K. Such, A. P. R. Johnston, K. Liang, F. Caruso, Prog. Polym. Sci. 37 (2012) 985-1003.

[196] C. Constant, S. Albert, N. Zivic, K. Baczko, H. Fensterbank, E. Allard,Tetrahedron. 70 (2014) 3023-3029.

[197] M. Durka, K. Buffet, J. Iehl, M. Holler, J. -F. Nierengarten, S. Vincent, Chem. Eur. J. 18 (2012) 641-651.

[198] X. -H. Dong, W. -B. Zhang, Y. Li, M. Huang, S. Zhang, R. P. Quirk, S. Z. D. Cheng, Polym. Chem. 3 (2012) 124-134.

[199] A. M. Wen, M. J. Ryan, A. C.Yang, K. Breitenkamp, J. K. Pokorski, N. F. Steinmetz, Chem. Commun. 48 (2012) 9044-9046.

[200] K. Mulla, H. Shaik, D. W. Thompson, Y. Zhao, Org. Lett. 15 (2013) 4532-4535.

[201] K. Harano, K. Minami, E. Noiri, K. Okamotob, E. Nakamura, Chem. Commun. 49 (2013) 3525-3527.

[202] P. Cui, S. Seo, J. Lee, L. Wang, E. Lee, M. Min, H. Lee, ACS Nano. 5 (2011) 6826-6833.

[203] S. G. Yenchalwar, R. R. Devarapalli, A. B. Deshmukh, M. V. Shelke, Chem. Eur. J. 20 (2014) 7402-7409.

[204] (a) T. Prakasam, M. Dariusz, J. Krzysztof, Chem. Rev. 113 (2013) 4905-4979.

(b) J. Totobenazara, A. J. Burke, Tetrahedron Lett. 56 (2015) 2853-2859.

[205] A. H. El-Sagheer, T. Brown, Acc. Chem. Res. 45 (2012) 1258-1267.

[206] (a) O. Boutureira, G. J. L. Bernardes, Chem. Rev. 115 (2015) 2174-2195. (b) W.

Tang, M. L. Becker, Chem. Soc. Rev. 43 (2014) 7013-7039.

[207] (a) C. S. McKay, M. G. Finn, Chem. Bio. 21 (2014) 1075-1101. (b) Y. Duan, Y. Ma, E. Zhang, X. Shi, M. Wang, X. Ye, H. Liu, Eur. J. Med. Chem. 62 (2013) 11-19.

[208] (a) D. Y. Ko, U. P. Shinde, B. Yeon, B. Jeong, Prog. Polym. Sci. 38 (2013) 672-

701. (b) Y. Jiang, J. Chen, C. Deng, E. J. Suuronen, Z. Zhong, Biomaterials 35 (2014) 4969-4985.

[209] A. Lauria, R. Delisi, F. Mingoia, A. Terenzi, A. Martorana, G. Barone, A. Maria Almerico, Eur. J. Org. Chem. (2014) 3289-3306.

[210] C. Uttamapinant, A. Tangpeerachaikul, S. Grecian, S. Clarke, U. Singh, P. Slade, K. R. Gee, A. Y. Ting, Angew. Chem. Int. Ed. 51 (2012) 5852-5856.

[211] J. Martell, E. Weerapana, Molecules 19 (2014) 1378-1393.

[212] S. Hassan, T. J. J. Mülle, Adv. Synth. Catal. 357 (2015) 617-666. 